\title{
A conceptual method of learning jazz improvisation through studying the music of J. S. Bach
}

Gary Scott Jones

West Virginia University

Follow this and additional works at: https://researchrepository.wvu.edu/etd

\section{Recommended Citation}

Jones, Gary Scott, "A conceptual method of learning jazz improvisation through studying the music of J. S. Bach" (2014). Graduate Theses, Dissertations, and Problem Reports. 567.

https://researchrepository.wvu.edu/etd/567

This Dissertation is protected by copyright and/or related rights. It has been brought to you by the The Research Repository @ WVU with permission from the rights-holder(s). You are free to use this Dissertation in any way that is permitted by the copyright and related rights legislation that applies to your use. For other uses you must obtain permission from the rights-holder(s) directly, unless additional rights are indicated by a Creative Commons license in the record and/ or on the work itself. This Dissertation has been accepted for inclusion in WVU Graduate Theses, Dissertations, and Problem Reports collection by an authorized administrator of The Research Repository @ WVU.

For more information, please contact researchrepository@mail.wvu.edu. 


\title{
A CONCEPTUAL METHOD OF LEARNING JAZZ IMPROVISATION THROUGH STUDYING THE MUSIC OF J.S. BACH
}

\author{
by \\ Gary Scott Jones \\ Doctoral Research Project \\ submitted to the \\ College of Creative Arts \\ at West Virginia University \\ in partial fulfillment of the requirements \\ for the degree of \\ Doctor of Musical Arts \\ in \\ Trombone Performance
}

\section{Committee}

H. Keith Jackson, D.M.A. Committee Chairperson

David Taddie, Ph.D.

Virginia Thompson, D.M.A.

Paul Scea, M.M.

William J. Winsor, M.F.A.

School of Music

Morgantown, West Virginia

2014

Keywords: Improvisation, Bach

Copyright 2014 Gary Scott Jones 


\begin{abstract}
A CONCEPTUAL METHOD OF LEARNING JAZZ IMPROVISATION THROUGH STUDYING THE MUSIC OF J.S. BACH
\end{abstract}

\title{
Gary Scott Jones
}

Johann Sebastian Bach's music includes exceptional source material for learning jazz improvisation. This research document has three sections. Chapter 1 is a concise review of respected jazz studies literature. Chapters 2 through 4 introduce a jazz improvisation methodology with Bach's music as its source material. The appendix presents materials on topics such as using improvisation for learning music, understanding improvisation, and organ improvisation. The target audience members for this research document are improvisation teachers who already possess an applicable knowledge of improvisation, pop/jazz chord symbols, and traditional music theory. The figures contained in Chapters 2 through 4 guide educators through ways to incorporate each musical exercise into instruction. Other primary audience members for this improvisation methodology are classically-trained musicians who share a familiarity with J.S. Bach's music yet believe they have no improvisational creativity of their own. 


\section{Dedication}

This research document is dedicated to my wife, Furaha Henry-Jones, and children, Evan and Aurora, who have supported me throughout the completion of this degree. It is also dedicated to the spirit of my grandmother, Berniece Lorene Jones, who encouraged me to pursue higher education and live by my own set of rules. 


\section{Acknowledgements}

Several people have contributed to the realization of this research document. The first person I must recognize is Dr. H. Keith Jackson for recruiting me to attend West Virginia University, and for being a fierce mentor and friend every step of the way. I must recognize my entire committee: Professor Paul Scea, Dr. Virginia Thompson, Dr. David Taddie, and William J. Winsor for believing in this topic. Thanks go out to Ed Sarath, Dennis Wilson, and Steve Rush at the University of Michigan for broadening my improvisational framework. Much appreciation is expressed to Jim Smith, Dr. Mary Fahrenbruck, Dr. William Denza, and Christian Berg at Central State University for helping me to lay a firm foundation in music theory and jazz improvisation. Thank you, Dr. Constinia Charbonette at W.V.U, for believing in me and supporting my educational journey. Thanks to my wife, Furaha, for proofreading my drafts and being more to me than words can describe. Thanks go out to my family and friends, to my Junior High Band Director, Tim Humphrey, and my High School Band Director, Clifford Sykes. Thanks to my friends, Kori Hill and Kristin Chamberlin, for testing out some of my improvisation exercises in our lessons. 


\section{Table of Contents}

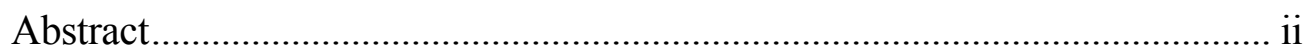

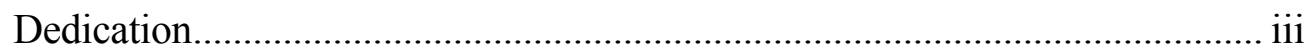

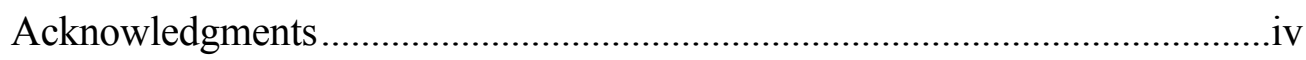

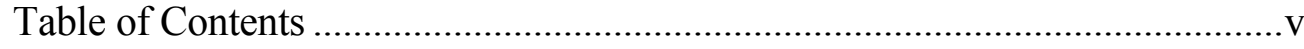

LIST OF FIGURES …................................................................................

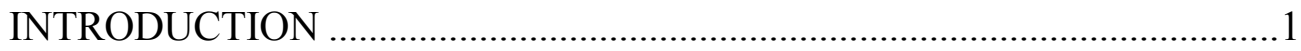

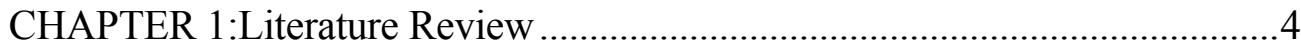

CHAPTER 2:Simplifying Melodic Contours and Harmonic Progressions .....25

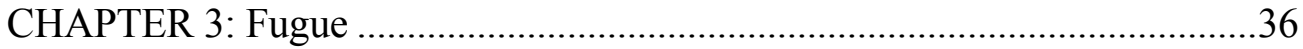

CHAPTER 4: Rhythm, Groove, and Drone ................................................49

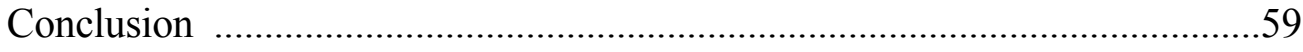

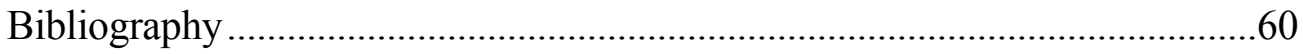

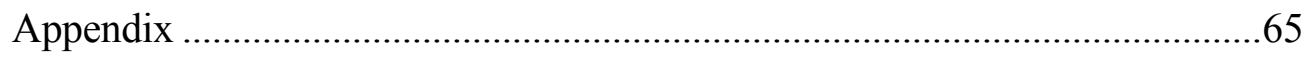

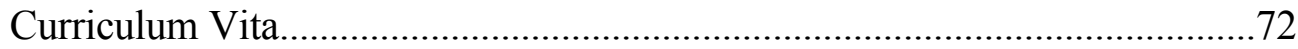




\section{List of Figures}

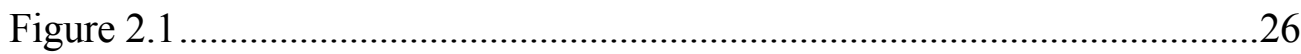

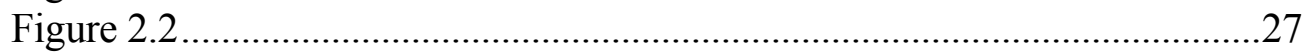

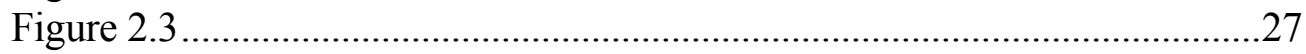

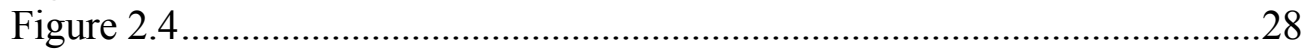

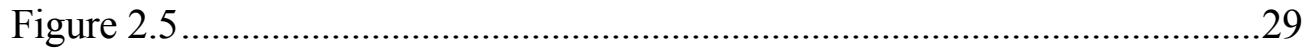

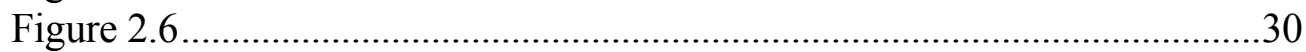

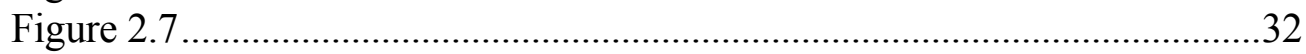

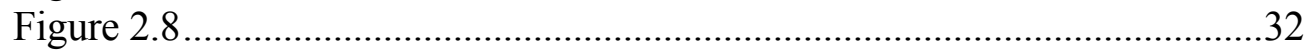

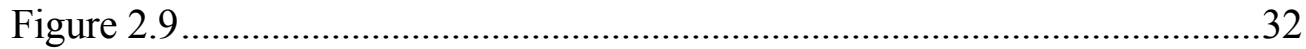

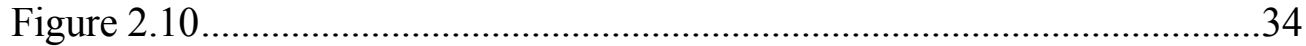

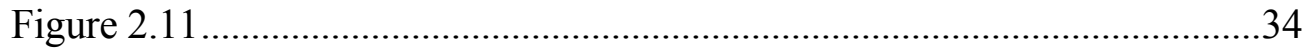

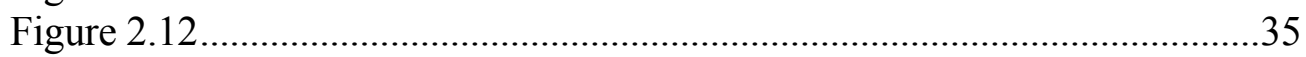

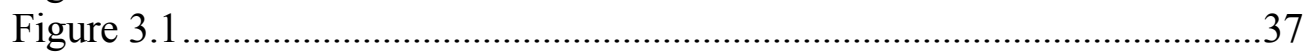

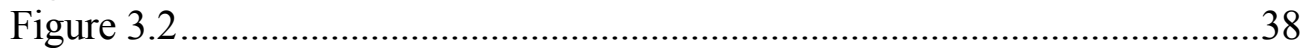

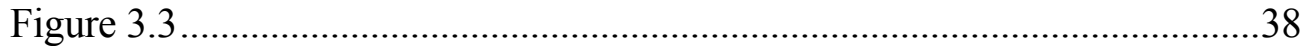

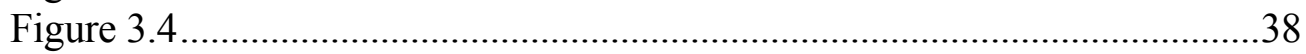

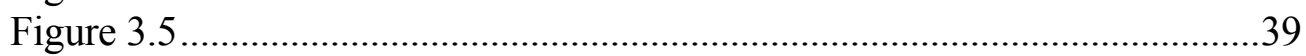

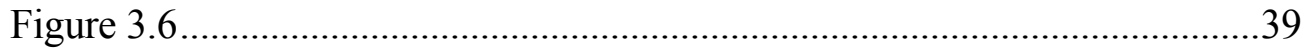

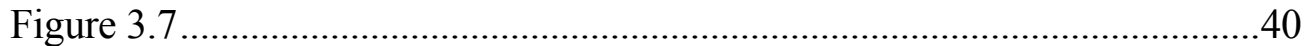

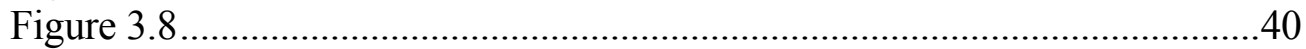

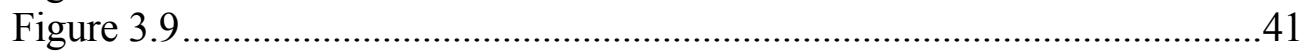

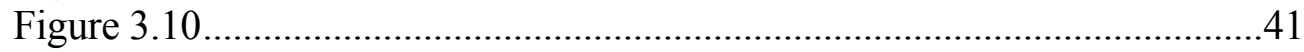

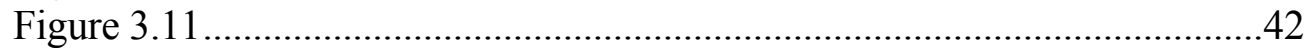

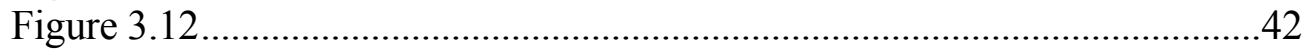

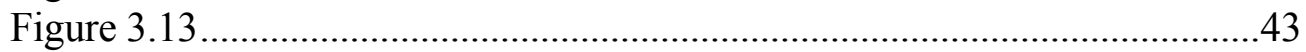

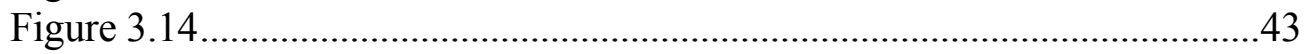

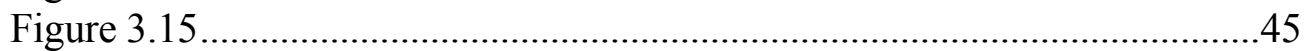

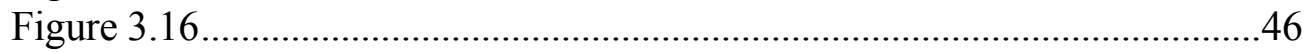

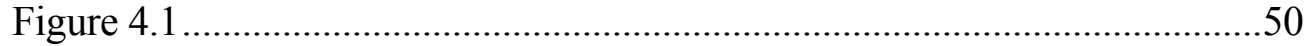

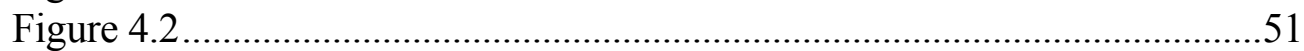

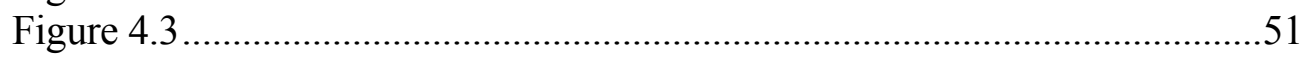

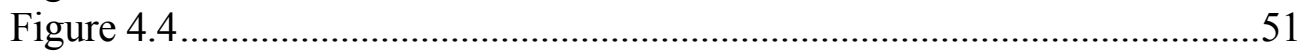

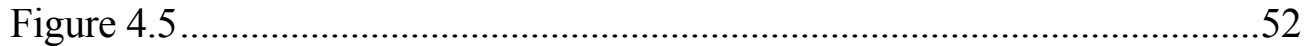

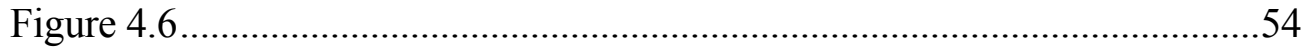

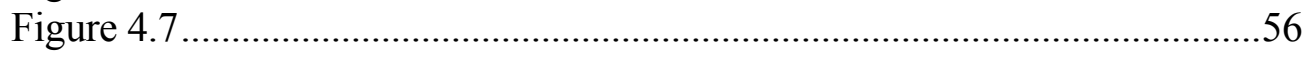

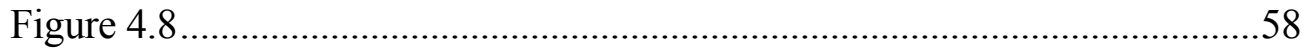




\section{Introduction}

\section{“Never mind majoring in Jazz-major in music! If you understand Bach, you get a better picture of where Bird is at. And vice versa." ${ }^{1 "}$ - Phil Woods}

Highly respected jazz artists and pedagogues have verbalized the notion that Johann Sebastian Bach's music provides the necessary components for learning jazz improvisation. However, they have not published a definitive guide, based on significant evidence to directly support this claim. Much of the preliminary evidence that has been proposed, and supported in publications, comes from the research projects of recent graduate students. The works that have been authored by pedagogues such as Lee Evans, David Baker, and Scott D. Reeves, are concerned with techniques that have become standards of jazz improvisation curricula. These include jazzrelated scale studies, melodic and intervallic patterns, and jazz-related harmonies. The scale studies and melodic patterns are often hypothetical and conceptual, created by their respective authors or based on transcriptions of recorded jazz solos, instead of being extracted from pre-existing completely notated compositions such as those by Bach or other composers. The most common musical examples that are published are transcriptions of jazz solos by famous artists.

This hybridized research document presents a review of literature by respected jazz pedagogues, and others. It introduces readers to the foundation for a new, Bach-based jazz improvisation method for producing melodic lines in the jazz idiom based on the music of Johann Sebastian Bach. As stated above, the initial impetus for this methodology comes from an apparent absence of a readily available, definitive guide for teaching jazz improvisation using J.S. Bach's music as source material, published in book format.

\footnotetext{
${ }^{1}$ Bouchard, Fred. “Phil \& Chris Rap," Down Beat Magazine, October, 1991.
} 
This research document has three sections. Chapter 1 is a review of literature. Chapters 2 through 4 introduces the Bach-based jazz improvisation method. The Bibliography and Appendix contain materials discussed in the study, as well as additional woks on related improvisation topics, such as using improvisation for learning music, understanding improvisation, and organ improvisation.

The primary target audience members for this research document are improvisation teachers who already possess an applicable knowledge of improvisation, pop/jazz chord symbols, and traditional music theory. Other, secondary audience members for this Bach-based jazz improvisation method are classically-trained musicians who share a familiarity with Bach's music and seek to begin learning to improvise jazz, yet believe they have no improvisational creativity of their own. These performers are often intimidated by the sight of pop chord symbols and slash marks in otherwise empty measures. They are pianists and double bass players who have learned to voice-lead a dominant $7^{\text {th }}$ chord and freeze when improvising their own ideas. They are bassoonists and low brass players who study the Cello Suites and struggle to improvise jazz ballads.

Several of the books included in this review of literature contain exercises that are similar to those presented in Chapters 2 through 4 of this document. Each author in Chapter 1 is either a highly respected jazz pedagogue or a writer who has published material that adds unique content to the literature review.

Pedagogues such as David Baker and Jerry Coker base their methodologies on the belief that improvisation students need to internalize scale patterns, chord patterns, and other melodic devices in order to develop aural skills and improvise melodic ideas. Improvisation techniques are not exclusive to any single style of music. What works for bebop chord changes is also applicable to a collectively improvised Baroque fugue. The Bach-based jazz improvisation method introduced 
by the author of this research document can be applied to the study of non-jazz, tonal improvisation, regardless of genre-related boundaries. However, this preliminary representation of this Bach-based improvisation methodology is specifically focused on the needs of jazz practitioners.

Bach's compositions employ several of the musical elements that improvisers study, including melodic contours, harmonic progressions, and melodic ranges that musicians can perform on most chordal and non-chordal instruments. Bach's musical output has a global audience and a diverse body of performers. Every player has her/his own interpretation of each piece. These pieces are particularly important because of their varying degrees of melodic, harmonic, and rhythmic complexity. Bach's compositions have also become the foundation for common practice music theory. Thus, they have provided source material for a new progression of musical exercises that aid students in learning improvisation while alleviating much of the stress that can accompany studying new material.

As a general rule, the practice philosophy that accompanies this Bach-based jazz improvisation method centers on conceptualizing and internalizing musical ideas. The exercises in Chapters 2 through 4 are not necessarily for students to memorize. The primary goal is for students to internalize each concept. Some of the exercises are more specific than others. Instructors should guide students through the series of challenges, and entrust them with the act of creating modified versions of each exercise that fit their individual needs and preferences. Many of the exercises contained in this Bach-based jazz improvisation method are abbreviated. For the sake of conciseness, most musical examples are short excerpts of the pieces under discussion. 


\section{Chapter 1:}

\section{Literature Review}

This literature review discusses books, scholarly journal articles, theses, and doctoral dissertations that fall into three degrees of significance to this topic; closely-related, related, and distantly-related. In order to maintain the primary focus of this review of literature, which supports the Bach-based jazz improvisation method introduced in subsequent chapters of this research document, methodologies published in book format are given greater discussion than other materials. Some of the book reviews are more detailed than others, due to variations in the informational depth of each book. Hands-on method books, for example, often contain significantly less prose than classroom textbooks. Each book entry includes its text's title, topic, a writing style overview, a description of the target audience, and an outline of chapters and/or sections.

The closely-related listings are specifically concerned with meeting the needs of jazz improvisation students and teachers. These sources include methodologies for internalizing scales, patterns and harmonies for application in jazz improvisation. The related entries focus on topics that are similar to the closely-related materials, but not as strongly connected to the topic, these include method books and articles about piano improvisation and how to teach improvisation in ensemble rehearsals. Robert Gillespie’s document, “Teaching Improvisation in the School Orchestra: Classical Practical Approaches ${ }^{2}$, " for example, addresses the needs of improvisation teachers and students in an ensemble. He presents a set of fundamental ensemble improvisation concepts that each director should develop for application within her/his rehearsals. He does not,

\footnotetext{
${ }^{2}$ Gillespie, Robert. "Teaching Improvisation in the School Orchestra." Midwest Clinic. http://www.midwestclinic.org/user_files_1/pdfs/clinicianmaterials/2001/gillespie.pdf (accessed March 8, 2014).
} 
however, present notated techniques such as those contained within standard jazz improvisation manuals.

Other related materials are concerned with improvisation outside of the jazz idiom, or other aspects of jazz studies curricula, such as Listening to $\mathrm{Jazz}^{3}$ by Jerry Coker. Additional materials focus on distantly-related concepts, such as the cognitive aspects of improvisation, and using improvisation in corporate/business settings. These works are authored by highly respected pedagogues whose contributions to jazz and improvisation curricula deserve recognition and future research into their respective topics.

Presenting a small number of related and distantly-related source materials helps to further shape the boundaries of this literature review, and is necessary for understanding the unique focus of this research document. For example, the review of materials is not primarily concerned with reasons for the decline of improvisation in Western musical practices, such as those provided by Robin Moore's article, “The Decline of Improvisation in Western Art Music: An Interpretation of Change "." Contrarily, Bach and the Art of Improvisation ${ }^{5}$, by Pamela Ruiter-Feenstra, addresses a seemingly related topic — teaching improvisation "in eighteenth-century styles" (Ruiter-Feenstra forward). However, because Ruiter-Feenstra is addressing improvisational practices during Bach's time, her text is also not discussed at length herein.

\footnotetext{
${ }^{3}$ Coker, Jerry. Listening to Jazz. Englewood Cliffs, NJ. Prentice-Hall, Inc., 1978.

${ }^{4}$ Moore, Robin. "The Decline of Improvisation in Western Art Music: An Interpretation of Change." International Review of the Aesthetics and Sociology of Music. Vol. 23, no. 1. (June 1992). http://www.jstor.org/stable/836956 (accessed January 18, 2014).

${ }^{5}$ Ruiter-Feenstra, Pamela. Bach and the Art of Improvisation. Chi Press. 2011
} 
“Gospel and Blues Improvisation" ${ }^{6}$ by Richard Smallwood deliberates three primary characteristics shared by the blues and black gospel music: blue notes, left-hand ostinatos played on piano, and embellishing vocal melodic lines. It does provide several notated illustrations and a small amount of instruction to improvisation students. Thus, it is related to this research topic. In his article, "Speaking of Jazz: Jazz Improvisation through Linguistic Methods ${ }^{7}$," Barry Velleman provides philosophical ideas on how to teach improvisation similarly to how one learns language. His article is aimed at addressing the needs of classroom instructors, but is not a methodology for learning improvisation. Publications that focus on the relationship between Bach's compositions and improvisation during Bach's life-time, such as "Composition and Improvisation in the School of J.S. Bach" ${ }^{8}$ by David Schulenberg, are distantly-related because they are focused on drawing historical connections, rather than satisfying the needs of contemporary improvisation students through a guided methodology of exercises and techniques.

Several pedagogues have written articles that discuss techniques of using improvisation as a teaching tool for learning music. These are also distantly-related to the primary topic of this document. For example, "Using Improvisation as a Teaching Strategy" 'by Janine Riveire is a discussion of ways to use improvisation as a tool for improving musicianship, rehearsals, and

\footnotetext{
${ }^{6}$ Smallwood, Richard. "Gospel and Blues Improvisation." Music Educators Journal, Vol. 66, no. 5. (January 1980). http://www.jstor.org/stable/3395785. (accessed February 1, 2014).

7 Velleman, Barry L. "Speaking of Jazz: Jazz Improvisation through Linguistic Methods." Music Educators Journal, Vol. 65, no. 2. (October, 1978). http://www.jstor.org/stable/3395505 (accessed February 1, 2014).

${ }^{8}$ Schulenberg, David. "Composition and Improvisation in the School of J. S. Bach." Bach Perspectives. (January 1995). Music Index, EBSCOhost. (accessed March 3, 2014).

${ }^{9}$ Riveire, Janine. "Using Improvisation as a Teaching Strategy." Music Educators Journal , Vol. 92 , no. 3 (January 2006). http://www.jstor.org/stable/3401139 (accessed January 18, 2014).
} 
manipulating musical materials. "Improvisation: A Tool for Music Learning ${ }^{10 ”}$ by David N. Baker" is another item that fits into this sub-category.

\section{Research Method}

The journal articles, dissertations, and theses discussed in this survey come from Internet databases and search engines. The result is a narrowed focus that helps to ensure that readers of this document have reasonable access to the same information. The first portion of research was completed using EBSCO Host databases: Academic Search Complete, ERIC, RILM Abstracts of Music Literature, and Music Index. Secondly, in order to maximize access to complete texts and ensure adequate search results for each Boolean search phrase, JSTOR was queried for crossreferencing sources provided in RILM Abstracts of Music Literature. This follow-up strategy became extremely helpful for making initial delineations between closely-related, related, and distantly-related sources prior to scanning each publication. Google.com, and Amazon.com were extremely useful for finding books, and articles whose texts were not available from their respective databases. ProQuest Dissertations \& Theses was useful for locating materials as well.

The article, A Sense of the Possible: Miles Davis and the Semiotics of Improvised Performance ${ }^{11}$, by Christopher Smith was the first article to be reviewed. Smith speaks of the creativity of Miles Davis, instead of an improvisation methodology introduced, or studied, by Davis. Another item, that supports the need for non-jazz students to study improvisation, is

\footnotetext{
${ }^{10}$ Baker, David N. “Improvisation: A Tool for Music Learning." Music Educators Journal, Vol. 66, no. 5. (January 1980). http://www.jstor.org/stable/3395775 (accessed: June 27, 2014).

${ }^{11}$ Smith, Chris. "A Sense of the Possible: Miles Davis and the Semiotics of Improvised Performance." In Collected Work: In the course of performance: Studies in the world of musical improvisation. (1998): 261-289. RILM Abstracts of Music Literature, EBSCOhost (accessed March 8, 2014).
} 
"Unveiling the Mysteries of Musical Spontaneity ${ }^{12 "}$ by Patricia Campbell. Both of these articles are considered distantly-related to the topic of this research document.

\section{Limitations for Literature Review:}

The items below are displayed in four subcategories: Jazz Improvisation, Jazz Patterns, Jazz Theory, and How to Listen to Jazz. Jazz Improvisation is the broadest category below. A standard jazz improvisation textbook contains an introduction/statement of philosophy, a listing of scales and chords that are commonly and/or uncommonly used in jazz, and an array of melodic patterns using scale-wise motion and leaps. A jazz theory or harmony book often presents studies in harmony, and scales, without placing much emphasis on melodic patterns. A jazz patterns book is focused almost exclusively on melodic pattern exercises.

It is imperative that clear lines be drawn between the intentions of this research document and other similar documents. The primary objective of this research document is to employ the music of J.S. Bach while presenting new and existing techniques for learning melodic jazz improvisation. Other, similar documents have been published by emerging scholars, such as Vidas Pinkevicius's dissertation, "Improvisation of Keyboard Preludes in the Style of J.S. Bach"," which explains methods of learning to improvise Baroque-style keyboard music. What separates these two topics is their primary objectives. Pinkevicius's abstract clearly indicates its author's intention to "teach the art of improvising keyboard preludes in the style of J.S. Bach" (Pinkevicius abstract).

\footnotetext{
${ }^{12}$ Campbell, Patricia Shehan. “Unveiling the Mysteries of Musical Spontaneity.” Music Educators Journal , Vol. 78, no. 4 (December 1991) , pp. 21-24 http://www.jstor.org/stable/3398332 (accessed February 1, 2014).

${ }^{13}$ Pinkevicius, Vidas. "Improvisation of Keyboard Preludes in the Style of J. S. Bach: A Practical Method Comprising Techniques Derived from Selected Keyboard Works." The University of Nebraska - Lincoln, 2006. In ProQuest Dissertations and Theses, http://search.proquest.com/docview/305273808?accountid=2837 (accessed March 15, 2014).
} 
The Bach-based jazz improvisation methodology introduced throughout subsequent chapters of this research document is primarily focused on improving improvisation students' command of single melodic lines within the jazz idiom.

In addition to "Improvisation of Keyboard Preludes," publications about organ improvisation, violin improvisation, improvisation curricula, and other similar topics are not discussed at length within this literature review, because they are not closely-related to the primary objectives of this research document. For example, Robert Zwick’s dissertation, “Jazz Improvisation: A Recommended Sequential Format of Instruction ${ }^{14}$," is an extensive study of books concerned with a plethora of jazz studies-related topics. However, it does not present a stepby-step, notated methodology of learning to improvise jazz music. Additional distantly-related items are included in the Appendix. The remaining sources discussed in this survey are considered closely-related or related to the topic of this research document.

\section{Jazz Improvisation Books}

David Baker's Modern Concepts in Jazz Improvisation: A Comprehensive Method for All Musicians $^{15}$ is a manual of scales and harmonic patterns for developing facility in jazz improvisation. It is "designed to meet the needs of performers, teachers, students, and any others interested in the performance of contemporary (post-bebop) jazz" (Baker 4). Baker discusses modal compositions, such as Miles Davis's So What, and harmonically complex pieces, such as Giant Steps by John Coltrane.

\footnotetext{
${ }^{14}$ Zwick, Robert A. "Jazz Improvisation: A Recommended Sequential Format of Instruction." University of North Texas, 1987. In PROQUESTMS ProQuest Dissertations \& Theses Full Text, http://search.proquest.com/docview/303589918?accountid=2837. (accessed January 18, 2014).

${ }^{15}$ Baker, David. Modern Concepts in Jazz Improvisation: A Comprehensive Method for All Musicians. Van Nuys, CA. Alfred Publishing, 1990.
} 
Baker bases his scale studies on step-wise motion, fourths, and chromaticism. An early example of how to implement these exercises is to use "the major pentatonic on the flat-5" (11). Chapter 1, "Foundation Exercises: Pentatonics," contains patterns for internalizing the pentatonic scales. Chapter 3, "Foundation Exercises: Perpetual Motion," showcases patterns of perfect fourths and fifths that help to create harmonic motion over chord changes, such as "fourths approached from a minor $7^{\text {th }}$ above or a whole-step below" (33).

Chapter 5, "Bitonal Playing," highlights methods of placing a C diminished scale over a C7 chord. Baker also explains how John Coltrane harmonically converted songs such as My Favorite Things to fit the stylistic inclinations of post-bop music. In Chapter 8, "The Coltrane Changes," the author informs readers of the chord progressions in Countdown and Giant Steps, and how substituted harmonic motion in thirds replaced common, diatonic chord progressions in some of Coltrane's music.

In Creative Jazz Improvisation: Third Edition ${ }^{16}$ Scott D. Reeves presents his philosophy on such topics as "How to Practice" and "Whom To Listen To." He discusses his experiences in teaching improvisation as well as working as an improvising musician. Reeves also mentions extramusical notions that he believes affect music making, such as yoga. He includes exercises for strengthening readers' understanding of each topic. Each chapter concludes with transcriptions and discussions of solos by important performers.

Reeves's text has a more extensive depth of coverage than the other books in this chapter. It serves equally well in individual practice and group study. It addresses many aspects of a jazz improvisation curriculum. Reeves provides the historical significance of such topics as how ABA

\footnotetext{
${ }^{16}$ Reeves, Scott D. Creative Jazz Improvisation, $3^{\text {rd }}$ ed. Upper Saddle River, NJ. Prentice Hall, 2001.
} 
form evolved from its use in European art music to marches by John Philip Sousa and Scott Joplin's Maple Leaf Rag. Each of Reeves' chapters has a similar structure: introductory prose, musical examples, transcriptions, exercises, and suggested listening. Given its breadth of information, readers should study Creative Jazz Improvisation patiently, similar to a reference manual.

Reeves organizes Creative Jazz Improvisation into five parts. "Part 1: The Art of Improvisation" contains chapters on "How To Practice, Creatively Improvise, and Teach Jazz Improvisation," "Whom To Listen To," and "Rhythm." The lists of players on each instrument in Chapter 2 progress from "Early Jazz Pioneers" through "Preservers of the Legacy" such as Sidney Bachet and Wynton Marsalis, respectively. "Part 2: Diatonic Chords and the Modes in the Major Scale" discusses major scales and modes, tonic and dominant chords, and the ii-V-I progression. "Part 3: Chord Substitutions, Harmonic Structures, and Forms" covers the blues scale, harmonic structures, and standard jazz forms.

The title of "Part 4: Altered Chords, Diminished Modes, Whole-tone and Harmonic Minor Scales, and Melodic Minor Modes" clearly reveals its content. It provides the following sequence of scales, modes, and chords: diminished, whole-tone and augmented, minor, locrian, and lydian. "Part 5: Pentatonic Scales and Intervallic Improvisation" also clearly indicates its contents in its title. This unit has three chapters that explore "Pentatonic Scales," "Four-Note Groupings Derived from Pentatonic Scales," and "Intervallic Improvisation," respectively.

Richard Lawn has published three books: Jazz Theory and Practice ${ }^{17}$, The Jazz Ensemble Directors Manual ${ }^{18}$, and Experiencing Jazz: Second Edition ${ }^{19}$. Experiencing Jazz is an integrated

\footnotetext{
${ }^{17}$ Lawn, Richard J. and Jeffrey L. Hellmer. Jazz Theory and Practice. Los Angeles. Alfred Publishing Company, Inc., 1996.
} 
textbook with online resources for jazz appreciation and history courses. Through readings, illustrations, timelines, listening guides, and a streaming audio library, it immerses the reader in a journey through the history of jazz, while placing the music within a larger cultural and historical context. Designed for new listeners of jazz music, Experiencing Jazz describes the elements of jazz music, and the characteristics and roles of different instruments. Prominent artists and styles from the roots of jazz to present day are relayed in a story-telling prose. This edition features expanded coverage of women in jazz, the rise of jazz as a world music, the influence of Afro-Cuban and Latin jazz, and streaming audio.

\section{Jazz Improvisation Articles}

Improvisation is a topic of increasing concern among scholars and performers from a variety of disciplines. Classical musicians in particular have recently published numerous articles that identify methods of incorporating improvisation in the study, and performance, of classical music. Several of these essays deliberate the needs of jazz improvisation educators and students. Many include discussion alone, others add notated exercises that support their respective author's arguments. The following articles are either related or closely-related to this research topic. Additional articles, cited in the appendix, provide bibliographies of improvisation books, elements of jazz improvisation, and other self-guided improvisation studies.

In his article, "Using Classical Music in Jazz Improvisation, ${ }^{20,}$ John Goldsby offers insight into applying elements of classical music within the study of jazz improvisation. He notes that jazz

\footnotetext{
${ }^{18}$ Lawn, Richard. The Jazz Ensemble Directors Manual. Oskaloosa, lowa : C.L. Barnhouse, 1995.

${ }^{19}$ Lawn, Richard. Experiencing Jazz. New York : McGraw-Hill, 2007.

${ }^{20}$ Goldsby, John. “Using classical music in jazz improvisation." Strad 121, no. 1442 (June 2010): 70-73. Music Index, EBSCOhost (accessed January 27, 2014).
} 
musicians can use these elements for improving their technique and expanding their melodic capabilities. He discusses Bach's Cello Suites as providing harmonic content that can be applied to jazz improvisation. Goldsby also provides sample musical notations which apply elements of classical music to the study of jazz improvisation.

“Learn to Improvise in Fifteen Minutes a Day ${ }^{21}$," by Christa Rakich provides exercises for organists to improvise idiomatic works, such as chorales and fugues in Baroque styles. Although her essay is not jazz related and is intended for use by organists, it is related to the topic of this research document, specifically because of its use of Bach's compositions as source material for basing improvisations.

Robert Witmer and James Robbins's article, “A Historical and Critical Survey of Recent

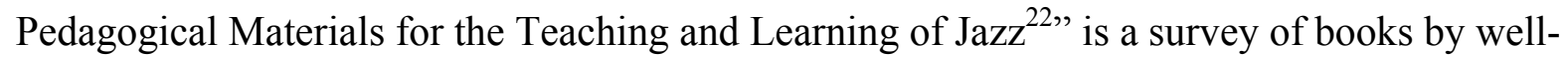
respected writers, many of whom are also included in the bibliography of this research document, such as Jamey Aebersold, David Baker, and Kenneth Stanton.

"Predicting Jazz Improvisation Achievement through the Creation of a Path-Analytical Model $^{23}$," by Charles R. Ciorba, addresses some of the needs of improvisation instructors. However, it does not include a step-by-step notated methodology for jazz improvisation. Richard

\footnotetext{
${ }^{21}$ Rakich, Christa. "Learn to Improvise in Fifteen Minutes a Day! Gerre Hancock: Toccata, part 1." The American Organist 40, no. 2. RILM Abstracts of Music Literature, EBSCOhost. 2006. (accessed March 3, 2014).

${ }^{22}$ Witmer, Robert and James Robbins. "A Historical and Critical Survey of Recent Pedagogical Materials for the Teaching and Learning of Jazz." Bulletin of the Council for Research in Music Education, no. 96, (1988). http://www.jstor.org/stable/40318207 (accessed: 02/01/2014)

${ }^{23}$ Ciorba, Charles R.. "Predicting Jazz Improvisation Achievement through the Creation of a Path-Analytical Model." Bulletin of the Council for Research in Music Education, no. 180. (Spring 2009).

http://www.jstor.org/stable/40319319. (Accessed: 02/01/2014).
} 
Rose's article, “Eight Elements of Jazz Improvisation"24,” provides simple explanations of jazz elements without being an improvisation method. Articles and sources, such as James McGowan's "Riemann's Functional Framework for Extended Jazz Harmony ${ }^{25 "}$ are related to this research topic, but are a bit too advanced for the primary target audience.

“Improvising Jazz: A Beginner's Guide ${ }^{26}$," by Eddie Meadows, is a discussion on how one should begin to learn improvisation from a philosophical perspective, instead of a hands-on methodology. "Slicing the Beat: Jazz Eighth-Notes as Expressive Microrhythm²," by Fernando Benadon, is a survey of various ways to play jazz eighth notes, but is not a method of learning or teaching improvisation. As indicated in its title, it is focused on understanding rhythm, instead of pitch and harmony, as most jazz manuals do.

Tanya Kalmanovitch’s essay, "Contemporary Improvisation for Classical Musicians"28," reports on an improvisation ensemble for classical performers and composers that the author directs at the New England Conservatory in Boston, Massachusetts. This paper is an account of Kalmanovitch's approach to the pedagogy of improvisation, situated within historical and theoretical contexts, as well as a narrative account of the author's path from training in classical

\footnotetext{
${ }^{24}$ Rose, Richard. "Eight Elements of Jazz Improvisation." Music Educators Journal , Vol. 71, no. 9 (May, 1985). http://www.jstor.org/stable/3396523 (accessed January 18, 2014).

${ }^{25}$ McGowan, James. "Riemann's Functional Framework for Extended Jazz Harmony.” Intégral, Vol. 24. (2010). Special Issue in Honor of Robert Wason. http://www.jstor.org/stable/41495296 (accessed January 27, 2014).

${ }^{26}$ Meadows, Eddie S. “Improvising Jazz: A Beginner's Guide.” Music Educators Journal , Vol. 78, no. 4 (December 1991). http://www.jstor.org/stable/3398336 (accessed 02/01/2014).

${ }^{27}$ Benadon, Fernando. "Slicing the Beat: Jazz Eighth-Notes as Expressive Microrhythm." Ethnomusicology, Vol. 50, no. 1 (Winter 2006). http://www.jstor.org/stable/20174424 (accessed February 1, 2014).

${ }^{28}$ Kalmanovitch, Tanya. "Contemporary Improvisation for Classical Musicians." New Sound: International Magazine For Music no. 32 (December 2008): 130-142. Music Index, EBSCOhost (accessed January 27, 2014).
} 
music to a career as an improvising violist. Although this paper is concerned with the topic of improvisation, it does not discuss a methodology for learning or teaching improvisation. (Based on Abstract provided by author)

Lee Evans's contributions to jazz pedagogy include numerous articles and several books. "Techniques of Melodic Development in Jazz Improvisation"," is very much in support of the need for improvisers to develop their command of melodic lines so that their improvised music will in turn be more accessible to lay audience members. Evans provides a few techniques for developing melodic ideas through concepts such as rhythmic and intervalic diminution and augmentation. The article focuses on incorporating compositional devices, such as repetition and sequence, into melodic techniques for improvised jazz solos. These techniques, along with rhythmic, and intervallic, diminution, and fragmentation are applicable to twelve-bar blues, and other jazz structures.

Many of Evans's articles focus on the use of modes in jazz improvisation. "Modal Harmony In Jazz: Part Two ${ }^{30}$," examines modal possibilities in jazz improvisation. It discusses the use of the Lydian mode whenever major seventh chords appear in a composition. The article also discusses the use of the Aeolian and Phrygian modes whenever minor seventh chords arise.

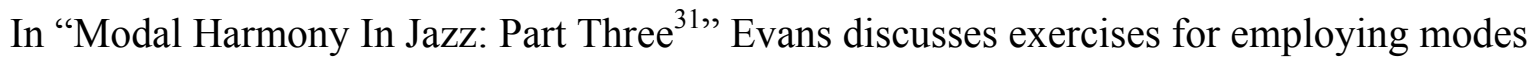
when harmonic motion is static, wherein each chord lasts several beats or bars and allows time for

\footnotetext{
${ }^{29}$ Evans, Lee. "Techniques of Melodic Development in Jazz Improvisation." Jazzed: The Jazz Educator's Magazine 5, no. 1 (January 2010): pp. 52-56. Music Index, EBSCOhost (accessed January 22, 2014).

${ }^{30}$ Evans, Lee. “Modal Harmony In Jazz: Part Two." Piano Today: The Magazine You Can Play 28, no. 1 (Winter 2008): 25-26. Music Index, EBSCOhost (accessed January 22, 2014).

${ }^{31}$ Evans, Lee. “Modal Harmony In Jazz: Part Three.” Piano Today: The Magazine You Can Play 28, no. 2 (Spring 2008): 36-37. Music Index, EBSCOhost (accessed January 22, 2014).
} 
performers to establish the modality. Moreover, repeated alternating chords are effective in modal jazz improvisation over relatively static harmonic motion. Sample piano exercises are also included. The article, “The Interchangeability of Modes ${ }^{32}$," focuses on alternating diatonic modes within a single modal jazz composition or improvisation. These items present a brief snapshot of Evans's extensive knowledge of improvisation. They presents strategies for internalizing all seven diatonic modes that share the same tonic, e.g. C. "The Interchangeability of Modes" also highlights instructions for Mode Interchange Exercises which a music student should strive to learn. Other articles by Evans are cited in the appendix.

Kevin Daniel Woosley introduces his own improvisation methodology in his D.M.A. Research Document, “The Lost Art of Improvisation: Teaching Improvisation to Classical Pianists 33 " "Chapter 3: Methods for Teaching Improvisation to Classical Pianists," begins with exercises in embellishing rhythmic motives on unpitched percussion instruments, and progresses through melodic improvisation, and voicing chords. One of the differences between Woosley's closely-related methodology and the Bach-based jazz improvisation method introduced in this research document, is that Woosley references several familiar songs by various composers, e.g. Mary Had a Little Lamb, Joy to the World, and Bach's Minuet in G Major for developing improvisation techniques. Another difference between both documents is that Woosely also uses prose to describe some of his exercises, rather than presenting them with musical notation.

\footnotetext{
${ }^{32}$ Evans, Lee. "The Interchangeability of Modes." Jazzed: The Jazz Educator's Magazine 5, no. 6 (November 2010): 3841. Music Index, EBSCOhost (accessed January 22, 2014).

${ }^{33}$ Woosley, Kevin Daniel. "The Lost Art of Improvisation: Teaching Improvisation to Classical Pianists." The University of Alabama, 2012. In ProQuest Dissertations \& Theses Full Text, http://search.proquest.com/docview/1284867846?accountid=2837 (accessed March 23, 2014).
} 
Yuusaku Ichio’s thesis, Bach and Improvisation: A Research on How Useful Bach is for Improvising $\mathrm{Music}^{34}$, has direct relevance to the topic of this research document. Similar to a jazz improvisation method book, Ichio discusses the use of closed triads for arpeggiating chords. Ichio not only mentions the possibility of using Bach for learning improvisation, he provides support for his self-describing argument through notated excerpts and harmonic analyses of pieces such as "Corrente" from Partita for Violin. His culminating musical example is All the Things You Are, presented in 3/4 meter, so that a closer relationship to Bach's 3/4 works is drawn.

\section{Jazz Patterns}

Several of the texts within the Jazz Improvisation section of this chapter reference the use of jazz patterns for learning improvisation; however, Patterns for Jazz ${ }^{35}$ by Jerry Coker, Jimmy Casale, et al. exclusively focuses on this concept. The authors inform readers of a need for the following:

a collection of patterns to be practiced diligently by the serious student of jazz improvisation... In the first portion of the book we have stressed rudimentary exercises, rather than practical patterns, feeling that the student should first absorb the foundations for patterns, such as scales, modes, simple chords, and four basic kinds of chord movement: (1) cycle of fifths; (2) chromatic; (3) stepwise; and (4) in minor thirds. (Introduction)

After the book's introduction, the authors' prose is minimal. The authors provide patterns for internalizing major scales and chords, diatonic chords, minor chords, diminished and augmented scales, and more. "This book is meant to be played, rather than to be read in an armchair" (Introduction). Instead of chapters, the authors have organized the text into groupings of musical elements and exercises.

\footnotetext{
${ }^{34}$ Ichio,Yuusaku. "Bach and Improvisation: A Research on How Useful Bach is for Improvising Music." Thesis. Göteborgs Universitet, 2011. https://gupea.ub.gu.se/bitstream/2077/26673/1/gupea_2077_26673_1.pdf (accessed March 3, 2014).

${ }^{35}$ Coker, Jerry, Jimmy Casale, Gary Campbell, and Jerry Greene. Patterns for Jazz. Miami. Studio Publications Recordings, 1970.
} 
The section titled "Musical Chords and Major Scales" begins with the C major scale in two octaves and an explanation of the $\mathrm{C}$ major triad, major $6^{\text {th }}$, major $7^{\text {th }}$, and major $9^{\text {th }}$ chords. Next is a chart of chord tones extending to the $13^{\text {th }}$ in every major key. Following this chart is a set of patterns based on major triads that progress chromatically or in perfect fourths. Some patterns ascend and descend prior to the author modulating them by half-steps. The authors also include patterns for learning turnarounds, polychords, the lydian augmented scale, and other tonalities. The text concludes with “An Essential Discography” of albums by various jazz masters.

Mike Richmond designed Modern Walking Bass Technique ${ }^{36}$ for all musicians interested in developing their skills regarding walking bass lines. Unlike the structure of the aforementioned texts, Richmond's book opens with an introduction and follows with a series of sample bass lines that progress from diatonic quarter-notes to more intricate examples, such as intervalic skips, ghost skips, syncopations, and more. Even though all of the bass line examples are blues progressions, the techniques that Richmond introduces apply to any jazz compositions that require walking bass lines.

Expansions: A Method for Developing New Material for Improvisation, $2^{\text {nd }}$ Edition ${ }^{37}$ by Gary Campbell is a forty-six page text containing patterns of triads and scales for musicians to internalize and use during improvisation. The primary "purpose of this book is to expand and explore the sounds that can be created from the basic scales and chords that have been used in jazz improvisation and composition for many decades" (Campbell 2).

\footnotetext{
${ }^{36}$ Richmond, Mike. Modern Walking Bass Technique. Englewood, NJ. Ped Xing Music, 1983.

${ }^{37}$ Campbell, Gary. Expansions: A Method for Developing New Material for Improvisation, $2^{\text {nd }}$ ed. Milwaukee. Hal Leonard Corporation, 1998.
} 
Expansions is a book of scale and chord patterns for improvisers to internalize in all twelve keys. Campbell begins his presentation of patterns with ascending triads in $\mathrm{C}$ major, and progresses through pentatonic scales, harmonic scales, and combinations of scales and chords, such as an ascending $\mathrm{C}$ major seventh arpeggio followed by a descending tetrachord a step away. This is another example of a text that is intended to be practiced and studied closely so that each technique is memorized, perfected, and expanded into individualized routines.

Chapter 1, "How to Practice Patterns," begins with a presentation of a "Basic Routine." Triads and seventh chords are displayed in ascending and descending three and four-note groups. Chapter 2,"Scales," exposes readers to less common scales such as the pentatonic flat-3, augmented scale, tritone scale, and others. The remaining chapters' contents are explorations of such topics as triad variations, lower neighbor tones, interval sets, intervals and chords, and chord/scale exercises.

Similar to Campbell's Expansions, Ramon Ricker's book, Pentatonic Scales for Jazz Improvisation $^{38}$, is a collection of scale patterns and exercises focused exclusively on the endless possibilities contained within pentatonic scales. Ricker's chapters explore "Construction of Pentatonic Scales," "Application of Pentatonic Scales to Various Chord Types," "Application of Pentatonic Scales to Chord Progressions," "Altered Pentatonics," "Improvised Solos," and additional "Exercises."

Intended for advanced improvisers, Technique Development in Fourths for Jazz Improvisation by Ramon Ricker is "is a supplement, another tool to aid and expand the serious student's harmonic and melodic vocabulary" (Ricker Introduction). This is another method book

\footnotetext{
${ }^{38}$ Ricker, Ramon. Pentatonic Scales for Jazz Improvisation: The Ramon Ricker Jazz Improvisation Series. Alfred Publishing Company, Inc. 1976.
} 
filled with patterns for internalizing and strengthening one's improvisations. What makes this book unique is its almost exclusive employment exercises based on fourths instead of scales and triads.

\section{Jazz Theory Books}

Jazz Theory and Practice ${ }^{39}$ by Richard Lawn and Jeffrey Hellmer is primarily "intended for use in the college classroom, by students who have completed one year or more of traditional theory or who demonstrate a prerequisite background" (Lawn xiv). Lawn and Hellmer provide comprehensive coverage of jazz theory. The text has fifteen chapters that introduce scales and chords, melodic construction, harmonies, harmonic substitutions, keyboard voicings, rhythm, modal structures, popular jazz forms, and contemporary improvisation techniques. Summaries and exercises conclude each chapter. Students who already possess a knowledge of intervals, scales, modes, and chords may skip or skim several of the introductory chapters as review materials.

Throughout their treatise, Lawn and Hellmer delineate between Western music theory and jazz theory, arguing that most traditional music theory courses do not provide practical materials for players of jazz and other popular music genres. Jazz Theory and Practice is a method for teaching and learning jazz theory, but not necessarily for learning jazz improvisation. However, its depth of coverage serves the needs of teachers and students alike. Among the similarities shared by Bach's music and improvised jazz solos are thematic variations based on non-chord tones. Chapter 7, "Diatonic and Chromatic Harmony," includes a review of roman numeral labeling from common practice music theory that runs parallel to an explanation of jazz chord labeling. This chapter also discusses cadences and presents the plagal cadence, for example, in conjunction with the ii-V7-I progression.

\footnotetext{
${ }^{39}$ Lawn, Richard J. and Jeffrey L. Hellmer. Jazz Theory and Practice. Los Angeles. Alfred Publishing Company, Inc., 1996.
} 
Kenneth Stanton's Introduction to Jazz Theory: A Beginning Text in Jazz Harmony in

Workbook Form ${ }^{40}$ is a method for learning music theory within a jazz context. Exercises and blank manuscript paper follow each of its short chapters. Stanton articulates his objectives in his introductory pages:

In this age of contemporary pop music, jazz and rock ' $n$ ' roll, musical people must be aware of the beginning concepts of harmony in order to be able to put together a song, a piano or guitar piece, or whatever type of composition they want to write... The purpose of Introduction to Jazz Theory is to unite the enjoyability of music with some of the fundamentals of harmony in a way that the student will want to actively and creatively apply himself. (Stanton Foreword)

Given the benefit of applying harmonic and melodic concepts at the keyboard, Introduction to Jazz Theory may be extremely useful as a supplemental guide within a course of study in improvisation. It is not specifically intended for learning improvisation. However, a firm foundation in harmony is an invaluable asset to improvising musicians.

Chapter 1, "The Major Scale," describes the anatomy of the major scale. Chapter 2, "The Tonic Chord," introduces tonal centers, the scale degrees that constitute a chord, and labeling chords with roman numerals and jazz symbols. Chapter 3, "The Dominant Seventh Chord; --'The Five-Seven' or 'V7' Chord," explains the construction of the dominant $7^{\text {th }}$ chord and its importance within modern harmonic progressions. Chapter 4, "The Dominant Seventh Cadence: 'V7 to I,'” discusses the forward motion that cadences create. Chapter 5, "The Minor Seventh Chord," explains the roman numerals that are appropriate for labeling minor chords.

The next few chapters of Introduction to Jazz Theory discuss common jazz chord progressions and the importance of using inversions while voice leading chord changes. Chapter 8a, "Breaking Out of the Diatonic Mold --The Diminished Seventh Chord," is the beginning of a

\footnotetext{
${ }^{40}$ Stanton, Kenneth. Introduction to Jazz Theory. Boston. Crescendo Publishing Company, 1976.
} 
different direction in tonal exploration. It includes an introduction to non-diatonic chords that teachers may separate from the first half of the book, which focuses on diatonic chords in major tonalities. The remaining pages are explorations of "Chord Patterns" and "Extension[s] of the V7 Chord.” Introduction to Jazz Theory concludes with Chapter 10, “Writing Jazz Harmony for Fun.”

Stanton introduces diminished $7^{\text {th }}$ chords in relationship to the major scale built on the root of each chord instead of the chord's function within the context of the music. This is potentially confusing for music theory and jazz harmony novices. The first diminished $7^{\text {th }}$ chord he analyzes is C\# diminished within the key of $\mathrm{C}$ major:

In the C\# Major Scale, the first, third, fifth and seventh degrees of the scale can plainly be seen as C\#, E\#, G\#, and B\#... The formula for building a Diminished Seventh chord is to allow the root only to remain natural but to flat the third and fifth degrees, and to double flat the seventh degree. (34)

Lee Evans' Topics in Jazz and Musical Creativity for the Classical Pianist ${ }^{41}$ is a brief jazz theory method book. His intended readers are classical pianists who wish to learn jazz keyboard techniques. Evans organizes his text into short sections that appear to be individual components from a series of lectures or masterclasses.

“Jazz Improvisation Part I: The Classical Teacher’s Guide to Easy Improvisation Techniques" is a brief discussion of how to place accents on the normally weaker beats of a $4 / 4$ measure. “Jazz Improvisation Part II: A Classical Teacher's Guide to Jazz Accompaniment Techniques" explains the primary functions of jazz piano playing: "indicating harmonic structure; giving music rhythmic definition and impetus; filling periods of melodic inactivity; and providing contrapuntal melodic material” (Evans 10).

\footnotetext{
${ }^{41}$ Evans, Lee. Topics in Jazz and Musical Creativity for the Classical Pianist. Milwaukee. Hal Leonard Publishing Corporation, 1989.
} 
“Jazz Improvisation Part III: The Classical Teacher's Guide to Chord Improvisation" is organized into two topics: "Voice-Leading" and "Chord Substitution." Another chapter, "Jazzing It Up in Style: Guidelines for Keyboard Jazz Performance," focuses on individuality and originality. It discusses "stylistic originality," "harmonic originality," and "melodic improvisation." Evans' primary goal for this component is internalizing patterns and techniques in order to develop one's creative voice.

\section{How to Listen to Jazz}

Jerry Coker's Listening to Jazz ${ }^{42}$ exposes readers to the benefit of learning jazz by listening to its master artists. Students of any style will benefit from listening to performances and recordings of musical genres in order to gain familiarity and learn to interpret music accurately. This text may be helpful in a jazz history course, possibly more so than some jazz history textbooks. Coker's primary goal is "to help the reader understand the objectives and accomplishments of the best of the jazz improvisers with a bare minimum of technical language" (Coker viii).

Coker organizes Listening to Jazz into five chapters and four appendices. He encourages readers to think about functions of instruments and musical ideas without burdening students with technical terminology. Each chapter concludes with suggested listening examples from The Smithsonian Collection of Jazz. Coker rejects the study of great musicians' personal histories as a means of understanding their music. He acknowledges the impact of sociological concerns such as poverty, drug abuse, and class on some artists' lives; however, he clearly articulates his intention to discuss music on its own merits as much as possible.

\footnotetext{
${ }^{42}$ Coker, Jerry. Listening to Jazz. Englewood Cliffs, NJ. Prentice-Hall, Inc., 1978.
} 
Chapter 1, "Listening to Jazz," previews the rest of the text. Coker shares his belief that the "real history of jazz is in the music itself, especially in the solos of such great improvisers as Louis Armstrong, Coleman Hawkins, Lester Young, Charles Parker, Miles Davis, and John Coltrane” (4). Chapter 2, "Formal Structures in Jazz," defines a chorus and introduces conventional jazz forms, such as AABA. Chapter 3, "The Rhythm Section," explains the rhythm section's relationship to the trumpet, trombone, and saxophone sections in a big band. Chapter 4, "The Improvised Solo," explores the allure of jazz that stems from not knowing what to expect during performances. It shares insight into the creative mindset of musicians. Chapter 5, "The Improviser's Hall of Fame," includes a roster of artists whose music is exceptional and accessible to readers. Its honorees are Louis Armstrong, Coleman Hawkins, Lester Young, Charles Parker, Miles Davis, and John Coltrane. Coker deliberates on the style, instrument, tone, and time period of each hall of famer. A discography follows the discussion of each artist. Coker's appendices chronicle jazz greats, provide historic overviews of jazz periods, and list dealers of discontinued recordings. 


\section{Chapter 2: \\ Simplifying Melodic Contours and Harmonic Progressions}

Mastery is a journey that demands a cycle of study, practical experience, and personal critique. The following chapters introduce the foundation for a jazz improvisation methodology based on source material from J.S. Bach's compositions. Simplifying melodic contours and harmonic patterns is necessary for comprehending this methodology. Internalizing each technique presented in Chapters 2 through 4 requires dedicated effort and experimentation. These exercises are similar to those presented in several of the books cited in Chapter 2, and have unlimited potential for personalization and exploration. Improvisation teachers should encourage their students to study all of the figures in this method with solfege in order to better incorporate each concept into improvisations.

Maintaining a macroscopic view of harmonic structures aids musicians in the creation of improvised melodic contours that develop into complex musical statements. Such a perspective alleviates stress for performers of harmonically intricate music. This chapter presents strategies for internalizing harmonic structures and melodic contours. Both skills are integral components of melodic improvisations. The musical examples in this chapter are excerpts from Prelude I of the Well-Tempered Clavier Book I, the Prelude to Cello Suite I, and the Allamande from the Sonata in A Minor for Flute Solo. These arpeggiated melodies outline harmonic tonal structures and provide a good starting point for internalizing harmonic structures. 
Figures 2.1 through 2.5 illustrate the following five-step process:

1. Study the music as written, beginning with a manageable, consistent tempo. Encourage students to use a metronome, as it is helpful for maintaining the tempo (see fig. 2.1).

2. Label the chords, and practice the melody and chords simultaneously on a keyboard (see fig. 2.2).

3. Identify tonalities based on chord functions (see fig. 2.3). Improvise based on the stylistic inclinations of the piece. The improvisations should be arpeggiations of the harmonic structure that are similar, but not identical, to the original work. Later, add scalar (stepwise) motion to the arpeggio-based improvisations.

4. Create a roman numeral analysis (see fig. 2.4). Transpose the chord structure and improvise in additional keys. It may not be necessary for each student to notate the harmonic structure separate from the melodic material. Figure 2.4 ensures a clear presentation of this step of the process.

5. Notate original improvisations and melodies based on this process (see fig. 2.5).

Figure 2.1: Measures 1-9 of Prelude I of the Well-Tempered Clavier in a compressed tessitura.
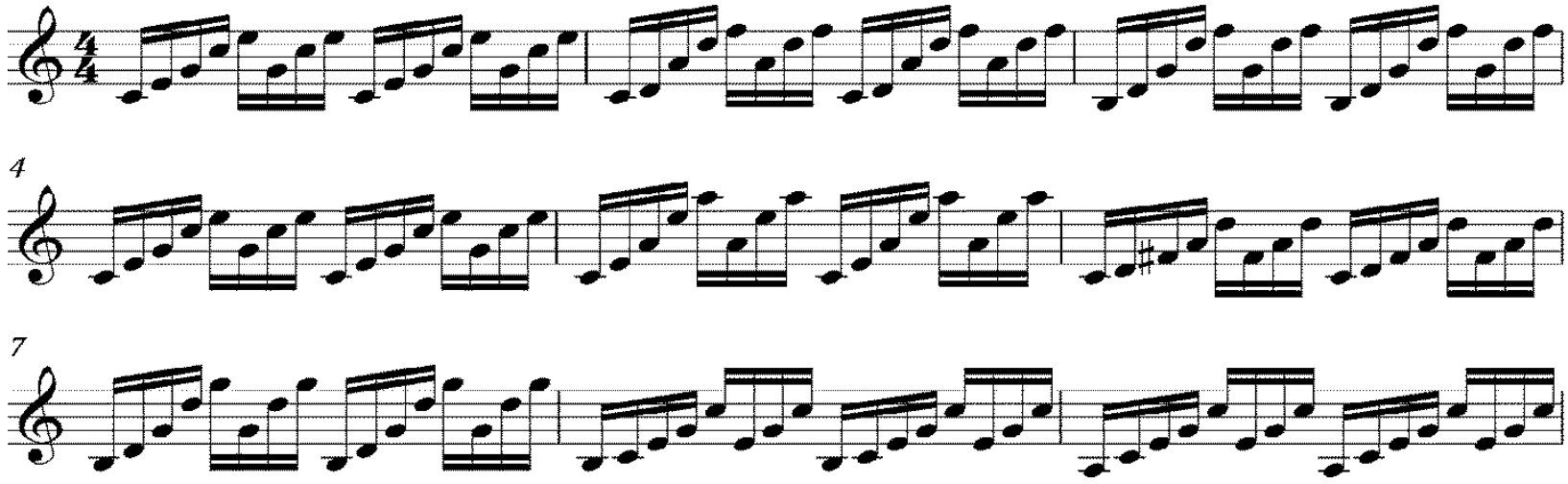
Figure 2.2: Measures 1-8 of Prelude I of the Well-Tempered Clavier with pop chord symbols.
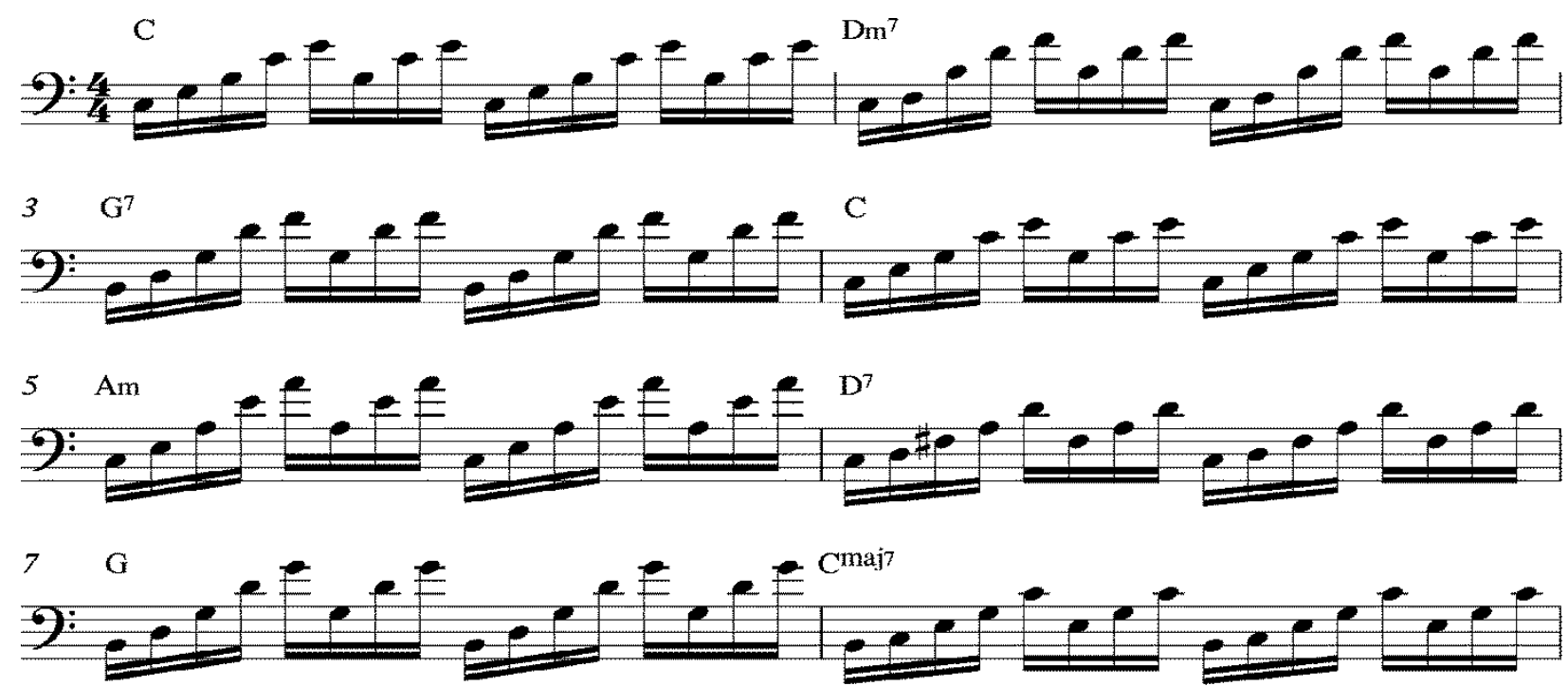

Figure 2.3: Pop chords and tonalities for measures 1-16 of Prelude I of the Well-Tempered Clavier.

Tonalities: C Major

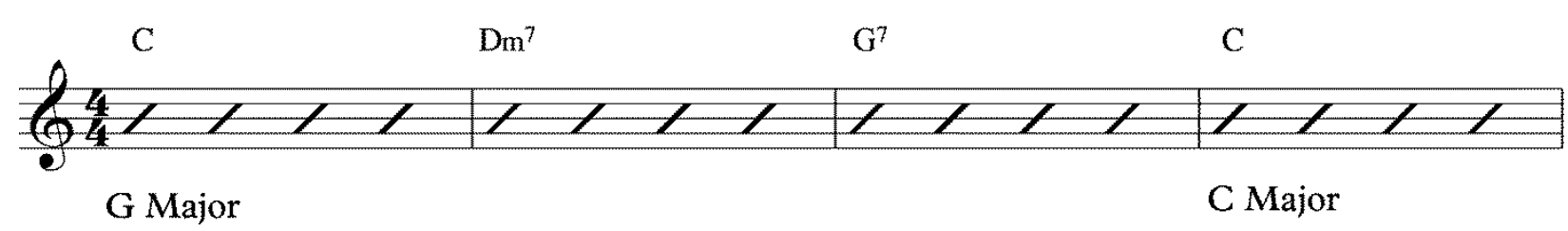
$5 \quad$ Am
$\mathrm{D}^{7}$
G
Cmaj7

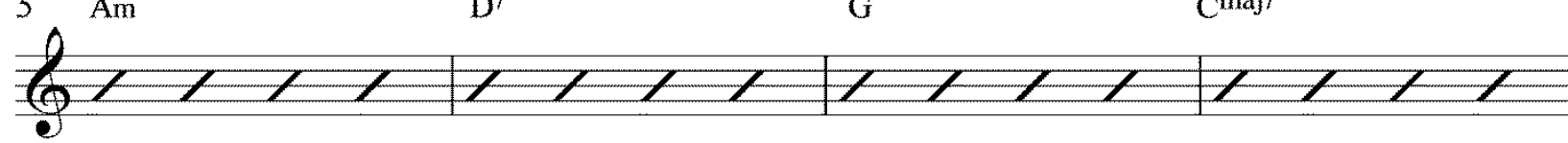

G Major
$9 \mathrm{Am}^{7}$
$\mathrm{D}^{7}$
G

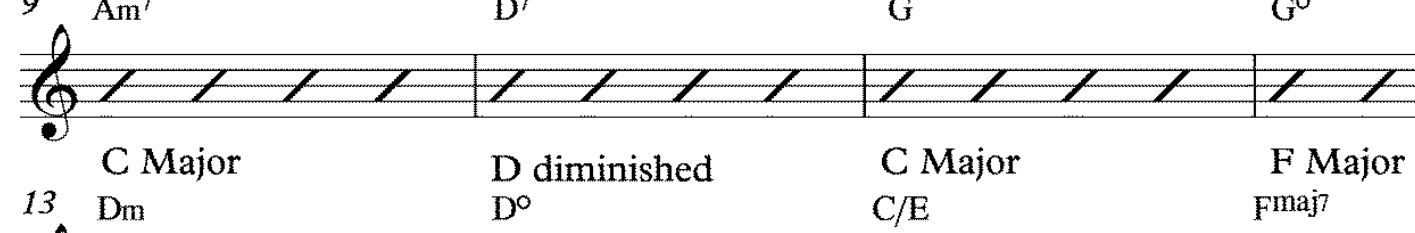
$13 \mathrm{Dm}$
$\mathrm{D}^{\circ}$
$\mathrm{C} / \mathrm{E}$
Fmaj

G diminished

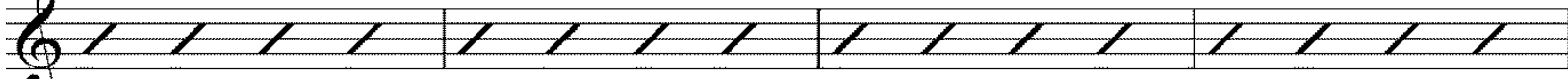


Figure 2.4: Roman numeral analysis of measures 1-16 of Prelude I of the Well-Tempered Clavier.
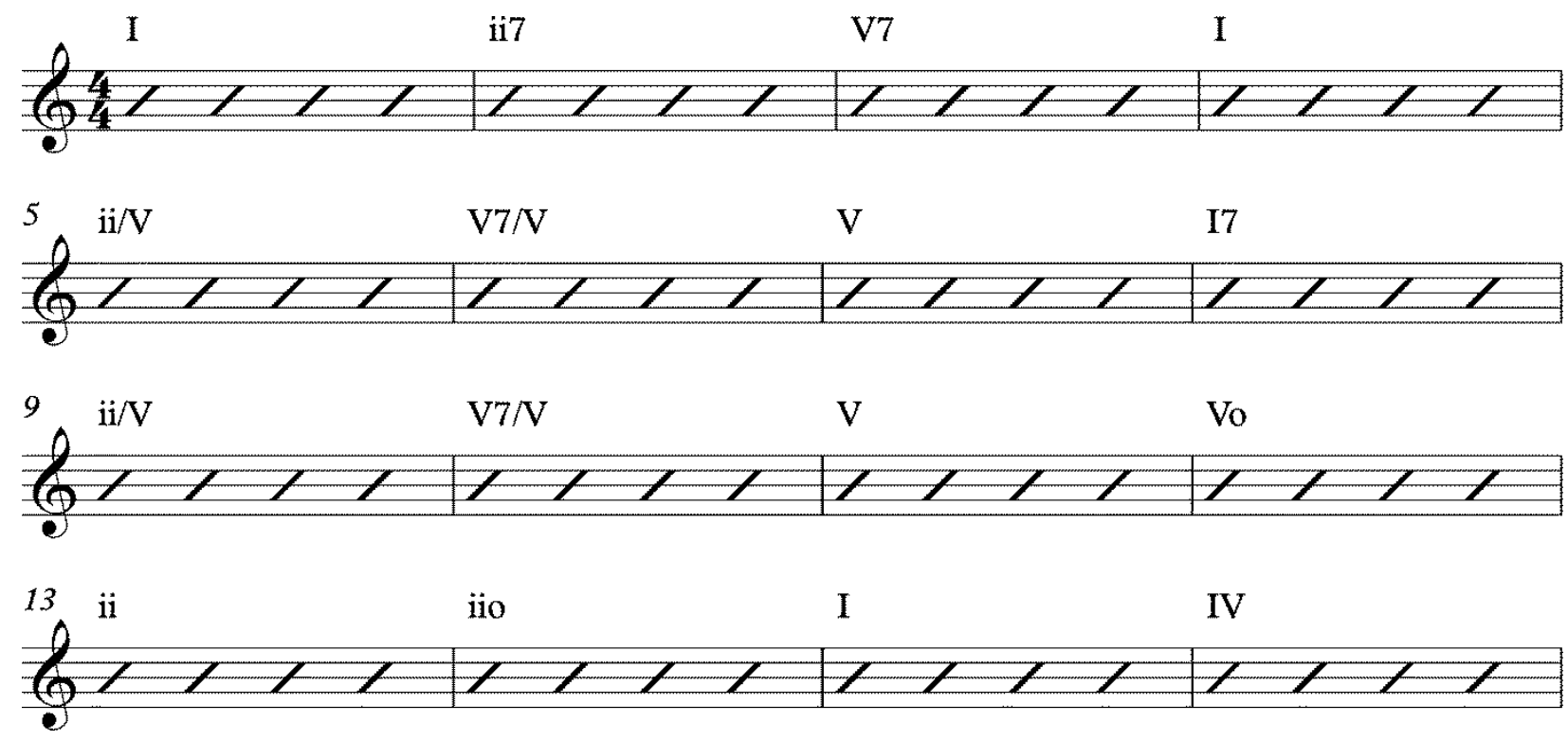
Figure 2.5: Improvisation over pop chords for measures 1-16 of Prelude I of the Well-Tempered Clavier.
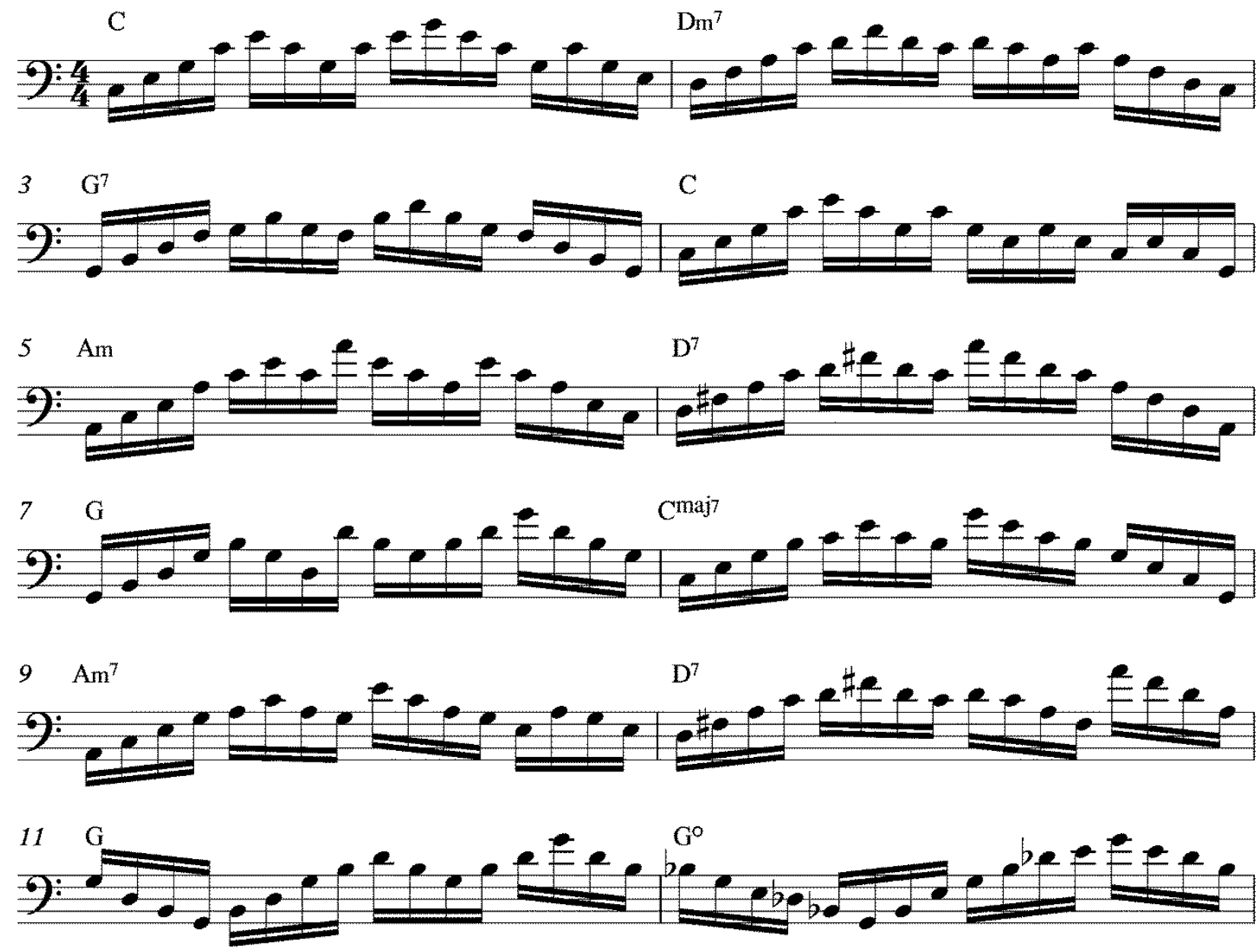

Improvisers should review the five-step process presented in figures 2.1 through 2.5 when studying additional compositions, such as the Prelude of Cello Suite I presented in figure 2.6. 
Figure 2.6: Analysis of Prelude from Cello Suite I, with pop chords, roman numerals, and tonalities.

Tonalities: G Major

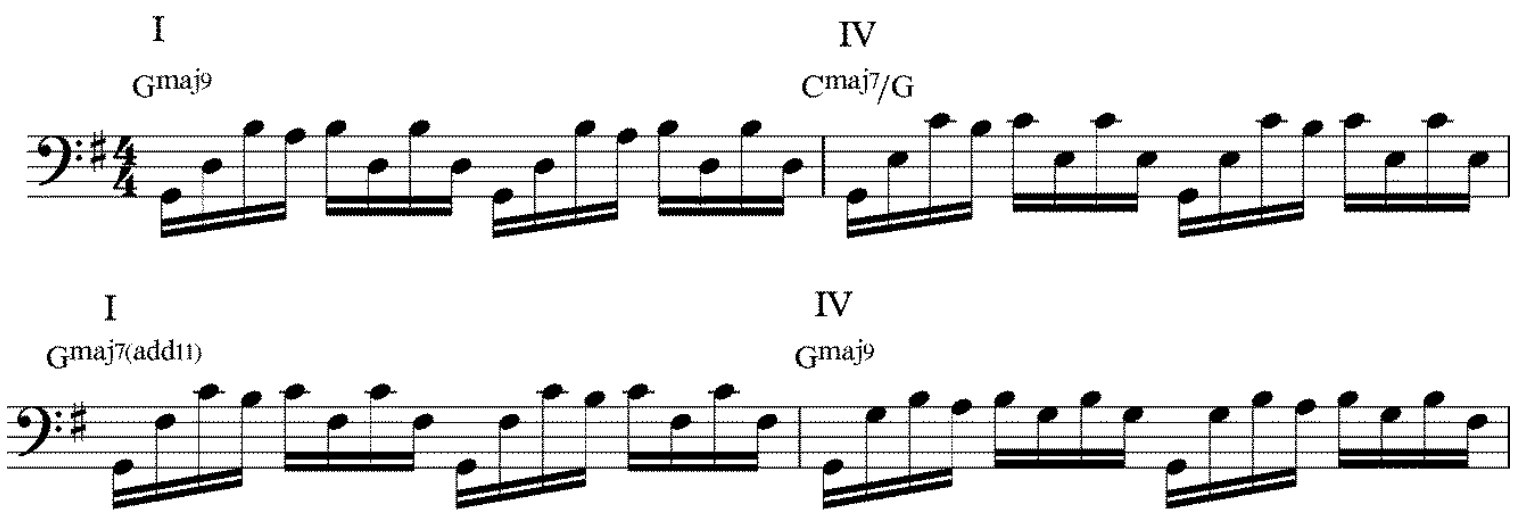

D Major

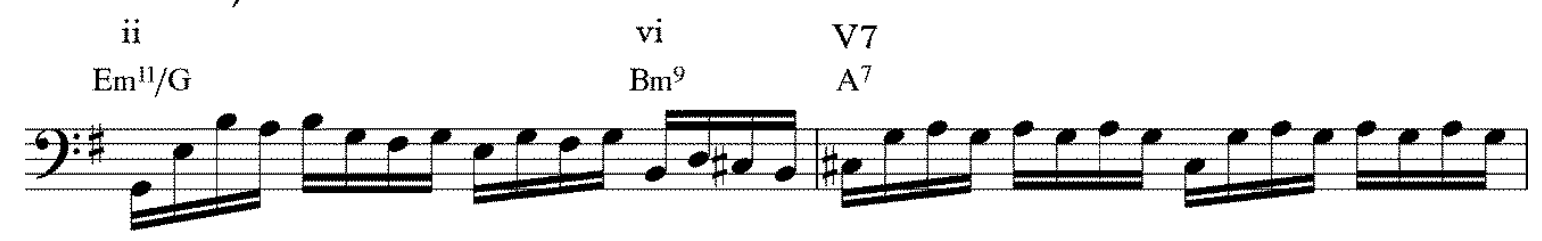

I

ii
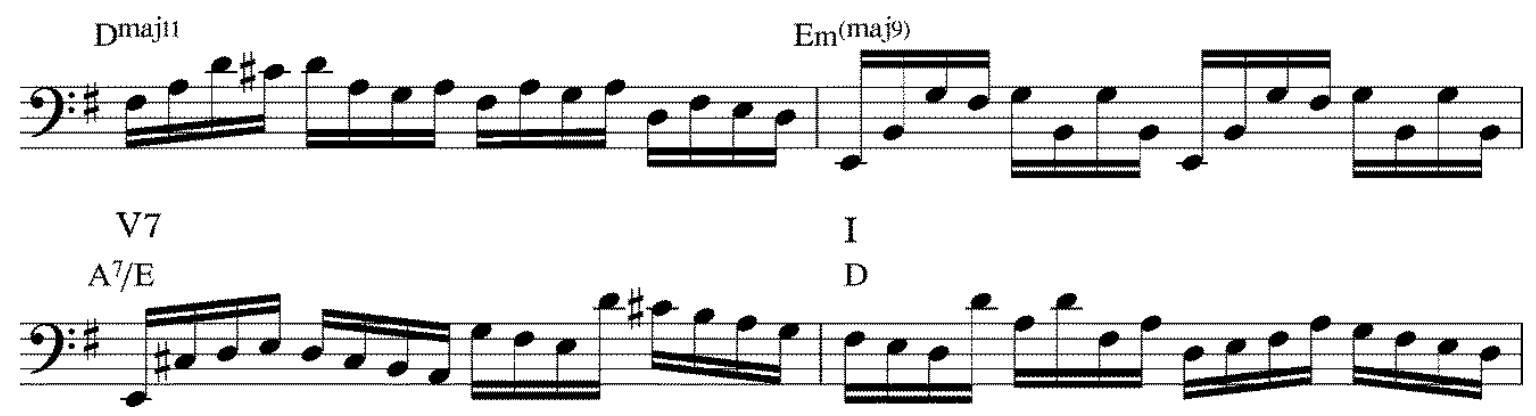


\section{The V7 Chord: Its Transitional and Cadencial Properties}

A common use of the V7 chord is the production of cadences and modulations. In jazz and other blues-influenced genres, V7 is often the home chord to which modulations resolve. This section covers the cadencial/transitional properties of the V7 chord. The musical examples are derived from passages that lead into cadencial resolutions to the respective tonic chords. Figures 2.7 through 2.12 are examples of how dominant and secondary, or substituted, dominant chords enhance and prolong cadencial resolutions.

Improvisers often use chord substitutions to color harmonies and present technical facility. The exercises contained in figures 2.7 through 2.12 employ chromatic modulations that add interest and appeal to improvised solos. The techniques presented in this section also add harmonic motion to modal pieces, such as Little Sunflower, by Freddie Hubbard and So What, by Miles Davis.

Melodic development that includes a beginning, middle, and end is essential in improvised music. Figures 2.7 through 2.12 will strengthen students' understanding of transitional, or development, sections. Students should internalize these figures conceptually, in order to apply each exercise throughout the entire range of their instruments. They dissect a process that begins with an excerpt of the music as written, and conclude with modifications of the same excerpt that can be used in a sequence that prolongs the cadencial resolution and builds harmonic and melodic motion. 
Figure 2.7: First 4 measures of Cello Suite I, repeating and modulating up by half-steps in a sequence of V7 chords.
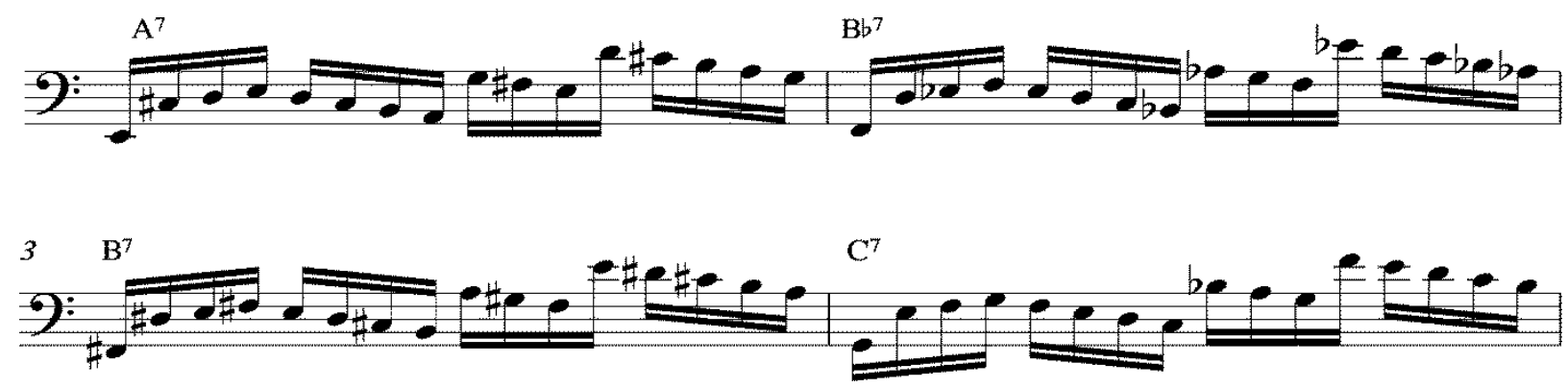

Figure 2.8: First 4 measures of Cello Suite I, repeating and modulating up by half-steps in a sequence and flowing from one key to the next in steps instead of leaps.
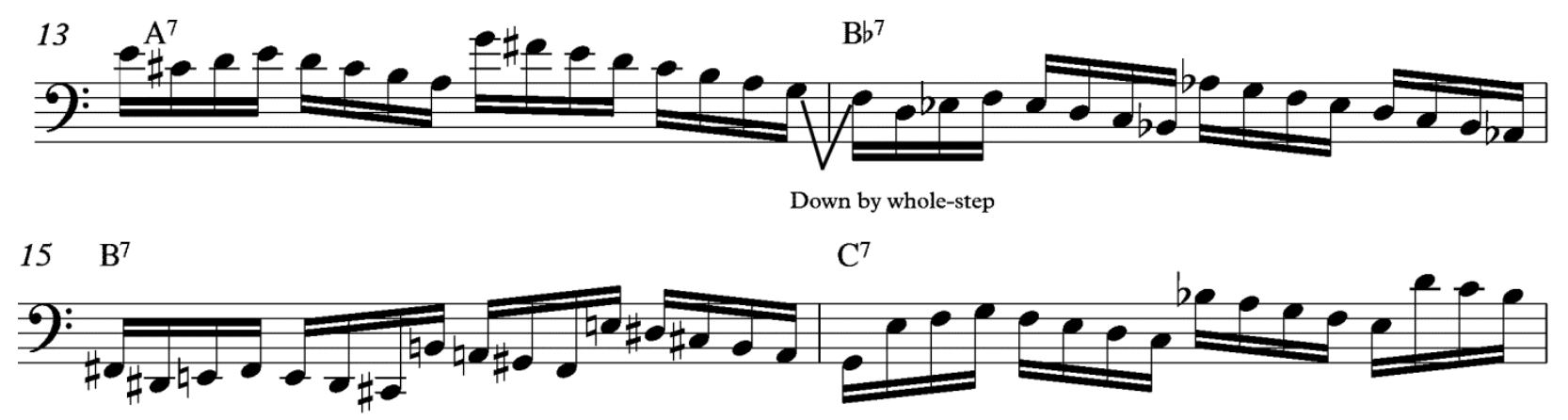

Figure 2.9: First 4 measures of Cello Suite I, repeating and modulating up by whole-steps.
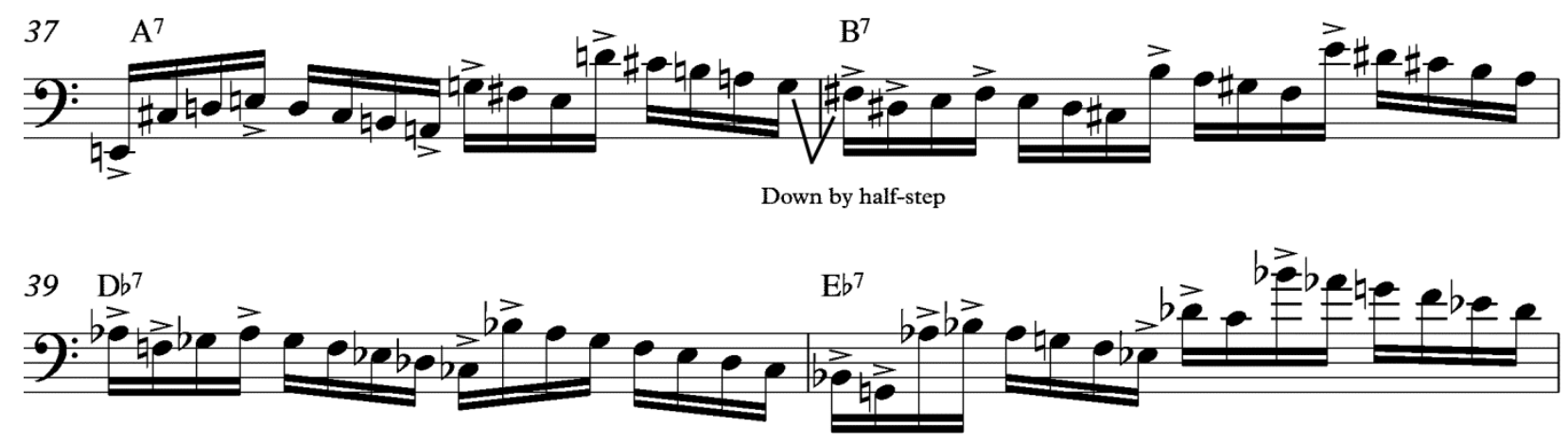
Once students possess an applicable understanding of each of these figures, teachers should instruct them to modify each exercise to their individual needs and preferences. Students should create additional methods of internalizing these types of cadencial motion. They should also derive their musical excerpts from other passages of Bach's music.

\section{Tonal Ambiguity}

When improvisers add "weak" scale degrees and altered tones in conjunction with strong harmonies, they enhance tonal transitions and chord structures and create harmonic and tonal ambiguity. Due to the intricate nature of this concept, teachers should instruct students to internalize and reinforce the exercises contained in figures 2.1 through 2.9 prior to studying figure 2.10 .

Figure 2.10 is an illustration of how improvisers can imply alternate/chromatic tonalities over tonal harmonies. It presents Sonata in A Minor for Flute Solo over a Bb major $7^{\text {th }}$ chord. The first pitch functions as the sharp $11^{\text {th }}$ scale degree, and the A and G\# briefly mix major and dominant tonalities. The final result is a suspension of the $\mathrm{Bb}$ major tonality that the performer may resolve later. This is an advanced technique and students who prematurely exercise these techniques may be overwhelmed by the harmonic implications of working in these advanced techniques. Students should utilize additional excerpts in creating their own tonal experiments and discovering what "works" and what "doesn't work" for expressing their original ideas. Figure 2.11 develops this harmonic suspension/ambiguity concept into a melodic sequence of tonal modulations. 
Figure 2.10: Measure 1 of Sonata in A Minor for Flute Solo over a B-flat major $7^{\text {th }}$ chord.

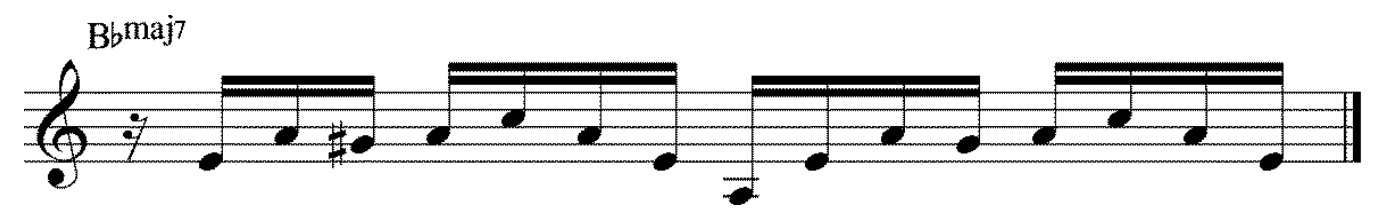

Figure 2.11 instructs students to revisit the techniques in figures 2.7 through 2.9. It introduces a chromatically descending melodic sequence over a chromatically ascending harmonic sequence. Teachers should instruct students to use these techniques on their instruments as well as at keyboard instruments. Students who work with these concepts will strengthen their internal concept of melodic motion, thus improving their command of using this motion in improvisations.

Figure 2.11: Measure 1 of Sonata in A Minor for Flute Solo over a descending series of half-step modulations.
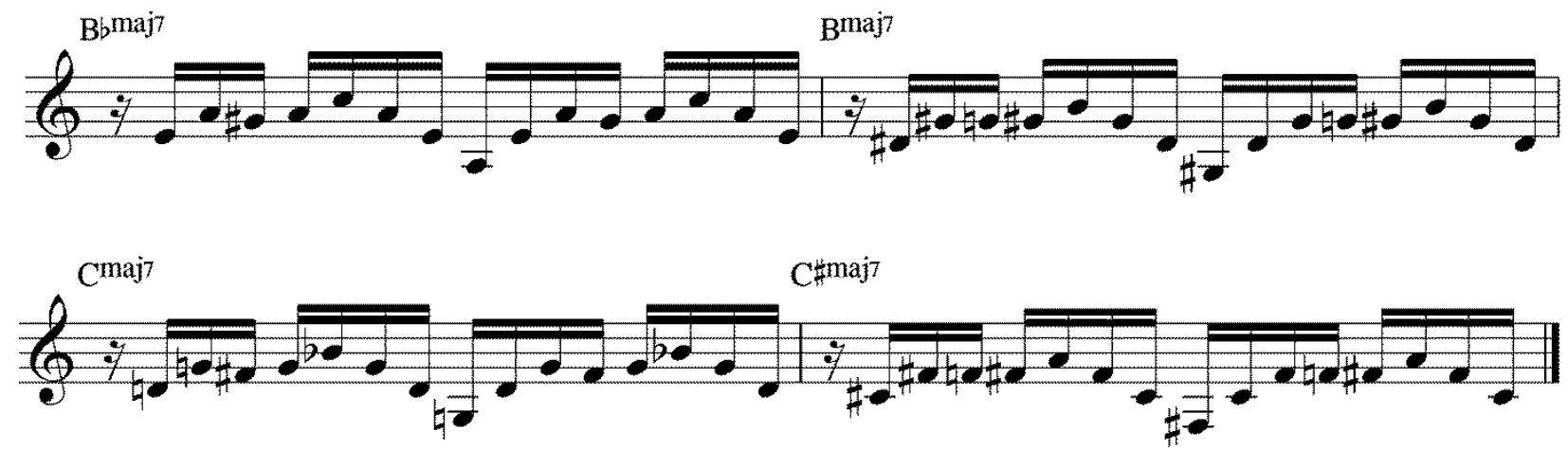

Studying the melodic passages contained in pieces such as the Sonata in A Minor for Flute will aid students in creating musical phrases that progress either toward the next musical phrase or toward the end of the improvisation. Figure 2.12 incorporates the opening of this sonata into a chromatically descending sequence that prolongs cadencial resolution. The resulting phrase can be superimposed over an $\mathrm{F}$ major triad or $\mathrm{F}$ dominant $7^{\text {th }}$ chord, resulting in a combination of major and minor tonalities over a single harmony. 
Figure 2.12: Four-note pattern based on measure 1 of the Sonata in A Minor for Flute Solo over a descending series of half-step modulations.

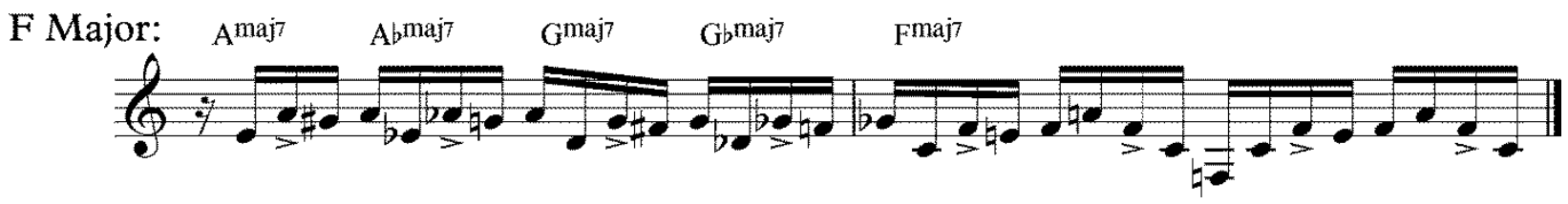

Once students have developed an understanding of forward harmonic motion it is important for instructors to incorporate tetrachords, or four-note patterns, into their improvisation lessons. These pattern studies should also include three-note and five-note groupings. Although this research document does not define specific scales, patterns studies such as those presented in figure 2.12 and figures throughout Chapter 3 are appropriate techniques for understanding the whole-tone, major pentatonic, and other scales and tonalities. 


\section{Chapter 3: Fugue}

Improvisers will strengthen their command of musical conflicts and resolutions by exploring subject-countersubject relationships. By experimenting with these polarized characters, improvisers can establish melodic and harmonic interest and familiarity. This chapter has two parts. The first section discusses ways to develop relationships between subjects and countersubjects. The second presents strategies for improvisers to use fugue-like devices in creating intricate melodic material based on simple harmonic statements. The subject-countersubject relationships don't necessarily have to be what Bach composed in order for musicians to cultivate these techniques. Teachers should encourage students to develop originality as well.

\section{Developing Subject-Countersubject Relationships}

Common harmonic progressions such as the blues and rhythm changes have development sections incorporated into their chord structures. However, when improvisers play random pitches that fit over the chord changes of the bridge, IV chord, or some other brief harmonic development they don't necessarily create nor sustain melodic interest. The following two guidelines aid musicians in creating improvised subjects:

1. Improvised melodies should progress toward either a conflict or a resolution.

2. It is extremely helpful if the subject material is somewhat tuneful and memorable. This makes the act of developing spontaneous material more feasible.

The first piece that students will study in this chapter is Fugue I of the Well-Tempered Clavier Book I. Figures 3.1 through 3.11 present techniques for students to employ when 
experimenting with fugal improvisation. The melody consists of a predominantly step-wise opening statement that students should internalize through solfeggio. Improvisers may interpret the first note as either tonic in the key of $\mathrm{C}$ major, or as dominant in the key of $\mathrm{F}$ major. The techniques that these figures introduce will aid improvisers in creating lines that develop throughout harmonic progressions.

Teachers should instruct their students to study the complete theme, including the subject and countersubject. The students should create a simple melodic statement that they will develop melodically and harmonically. The phrase does not necessarily need to be a metaphorically polite 'hello.' It can be a rowdy salutation as well, as long as it is something that the improviser is able to remember and develop. It can be a selection of somewhat long pitches that outline the harmonic progression, as in the Passacaglia in C Minor in Figure 4.5.

Figure 3.1: Well-Tempered Clavier Book I Fugue I theme including solfege.

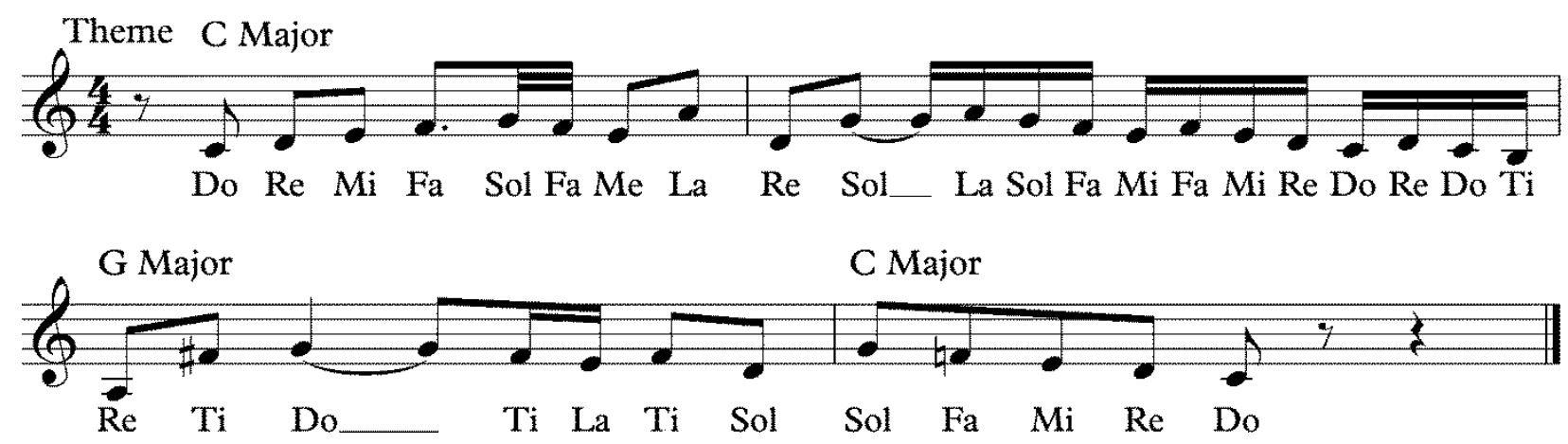


Next, the students should develop their subjects through inversions and variations (see fig 3.2).

Figure 3.2: Modified inversion of Well-Tempered Clavier Book I Fugue I theme.

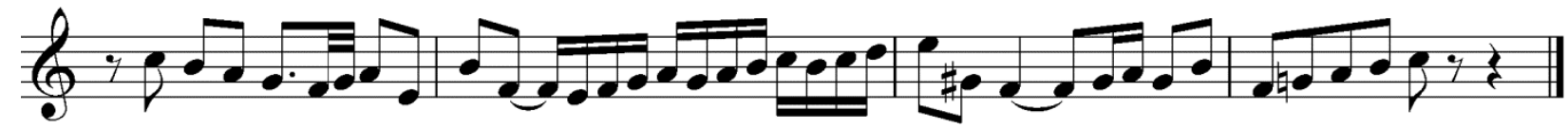

Instruct students to alter pitches and intervals to fit the parallel minor tonality (see fig. 3.3).

Figure 3.3: Well-Tempered Clavier Book I Fugue I theme altered to fit the parallel minor tonality.

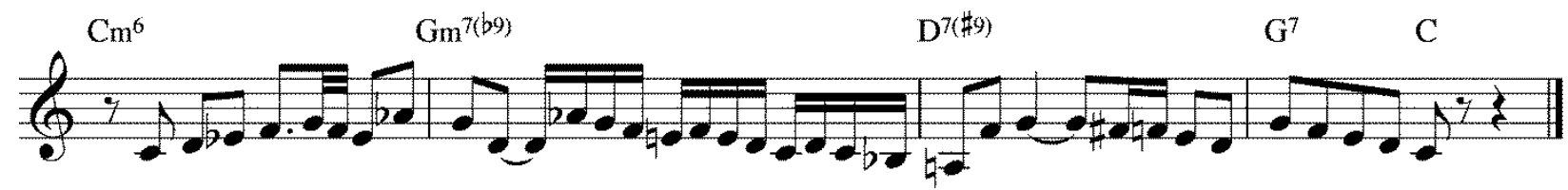

Experiment with the relationship between the subject and countersubject. Figure 3.4 is an alteration of the theme that juxtaposes A natural minor with the pre-existing $\mathrm{C}$ major tonality.

Figure 3.4: Well-Tempered Clavier Book I Fugue I theme altered to outline A natural minor over C major.
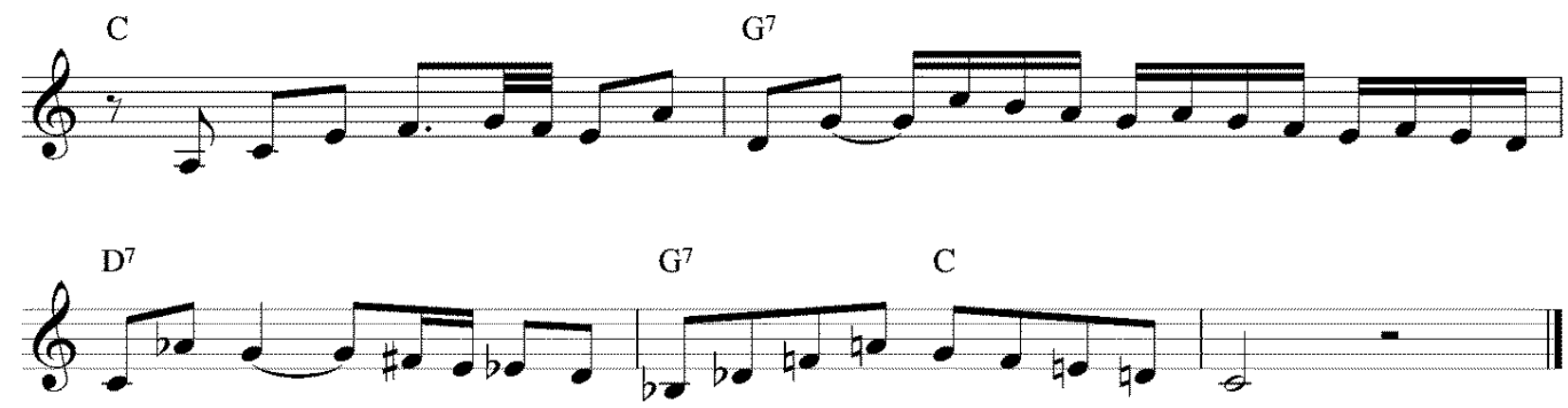
Incorporate four-note patterns (tetrachords) into sequences that repeat and modulate in ascending half-steps. Place accents on various notes in the sequence to add rhythmic interest as well (see fig. 3.5).

Figure 3.5: Well-Tempered Clavier Book I Fugue I four-note motive ascending in half-steps.

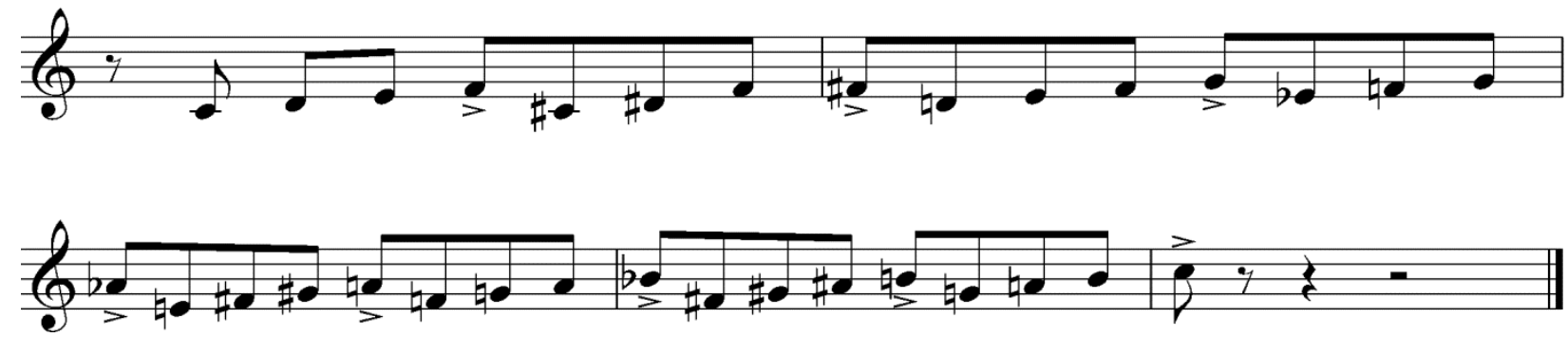

Create additional tetrachord sequences that outline ascending whole-tone scales (see fig.

\section{6).}

Figure 3.6: Well-Tempered Clavier Book I Fugue I four-note motive ascending whole-tone scales in halfsteps.
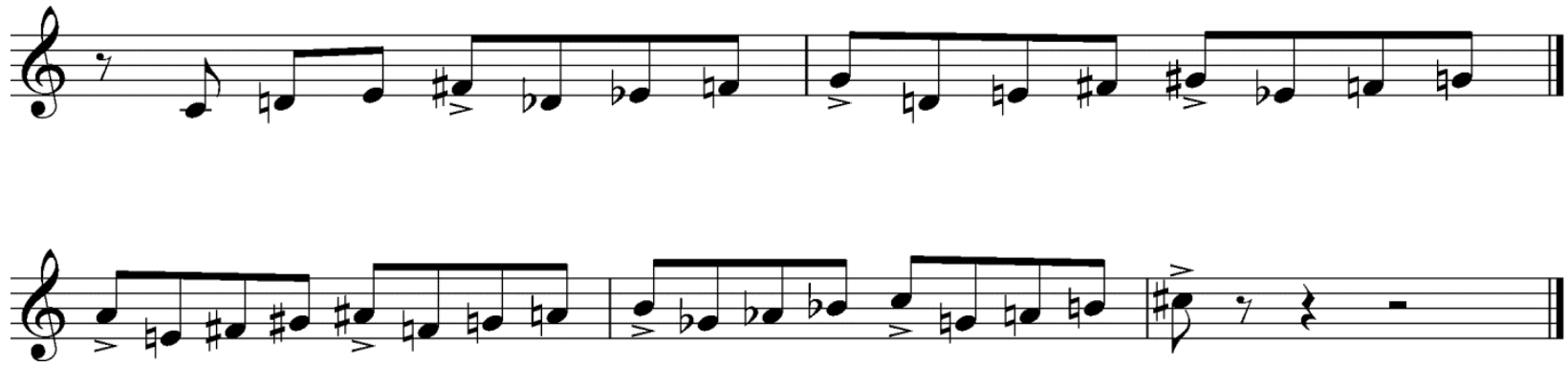
Outline ascending diminished $7^{\text {th }}$ chords in the same manner as figures 3.5 and 3.6 (see fig. $3.7)$.

Figure 3.7: Well-Tempered Clavier Book I Fugue I four-note motive ascending diminished $7^{\text {th }}$ chord in halfsteps.
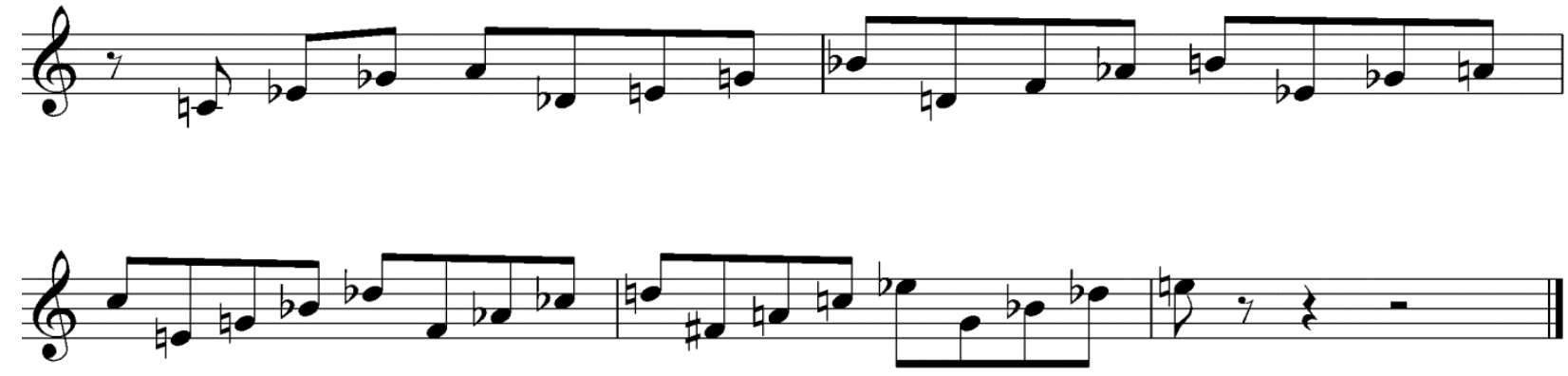

Instruct students to alter the first five notes of the subject to spell a major pentatonic scale (see fig. 3.8). This ascending sequence alternates between the tonic pentatonic and the pentatonic scale a tritone away. As Chapter 2 discusses, this type of melodic motion creates tonal ambiguity.

Figure 3.8: Well-Tempered Clavier Book I Fugue I four-note motive ascending major pentatonic scales a tritone apart.
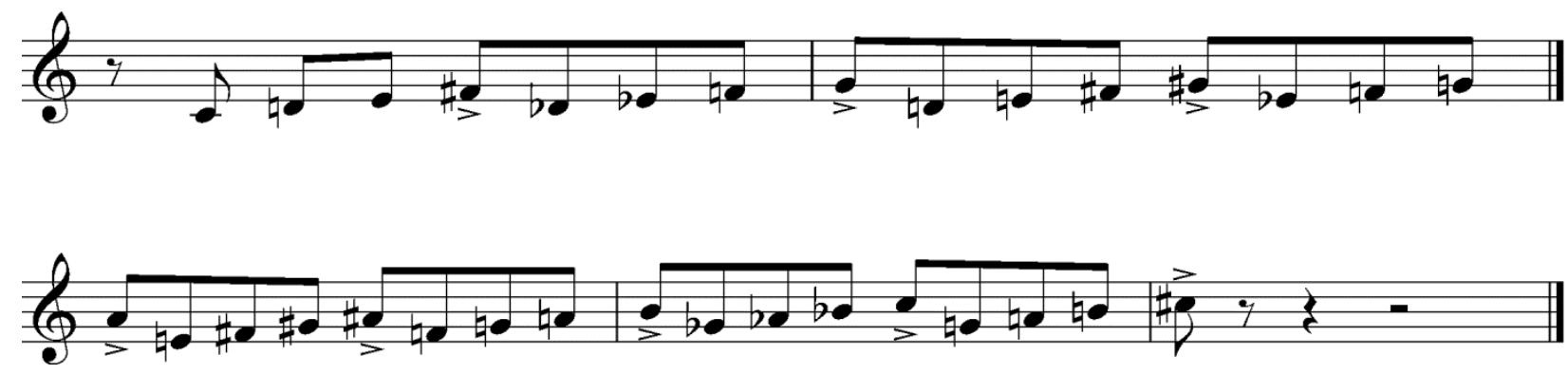
Students should also create variations of the subject that modulate in descending patterns (see fig. 3.9).

Figure 3.9: Well-Tempered Clavier Book I Fugue I three-note motive descending major pentatonic scales a tritone apart.

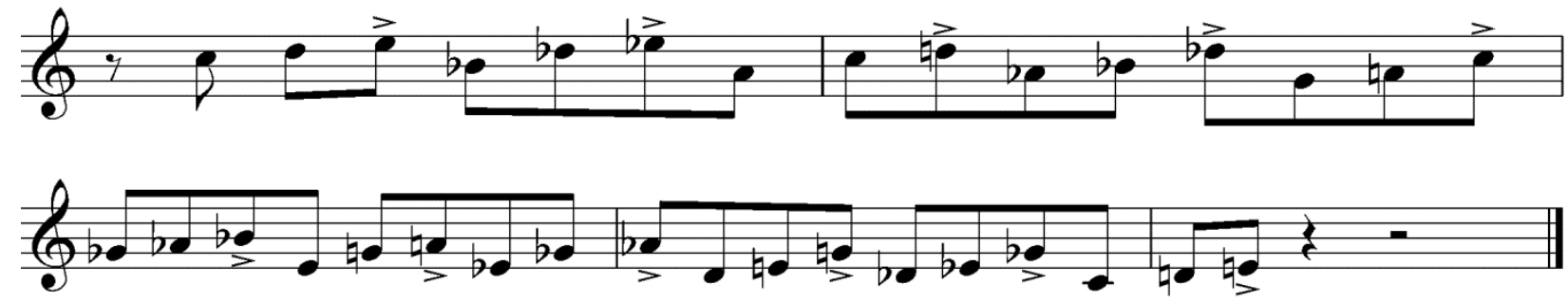

Produce a tonal sequence that ascends and descends within a single tonality (see fig. 3.10).

Figure 3.10: Well-Tempered Clavier Book I Fugue I four-note motive that ascends and descends within a single tonality.
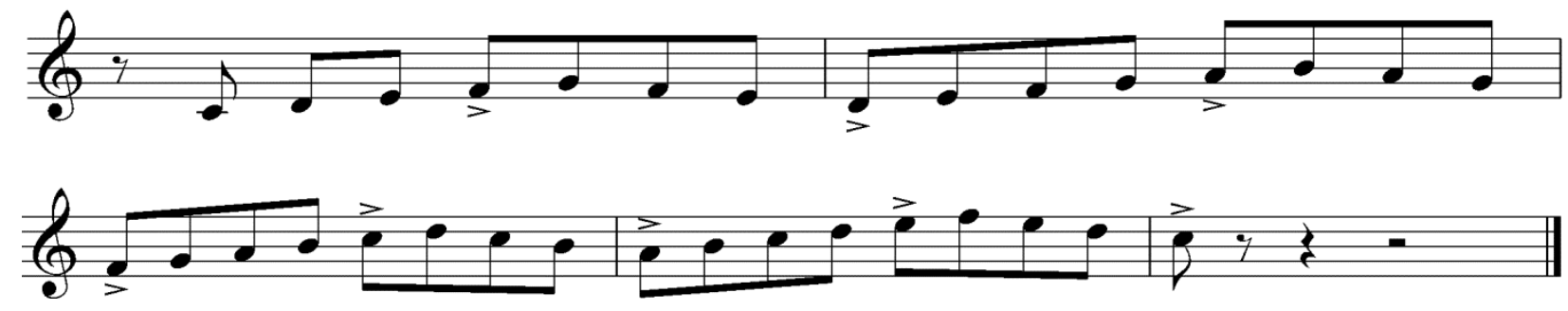
Alter the motive by combining ascending and descending pentatonic scales a tritone apart (see fig. 3.11).

Figure 3.11: Well-Tempered Clavier Book I Fugue I four-note motive that ascends and descends alternating pentatonic scales a tritone apart.

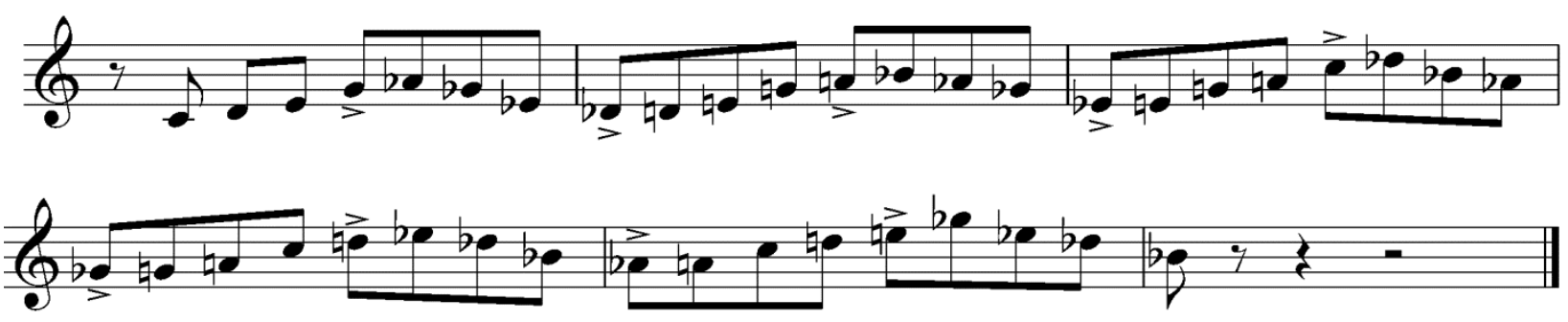

Invert the motive into an ascending combination of major pentatonic scales a tritone apart (see fig. 3.12).

Figure 3.12: Well-Tempered Clavier Book I Fugue I inverted four-note motive ascending alternating pentatonic scales a tritone apart.

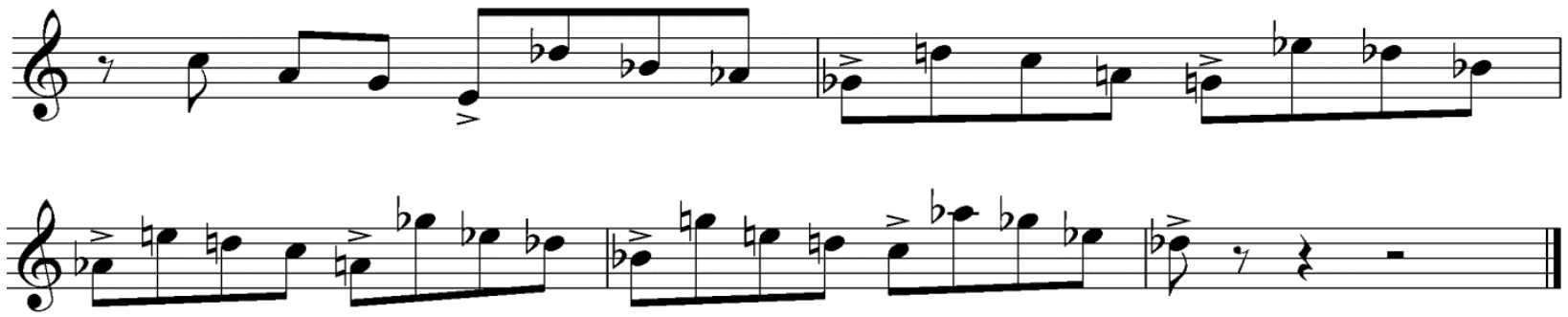


Instruct students to state the subject and counter subject with an ascending half-step modulation between them (see fig. 3.13).

Figure 3.13: Well-Tempered Clavier Book I Fugue I subject and countersubject with an ascending half-step modulation between them.

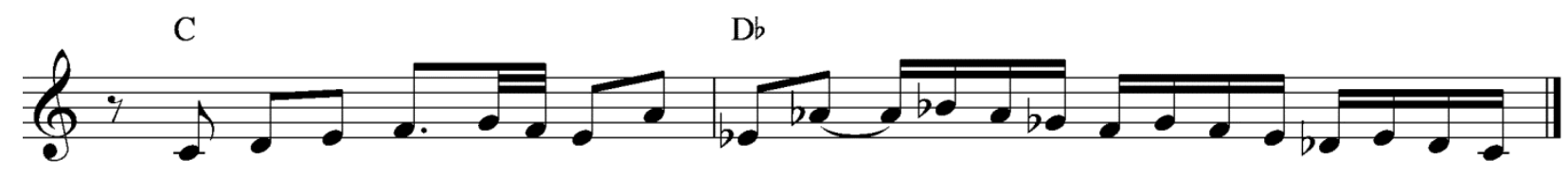

Create sequences that begin a whole-step below the original tonality and modulate throughout the entire statement of the theme (see fig. 3.14).

Figure 3.14: Well-Tempered Clavier Book I Fugue I theme with a sequence of ascending half-step modulations between measures.
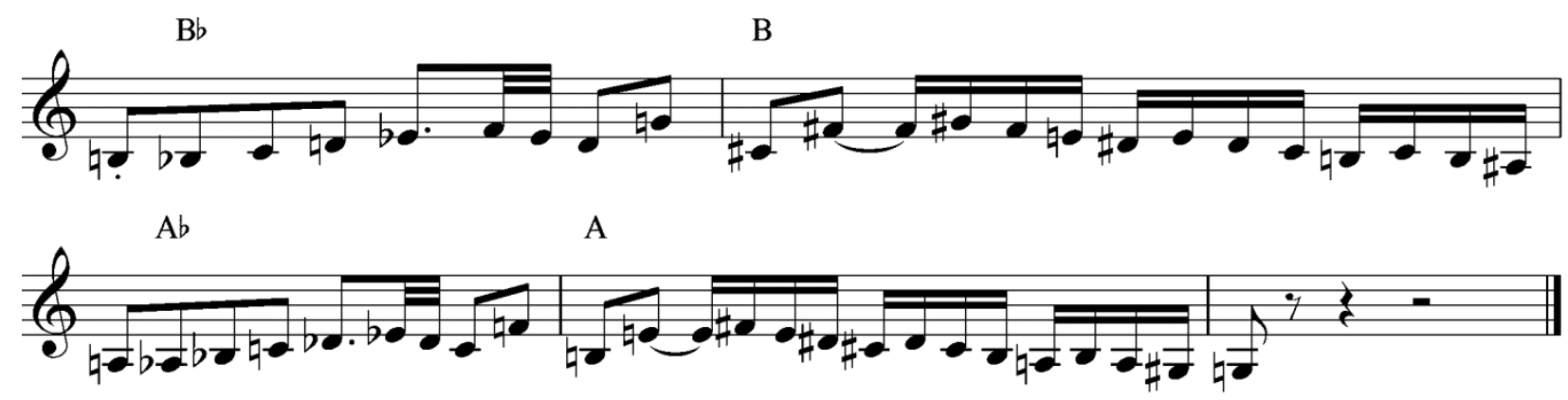

Students may become overwhelmed while learning these techniques. In order to alleviate stress, it is helpful for students to strengthen their understanding of each exercise prior to moving on to the next one. This will help to ensure a sense of empowerment that is vital to successful learning and performance of these improvisation techniques. 


\section{Developing Complex Melodic Material}

The next portion of this chapter discusses strategies for developing complex melodic material based on simple, introductory, harmonic statements. This section focuses on group improvisations, but teachers and students may alter the techniques for individual study. The musical examples in figures 3.15 and 3.16 come from Contrapuncti II and V of The Art of Fugue. The analyses of these fugues includes pop chord symbols.

It is often extremely challenging for performers to maintain command and melodic direction in improvised music. By basing melodies on simple, or simplified, harmonic material, practitioners can create new pathways toward manageable improvisations. Studying Contrapuncti II and V is especially helpful for improvisation students to hone strategies for gradual development of tonal harmonic structures. Both melodies are akin to improvisations and explore the diatonic harmonies associated with their respective tonalities. The limited melodic ranges of both pieces work well for various instrumental registers.

The melody in Contrapunctus II begins with a simple outline of the tonic triad, followed by an authentic cadence and alternation between G minor and D minor (see fig 3.15). Rather than outlining the tonic triad, Contrapunctus $\mathrm{V}$ begins with a simple exploration of the harmonic structure (see fig. 3.16). Both contrapuncti contain melodic material that students and teachers can extract for developing additional exercises that are similar to those in Chapters 2.

This section provides an opportunity for teachers to create their own exercises. It is essential that teachers of this Bach-based methodology create exercises that are tailored to the needs of their unique students. 
Figure 3.15: Art of Fugue Contrapunctus II with pop chords.

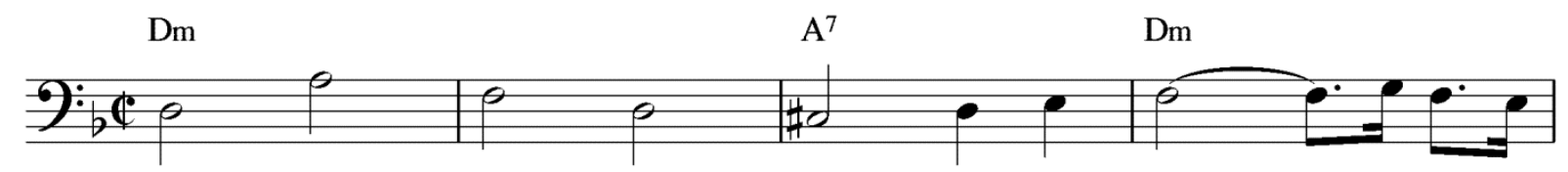

Second statement of subject. Over an exploration of the harmonic outline

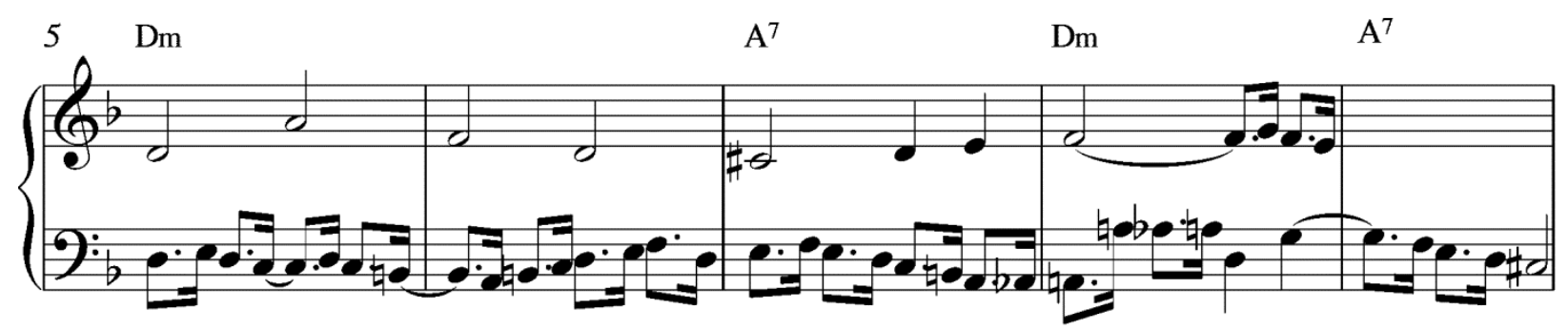

$10 \mathrm{Gm}$

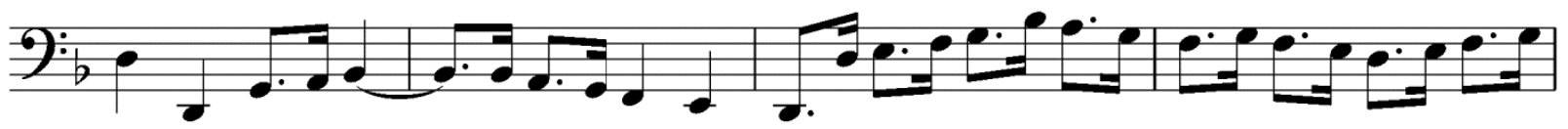

$14 \mathrm{Dm}$
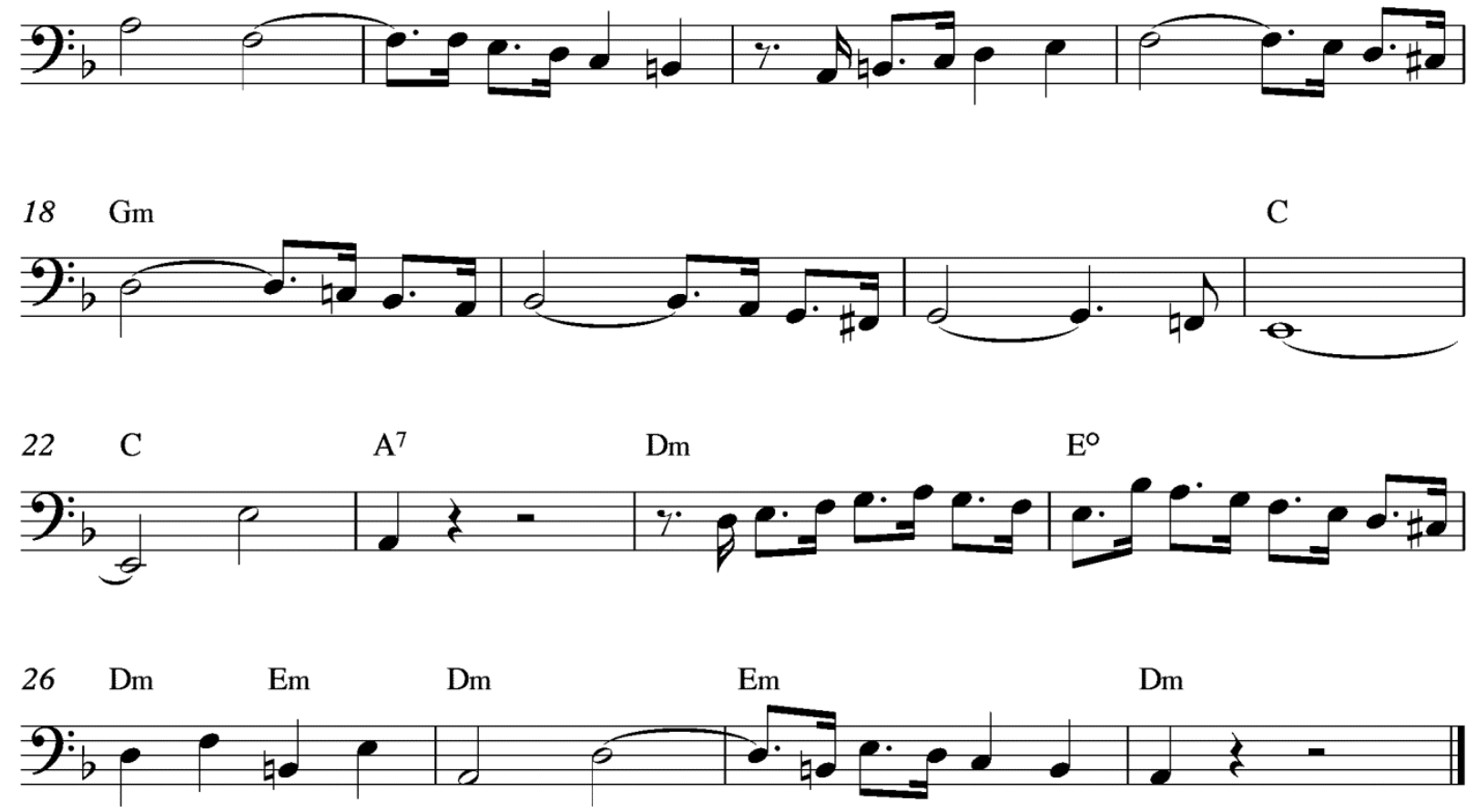
Figure 3.16: Art of Fugue Contrapunctus V with pop chords.
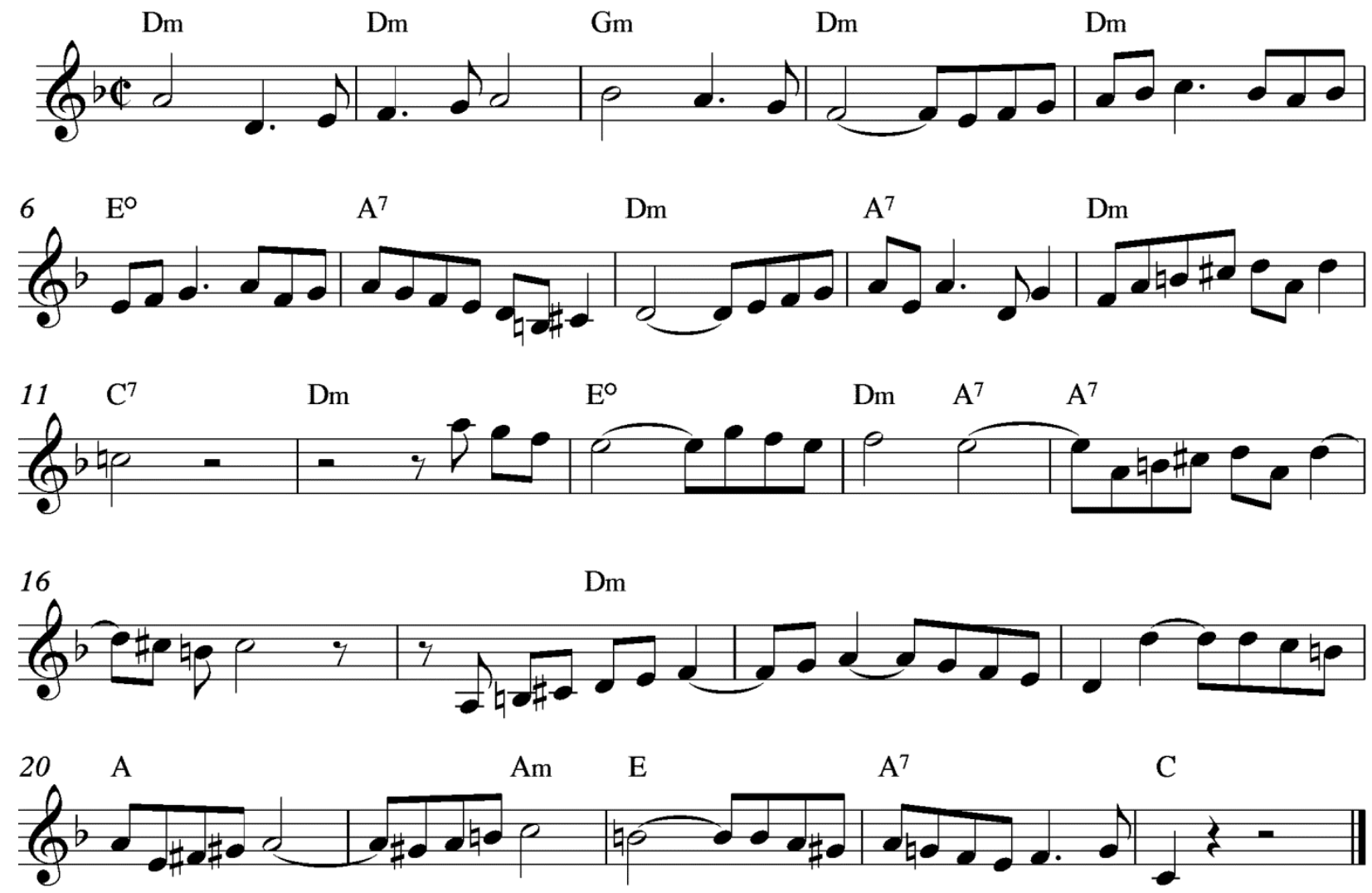

Newcomers to improvisation should make a few decisions about musical variables prior to beginning improvisations. They can determine in advance of the first note, the tonalities, tempo, harmonic structure, and any other information they will introduce in the piece. Once the improvisers choose these parameters, they should begin the piece with a simple, repeatable harmonic outline, such as the one from Contrapunctus II (see fig. 3.12). They should repeat this harmonic skeleton enough to internalize it and plant it in the audience members' minds. Next, should be the introduction of simple embellishments of the harmonic structure, followed by the first statement of motivic or thematic material. Performers should periodically return to the initial harmonic outline in order to reinforce familiarity and add breaks in the flow of spontaneous creativity. As the improvisation continues, the performers should introduce additional repeatable phrases. These phrases will maintain familiarity and add suspense. Improvisers should also add 
borrowed modes, secondary dominants, and bi-tonalities, as discussed in Chapter 2, to produce harmonic tension.

The above procedure aids in the creation of manageable improvisations, so that performers are not overwhelmed by complexity. Ending a fugal improvisation can be challenging for students, especially in pieces that have an overwhelming amount of forward motion, or that haven't developed enough to warrant an ending. In either of these cases, finding a simple way to end the piece is helpful. It is better to finish an overwhelming improvisation early, than to prolong its end so much that audience members lose interest.

\section{Ensemble Exercise}

Once improvising ensembles have established familiarity with Contrapuncti II and V, they should consult the procedure below:

1. One player introduces the harmonic progression, as in Contrapunctus II, and either repeats it, encouraging another ensemble player to develop the progression through the melodic contour, or develops it him/herself.

2. Another player joins in and restates the subject. Repeat this step until all of the musicians are playing, if so desired.

3. The players develop the subject-countersubject relationship collectively.

4. End the piece.

One challenge associated with this exercise is for each ensemble member to listen to the other players well enough to develop the piece collectively. Listening to each member of the 
ensemble is essential. This is another reason that starting with simple, manageable content is helpful. Basing group improvisations on pre-established melodies can help alleviate this difficulty.

Jazz improvisers should also find fugal improvisation techniques beneficial, especially when trading four or eight-measure phrases based on a repeating theme. Another application of this technique is the exchange of ideas over the course of an entire improvised piece. One soloist may begin or end an improvisation with a motive that the next improviser restates or references during his/her solo.

Fugal improvisations offer players opportunities to develop pieces that include a beginning, development, and conclusion. Although it is not imperative that every jazz or blues solo be a Baroque-like fugue, the formal attributes of fugue can challenge musicians to broaden their creativity and focus. Thus, the music will be more than simple acts of virtuosity and recitations of memorized scale patterns. It will offer audiences melodic themes that can hold their interest while morphing into counter-themes and bridging the gap between performance and observation. 


\section{Chapter 4: Rhythm, Groove, and Drone}

This chapter outlines strategies for strengthening students' command of rhythmic pulses, grooves, and drones. Another goal is for improvisers to understand ways to indicate significant rhythmic moments in a piece of music by using a minimal amount of activity. These moments include cadences, metric and tonal modulations, and other arrival points. Teachers should incorporate the exercises in figures 4.1 through 4.8 into individual and ensemble instruction. Figures 4.1 through 4.4 exemplify a process for creating rhythmic reductions that aid in strengthening improvisers' understanding of harmonic structures. Once students possess an applicable understanding of this strategy they should be instructed to discover their own possibilities. Figures 4.5 through 4.7 encourage students to experiment with combining existing compositions with their own melodic ideas. Figure 4.8 introduces students to drones. The author of this research document defines groove as a repeating bass part (ostinato) that music is improvised over, and drone as any sustained pitch.

Teachers should use the exercises contained in this chapter to empower students to manipulate pre-existing rhythms. The experiments contained in all of the figures will have varying results. The primary goal of this chapter is to broaden students' creativity through experiments that may or may not produce the desired final product. Working in this open-ended educational format reinforces techniques that students learn in Chapters 2 and 3, and builds confidence in these musicians' creative abilities.

Figures 4.1 through 4.4 illustrate the process of rhythmically reducing the Gigue from Cello Suite I. The melodic contour of the original piece serves as the basis for this reduction. The final result only contains indications of strong pulses that students should improvise over in predictable and unpredictable ways (see fig. 4.4). 
Similar to other techniques introduced in this research document, students should begin by studying the music as originally written (see fig. 4.1). Next, the students should place accents over rhythmically significant pitches (see fig. 4.2). What follows is reducing the melodic contour, so all that remains are notes with accents and rests (see fig. 4.3). The fourth step is to improvise using different pitches on the pulses that remain in the final reduction (see fig. 4.4). Players should repeat this improvisation using various tonalities. The last step is experimentation with similarly minimalist rhythmic improvisations. Teachers should also encourage their students to notate rhythmic reductions of the students' original compositions and other pre-existing material.

\section{Rhythm: Cello Suite I Gigue}

Figure 4.1: First 12 measures of Cello Suite I Gigue.

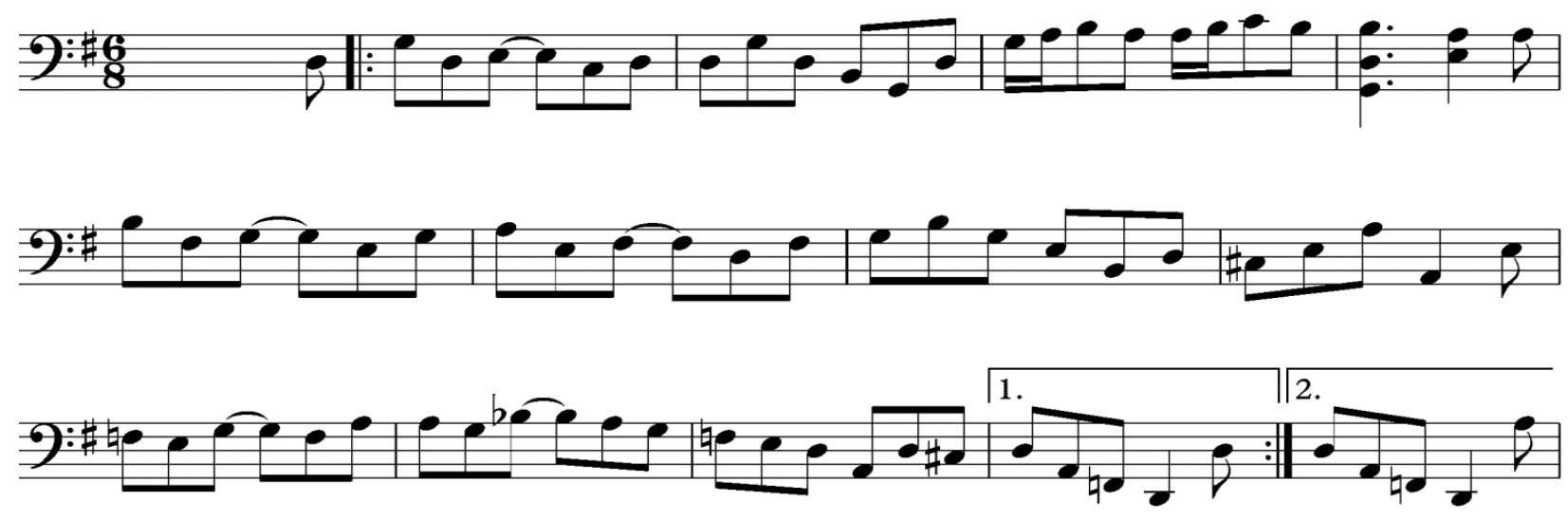


Figure 4.2: First 12 measures of Cello Suite I Gigue with accents added over strong pulses.
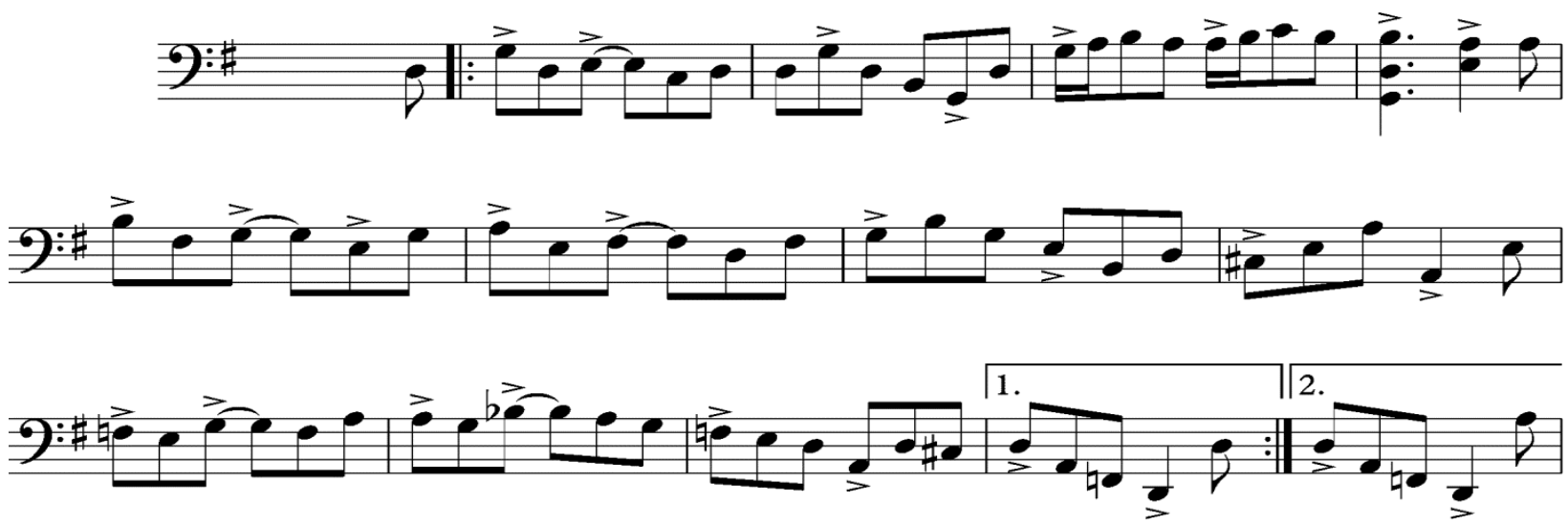

Figure 4.3: First 12 measures of Cello Suite I Gigue accented notes only.
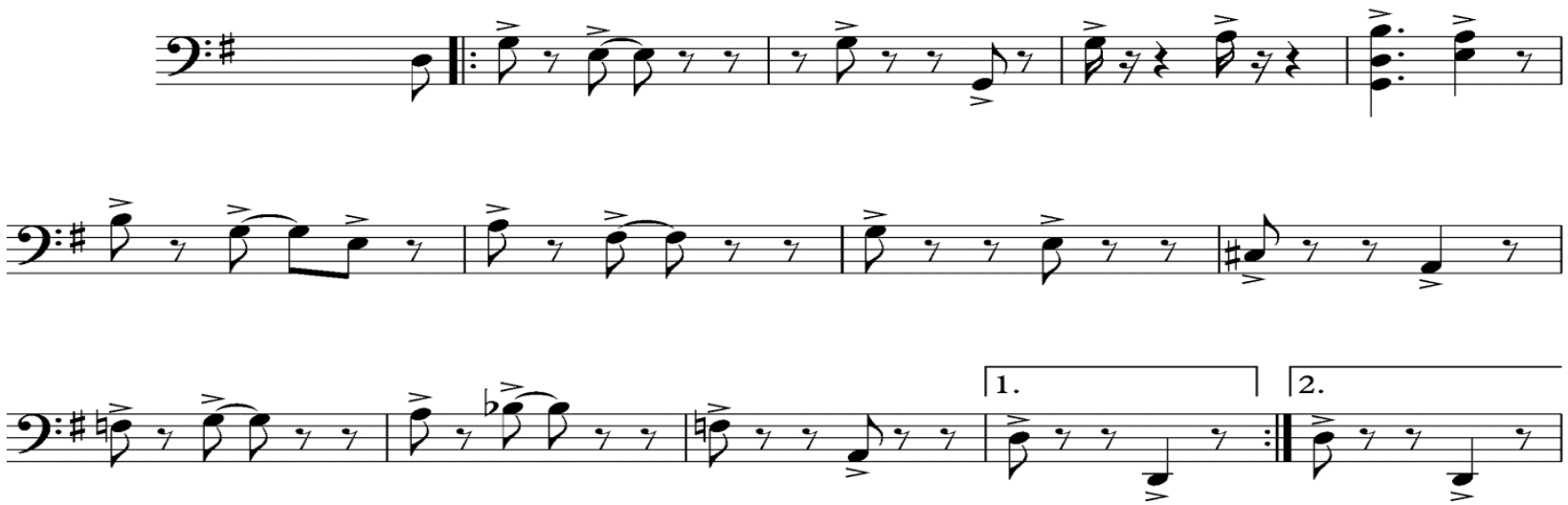

Figure 4.4: First 12 measures of Cello Suite I Gigue accented pulses only.
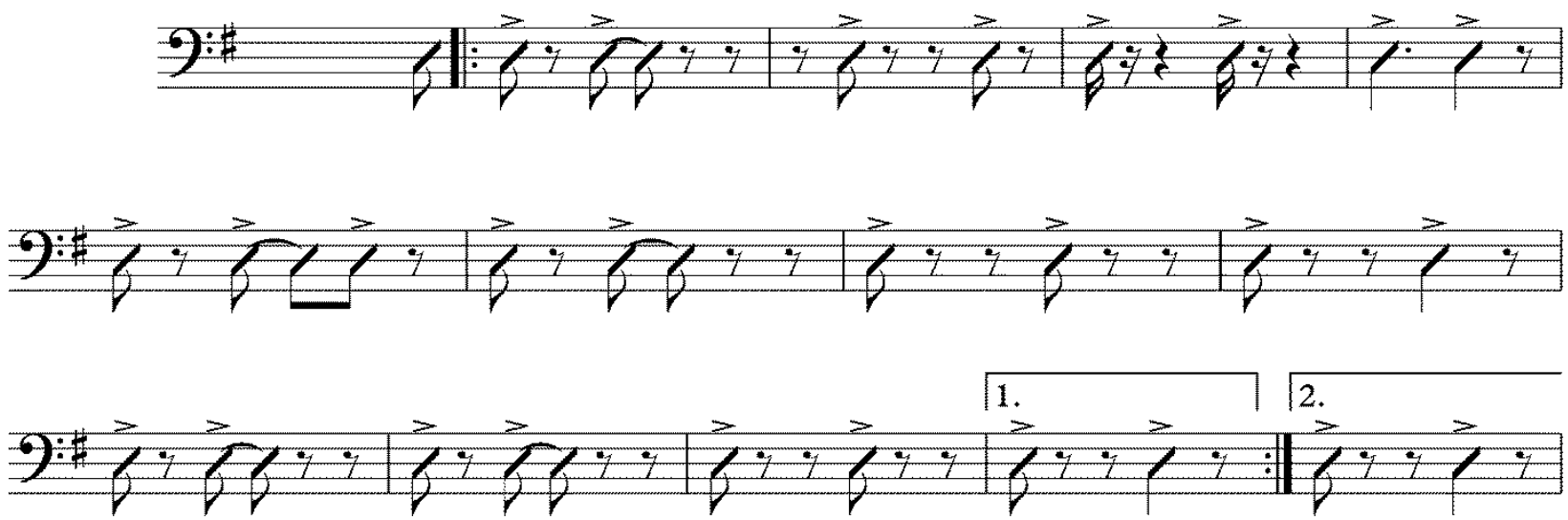


\section{Groove}

Improvising a melody over a bass line or drone is an effective way for students to internalize tonalities and harmonic structures. Contemporary popular music is groove-oriented. Much of it has simple harmonic structures. The remaining portion of the chapter is an introduction to how using repeating bass lines (grooves) and sustained pitches (drones) can strengthen students' improvisation skills.

Figures 4.5 through 4.8 expose students to methods of juxtaposing pre-existing works into new material that will expand their realm of harmonic and tonal possibilities. As with all exercises contained in this method, the goal with this section is the internalization of concepts and musical pathways so they become accessible during performances.

Figure 4.5 is the pedal part from the Passacaglia in C Minor. Improvisers should experiment and add harmonies and melodies over the bass part. They should begin with harmonically simple, manageable content, and gradually add more intricacies. Examples of this technique have intentionally been omitted by the author in order to ensure that students build upon what they learn in Chapters 2 and 3. This is another exercise that allows teachers and students to create exercises based on their unique pedagogical needs.

Figure 4.5: First 8 measures of Passacaglia in C Minor pedal part.

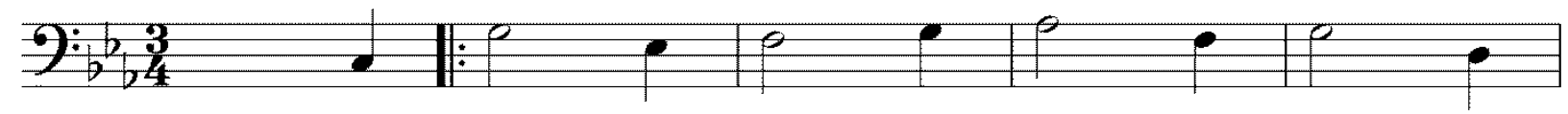

6

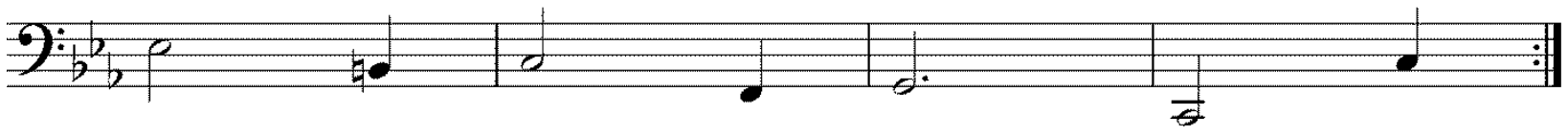


Harmonically simple grooves such as this lend themselves well to metric exploration. Allow students to reinforce and contradict the meter, thus creating metric contrast that can be developed and resolved. Encourage students to juxtapose subdivisions of 3/4, such as $6 / 8$ and $9 / 8$. Encourage them to imply $4 / 4$ and other related meters over the groove.

The use of simple grooves, such as this one, is helpful for inexperienced improvisers to gain confidence prior to working with more intricate techniques, such as Figures 4.6 through 4.7. By experimenting with the juxtapositions in these figures, students will broaden their concept of groove. Some musicians may view the exercises below as etude-like. The primary goal with each of these juxtapositions is to encourage improvisers to experiment based on what is conceivable; not necessarily what sounds "good" or "bad."

Figure 4.6 is a combination of the Sonata in A Minor for Flute Solo and Well-Tempered Clavier Prelude II. The top line is the Sonata in A Minor for Flute Solo as originally written. The bottom part is a version of Prelude II that has been altered into an ostinato in A minor. 
Figure 4.6: Combination of the Sonata in A Minor for Flute Solo and Well-Tempered Clavier Prelude II.
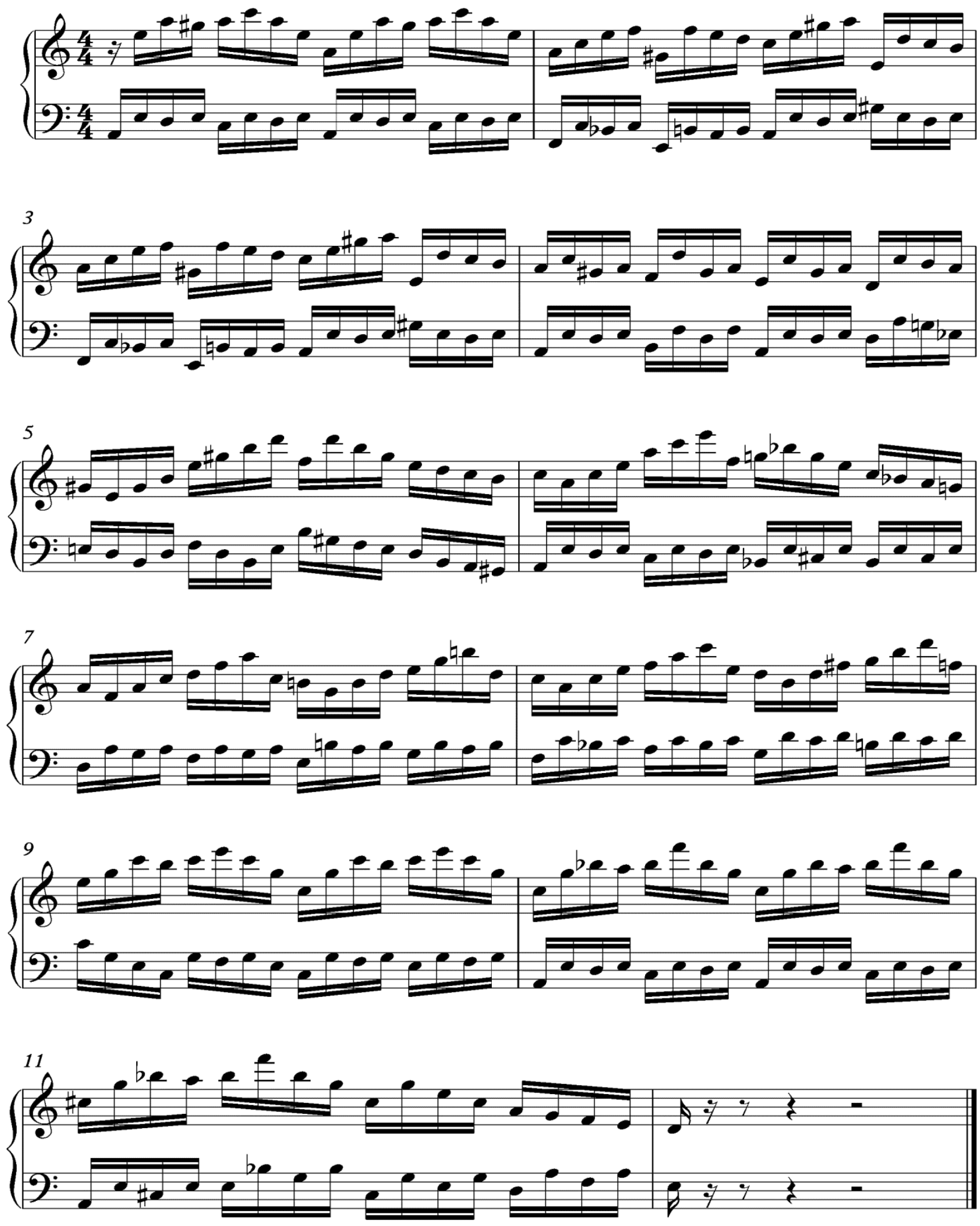
Improvisation students should study the melody (top line) first, then the bass part. If possible, they should practice both together on a keyboard, and experiment with the concepts of both parts. Combining these pieces presents opportunities for students to break the rhythmic rules that performers normally imply with the original motives.

These pieces have complimentary qualities. Both have melodic material that includes arpeggios and step-wise motion. The bass part, derived from WTC Prelude II, establishes the harmonic structure. The flute solo spells out harmonies as it dances around the harmonic structure. Even though the altered bass part fits the harmonic structure of the flute solo, there are brief harmonic clashes and odd notes. These anomalies are pronounced because the majority of the material works together, harmonically.

This improvisation method is not concerned with authentic performance and study of Bach's or other composers' music. What it does validate, however, is altering and experimenting with music to the likings of performers. Even though Bach's music is considerably tonal compared to twentieth-century and twenty-first-century music, it is fertile soil for beginning such study of groove and sonic possibilities. Below are additional guidelines for teachers to consult when encouraging students to juxtapose compositions:

1. Choose combinations of works that don't necessarily seem to fit together. This will empower improvisers by reassuring them of the freedom they have to work with musical masterpieces.

2. Encourage students to dissect and manipulate compositions to their liking and/or needs.

3. Assign roles to each piece in the juxtaposition. At minimum, decide which part will serve as the bass. This preparation will be useful for establishing grooves and emphasis. 
Figure 4.7 is a juxtaposition of the gigues from Cello Suite II and Violin Sonata VI. The violin part is on top and the cello part is on the bottom. The violin gigue is unaltered. However, the ostinato bass part utilizes only the first two measures of the cello gigue. The new material is in D harmonic minor. This combination works well in funk and swing, and possibly other genres.

Figure 4.7: Combination of the gigues of Cello Suite II and Violin Sonata VI.
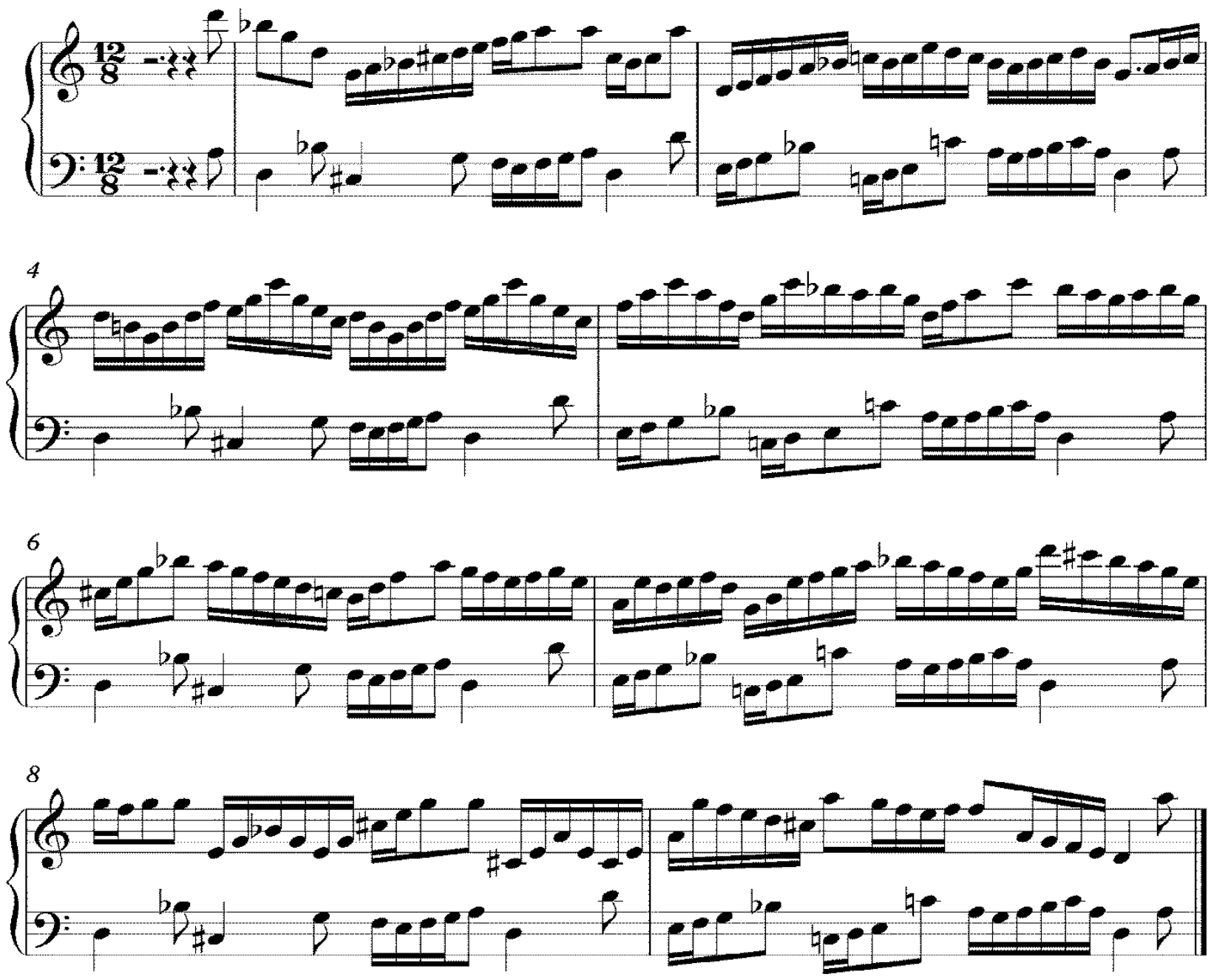

Students should study and analyze the gigue combination harmonically and rhythmically. Improvisers should imply rhythmic accents on certain beats. Beats 1, 4, and 9 of the odd-numbered measures should be accented by students in order to carry this implication. The even-numbered 
measures are lyrical and melodically lead into their odd-numbered counterparts. Students should study the top line part with placements of accents in various locations.

\section{Drones}

There are many inherent benefits associated with improvising melodies over drones. For the purposes of this Bach-based methodology, drones are any sustained pitches. In addition to the benefits of realizing instances of consonance and dissonance, and improving one's intonation, is the added challenge of creating intriguing content in the absence of harmonic structures. In cases such as these, improvisers can assume a dual-purpose role; that of soloist and harmonizer. They simultaneously imply harmonies and play melodic ideas over a drone. Drones also supply a consistent layer, or mood, that performers must develop or contrast.

This section encourages students to engage drones in experimental settings. A challenge to improvisers is to produce various moods in spite of the drone. This practice is not new for students of Bach's music. The Cello Suites, Violin Sonatas, and others, all require performers to create their own moods, or related moods, based on Bach's notation. Supplementing with a sustained tone modifies the challenge a bit.

Professors should encourage students to place emphasis on broadening their realm of harmonic and melodic possibilities. Bach's compositions contain enough harmonic information to conflict with various drone choices. The Prelude from Cello Suite II outlines harmonic progressions that conflict with the drone choices included in figure 4.8. There is no specific correct or incorrect choice regarding drones. Below is a strategy for beginning one's study of drones: 
1. Play the original piece in its entirety.

2. Play excerpts of the piece over a drone (see fig. 4.8).

3. Improvise a melody based on the original composition/excerpt.

4. Experiment with modulations, imitation, and fugal techniques.

5. Play through steps 1 through 4 in an ensemble.

Improvisers should not necessarily change drones while playing the melody. That may create a harmonic progression. Figure 4.8 simply presents more than one drone possibility.

Figure 4.8: First 4 measures of Cello Suite II Prelude over various drone choices.

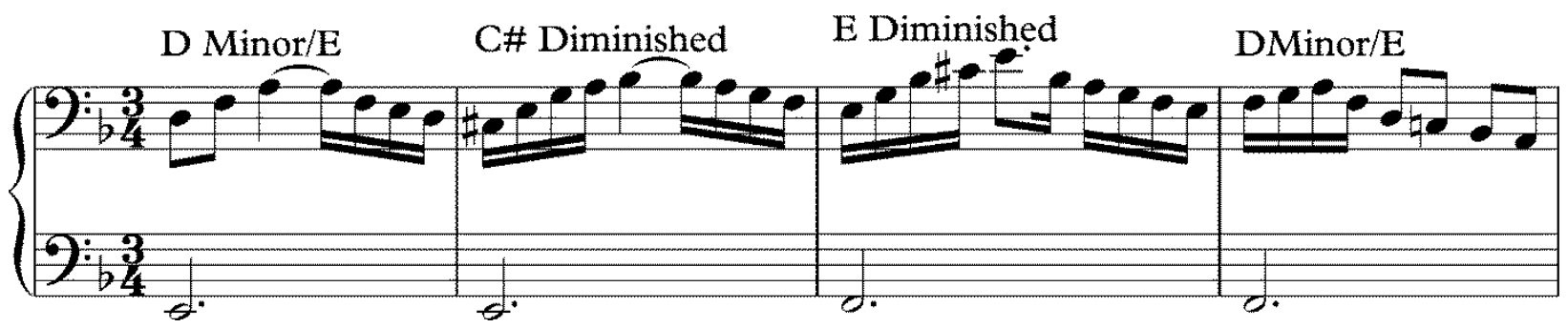

Regardless of musical genres or styles, it is absolutely necessary for students to understand the pulses which underlie music. When improvisers understand and internalize a groove, they can play melodies and rhythms that compliment and contradict the groove with conviction. If they do not possess a clear understanding of a particular groove, then the improvisers may be forced to play it "safe." Playing a piece in a compound meter and juxtaposing a simple meter onto it creates a rhythmic fusion. This can bring forth an evolutionary big bang of creativity, even if only for a few moments. 


\section{Conclusion}

Non-improvisers often believe improvisation to be a gift bestowed to only the select few who afford themselves opportunities to express their own musical creativity. Although creativity cannot be taught, educators can cultivate it in their students through guiding study and experimentation.

This research document addresses the needs of jazz educators and newcomers to jazz improvisation. The literature review contained in Chapter 1 presents a variety of perspectives on how to learn improvisation from highly-respected jazz pedagogues. It provides a broad overview of the readily available materials concerning a focused variety of jazz-related, and other, topics. By employing familiar musical materials, the Bach-based improvisation methodology showcased in Chapters 2 through 4 aids students in overcoming the anxiety associated with learning jazz improvisation. These techniques are rooted in the philosophy that, for some musicians, studying timeless masterpieces may be a more effective method for learning improvisation than studying hypothetical scale patterns, such as those contained in many jazz curricula.

There is still substantial work to be done with the development of this Bach-based improvisation methodology. Future efforts will include field studies, publishing journal articles, and presentations of workshops and lectures. 


\section{Bibliography}

\section{Books Included in Literature Review}

Baker, David. Modern Concepts in Jazz Improvisation: A Comprehensive Method for All Musicians. Van Nuys, CA. Alfred Publishing, 1990.

Campbell, Gary. Expansions: A Method for Developing New Material for Improvisation, $2^{\text {nd }}$ ed. Milwaukee. Hal Leonard Corporation, 1998.

Coker, Jerry. Listening to Jazz. Englewood Cliffs, NJ. Prentice-Hall, Inc., 1978.

Coker, Jerry, Jimmy Casale, Gary Campbell, and Jerry Greene. Patterns for Jazz. Miami. Studio Publications Recordings, 1970.

Evans, Lee. Topics in Jazz and Musical Creativity for the Classical Pianist. Milwaukee. Hal Leonard Publishing Corporation, 1989.

Lawn, Richard. Experiencing Jazz. New York : McGraw-Hill, 2007.

Lawn, Richard. The Jazz Ensemble Directors Manual. Oskaloosa, Iowa : C.L. Barnhouse, 1995.

Lawn, Richard J. and Jeffrey L. Hellmer. Jazz Theory and Practice. Los Angeles. Alfred Publishing Company, Inc., 1996.

Reeves, Scott D. Creative Jazz Improvisation, $3^{\text {rd }}$ ed. Upper Saddle River, NJ. Prentice Hall, 2001.

Richmond, Mike. Modern Walking Bass Technique. Englewood, NJ. Ped Xing Music, 1983.

Ricker, Ramon. Pentatonic Scales for Jazz Improvisation: The Ramon Ricker Jazz Improvisation Series. Alfred Publishing Company, Inc. 1976.

Ruiter-Feenstra, Pamela. Bach and the Art of Improvisation. Chi Press. 2011

Stanton, Kenneth. Introduction to Jazz Theory. Boston. Crescendo Publishing Company, 1976. 


\section{Articles Discussed in Literature Review}

Baker, David N. “Improvisation: A Tool for Music Learning.” Music Educators Journal, Vol. 66, no. 5. (January 1980). http://www.jstor.org/stable/3395775 (accessed: June 27, 2014).

Benadon, Fernando. "Slicing the Beat: Jazz Eighth-Notes as Expressive Microrhythm." Ethnomusicology, Vol. 50, no. 1 (Winter 2006). http://www.jstor.org/stable/20174424 (accessed February 1, 2014).

Bouchard, Fred. “Phil \& Chris Rap,” Down Beat Magazine, October, 1991.

Campbell, Patricia Shehan. "Unveiling the Mysteries of Musical Spontaneity." Music Educators Journal , Vol. 78, no. 4 (December 1991) , pp. 21-24 http://www.jstor.org/stable/3398332 (accessed February 1, 2014).

Ciorba, Charles R.. "Predicting Jazz Improvisation Achievement through the Creation of a PathAnalytical Model.” Bulletin of the Council for Research in Music Education, no. 180. (Spring 2009). http://www.jstor.org/stable/40319319. (Accessed: 02/01/2014).

Evans, Lee. “The Interchangeability of Modes.” Jazzed: The Jazz Educator's Magazine 5, no. 6 (November 2010): 38-41. Music Index, EBSCOhost (accessed January 22, 2014).

Evans, Lee. "Modal Harmony In Jazz: Part Three.” Piano Today: The Magazine You Can Play 28, no. 2 (Spring 2008): 36-37. Music Index, EBSCOhost (accessed January 22, 2014).

Evans, Lee. "Modal Harmony In Jazz: Part Two.” Piano Today: The Magazine You Can Play 28, no. 1 (Winter 2008): 25-26. Music Index, EBSCOhost (accessed January 22, 2014).

Evans, Lee. “Techniques of Melodic Development in Jazz Improvisation.” Jazzed: The Jazz Educator's Magazine 5, no. 1 (January 2010): pp. 52-56. Music Index, EBSCOhost (accessed January 22, 2014).

Gillespie, Robert. "Teaching Improvisation in the School Orchestra.” Midwest Clinic. http://www.midwestclinic.org/user_files_1/pdfs/clinicianmaterials/2001/gillespie.pdf (accessed March 8, 2014). 
Goldsby, John. "Using classical music in jazz improvisation.” Strad 121, no. 1442 (June 2010): 7073. Music Index, EBSCOhost (accessed January 27, 2014).

Kalmanovitch, Tanya. “Contemporary Improvisation for Classical Musicians.” New Sound: International Magazine For Music no. 32 (December 2008): 130-142. Music Index, EBSCOhost (accessed January 27, 2014).

McGowan, James. “Riemann's Functional Framework for Extended Jazz Harmony.” Intégral, Vol. 24. (2010). Special Issue in Honor of Robert Wason. http://www.jstor.org/stable/41495296 (accessed January 27, 2014).

Meadows, Eddie S. "Improvising Jazz: A Beginner's Guide.” Music Educators Journal , Vol. 78, no. 4 (December 1991). http://www.jstor.org/stable/3398336 (accessed 02/01/2014).

Moore, Robin. "The Decline of Improvisation in Western Art Music: An Interpretation of Change." International Review of the Aesthetics and Sociology of Music. Vol. 23, no. 1. (June 1992). http://www.jstor.org/stable/836956 (accessed January 18, 2014).

Rakich, Christa. "Learn to Improvise in Fifteen Minutes a Day! Gerre Hancock: Toccata, part 1.” The American Organist 40, no. 2. RILM Abstracts of Music Literature, EBSCOhost. 2006. (accessed March 3, 2014).

Riveire, Janine. "Using Improvisation as a Teaching Strategy.” Music Educators Journal, Vol. 92, no. 3 (January 2006). http://www.jstor.org/stable/3401139 (accessed January 18, 2014).

Rose, Richard. "Eight Elements of Jazz Improvisation.” Music Educators Journal , Vol. 71, no. 9 (May, 1985). http://www.jstor.org/stable/3396523 (accessed January 18, 2014).

Schulenberg, David. "Composition and Improvisation in the School of J. S. Bach.” Bach Perspectives. (January 1995). Music Index, EBSCOhost. (accessed March 3, 2014).

Smallwood, Richard. "Gospel and Blues Improvisation.” Music Educators Journal, Vol. 66, no. 5. (January 1980). http://www.jstor.org/stable/3395785. (accessed February 1, 2014).

Smith, Chris. "A Sense of the Possible: Miles Davis and the Semiotics of Improvised Performance." In Collected Work: In the course of performance: Studies in the world of 
musical improvisation. (1998): 261-289. RILM Abstracts of Music Literature, EBSCOhost (accessed March 8, 2014).

Velleman, Barry L. "Speaking of Jazz: Jazz Improvisation through Linguistic Methods.” Music Educators Journal, Vol. 65, no. 2. (October, 1978). http://www.jstor.org/stable/3395505 (accessed February 1, 2014).

Witmer, Robert and James Robbins. “A Historical and Critical Survey of Recent Pedagogical Materials for the Teaching and Learning of Jazz." Bulletin of the Council for Research in Music Education, no. 96, (1988). http://www.jstor.org/stable/40318207 (accessed: $02 / 01 / 2014)$

\section{Dissertations and Theses Discussed in Literature Review}

Ichio,Yuusaku. "Bach and Improvisation: A Research on How Useful Bach is for Improvising Music.” Thesis. Göteborgs Universitet, 2011. https://gupea.ub.gu.se/bitstream/2077/26673/1/gupea_2077_26673_1.pdf(accessed March $3,2014)$.

Pinkevicius, Vidas. "Improvisation of Keyboard Preludes in the Style of J. S. Bach: A Practical Method Comprising Techniques Derived from Selected Keyboard Works.” The University of Nebraska - Lincoln, 2006. In ProQuest Dissertations and Theses, http://search.proquest.com/docview/305273808?accountid=2837 (accessed March 15, 2014).

Woosley, Kevin Daniel. "The Lost Art of Improvisation: Teaching Improvisation to Classical Pianists." The University of Alabama, 2012. In ProQuest Dissertations \& Theses Full Text, http://search.proquest.com/docview/1284867846?accountid=2837 (accessed March 23, 2014).

Zwick, Robert A. "Jazz Improvisation: A Recommended Sequential Format of Instruction.” University of North Texas, 1987. In ProQuest Dissertations \& Theses Full Text, http://search.proquest.com/docview/303589918?accountid=2837. (accessed January 18, 2014). 


\section{Compositions/Collections}

Bach, Johann Sebastian. Die Kunst der Fuge. New York: Lea Pocket Scores, 1955.

Bach, Johann Sebastian. Six Suites for Violoncello Solo. Edited by Joseph Malkin. New York. Carl Fischer, 1918.

Bach, Johann Sebastian. Six Violin Sonatas for Violin Solo. Edited by Leopold Auer. New York. Carl Fischer, 1917.

Bach, Johann Sebastian. Sonata in A Minor for Flute Solo. Edited by Rampal. New York. International Music, 1967.

Bach, Johann Sebastian. The Well-Tempered Clavier. New York. Lea Pocket Scores, 1950.

Davis, Miles. So What. in The Real Book Volume I. Milwaukee. Hal Leonard Corporation, 2004.

Kosma, Joseph and Jaches Prevért. Autumn Leaves. in The Real Book Volume I. Milwaukee. Hal Leonard Corporation, 2004.

Noble, Ray. Cherokee. in The Real Book Volume I. Milwaukee. Hal Leonard Corporation, 2004. 


\section{Appendix}

The purpose of this appendix is to provide additional resources that may be useful for research into distantly-related topics, such as using improvisation to learn music, understanding what improvisation is, and organ improvisation. The materials are not limited to studies conducted within the jazz idiom. These materials are not discussed within the literature review in order to maintain the narrowed focus explained in the introductory pages.

\section{Books about Learning Music Through Improvisation}

Adolphe, Bruce. The Mind's Ear: Exercises for Improving the Musical Imagination for Performers. New York. MMB Music, 1991.

Agrell, Jeffrey. Improv Duets for Classical Musicians: A Concise Collection of Musical Games for Two Players. GIA Publications, 2012.

Agrell, Jeffrey. Improv Games for One: A Very Concise Collection of Musical Games for One Classical Musician. GIA Publications, 2009.

Agrell, Jeffrey. Improvisation Games for Classical Musicians: A Collection of Musical Games With Suggestions for Use. GIA Publications, 2008.

Agrell, Jeffrey. Improvised Chamber Music: Spontaneous Chamber Music Games for Four (or Three or Five) Players. GIA Publications, 2012.

Baily, Derek: Improvisation: Its Nature and Practice in Music. New York. Da Capo, 1993.

Brockmann, Nicole M. From Sight to Sound: Improvisational Games for Classical Musicians. Bloomington. Indiana University Press, 2009.

Cahn, William L. Creative Music Making. Routledge, 2005.

Coker, Jerry. The Jazz Idiom. Englewood Cliffs: Prentice-Hall, 1975. 
Haerle, Dan. Jazz Improvisation for Keyboard Players - Complete Edition. Alfred Music Publishing, 1978.

Kane, Brian. Constructing Melodic Jazz Improvisation - B Flat Edition. Cambridge. Jazz Path Publishing, 2007.

Konowitz, Bert. Music Improvisation as a Classroom Method. New York. Alfred Publishing Company, 1973.

Mathieu, W. A. The Listening Book: Discovering Your Own Music. Boston. Shambhala, 1991.

Ricker, Ramon. II-V-I Progressions: The Ramon Ricker Improvisation Series. Lebanon, IN. Studio Publications Recordings, 1979.

Poulin, Pamela Lee, (Ed. And Trans.) and Johann Sebastian Bach. J.S. Bach's Precepts and Principles for Playing the Thorough-Bass Or Accompanying in Four Parts (Leipzig, 1738). Oxford: Clarendon, 1994.

Sarath, Edward. Improvisation, Creativity, and Consciousness: Jazz as Integral Template for Music, Education, and Society. Albany, NY. SUNY Press, 2013.

Sarath, Edward. Music Theory Through Improvisation: A New Approach to Musicianship Training. New York. Routledge Taylor \& Francis Group, 2010.

\section{Improvisation-Related Journal Articles}

Alexander, David Charles. "Instructing the improviser.” Fontes Artis Musicae 36, no. 3 (July-Sept 1989): 220-223. RILM Abstracts of Music Literature, EBSCOhost (accessed March 16, 2014).

Aron, Tossi. "Music Improvisation and Related Arts.” Music Educators Journal 66, (January 1980): 78-83. Music Index, EBSCOhost (accessed March 16, 2014).

Azzara, Christopher D.. "Improvisation.” In Collected Work: The New Handbook of Research on Music Teaching and Learning: A Project of the Music Educators National Conference. 
(2002): 171-187. RILM Abstracts of Music Literature, EBSCOhost (accessed August 25, 2013).

Baker, David. "Improvisation: A Tool for Music Learning." In Music Educators Journal. Vol. 66, no. 5 (January 1980), pp. 42-51http://www.jstor.org/stable/3395775 (accessed August 25, 2013).

Barrett, Frank J. "Coda: Creativity and Improvisation in Jazz and Organizations: Implications for Organizational Learning,” Organization Science, Vol. 9, No. 5, Special Issue: Jazz Improvisation and Organizing (Sep. - Oct., 1998): 605-622.

http://www.jstor.org/stable/2640303 (accessed: January 14, 2014).

Bartlett, Andrew. "Michigan's Serath Seeks to Expand Horizons for Improvisation Students." Downbeat 63, no. 10 (October 1996): 74. Academic Search Complete, EBSCOhost (accessed March 16, 2014).

Borém, Fausto. "Improvisatory styles in the music of Bach." International Society Of Bassists Journal 18, no. 2 (Fall 1992): 54-62. RILM Abstracts of Music Literature, EBSCOhost (accessed March 16, 2014).

Brown, Matthew. "C.P.E. Bach, Schenker, improvisation, and composition." Intégral: The Journal Of Applied Musical Thought 24, (January 1, 2010): 3-27. RILM Abstracts of Music Literature, EBSCOhost (accessed March 16, 2014).

Buch, Laura. "Considering the Alternative: The Principle of Improvisation in C.P.E. Bach's Trios." (January 1, 2010): RILM Abstracts of Music Literature, EBSCOhost (accessed March 16, 2014).

Ciampa, Leonardo. "Learn How to Improvise in 15 Minutes a Day." American Organist Magazine 48, no. 2 (February 2014): 44-45. Academic Search Complete, EBSCOhost (accessed March 16, 2014).

Ciorba, Charles R.. "Predicting Jazz Improvisation Achievement Through the Creation of a PathAnalytical model." Bulletin Of The Council For Research In Music Education no. 180 
(Spring 2009): 43-57. RILM Abstracts of Music Literature, EBSCOhost (accessed March $16,2014)$.

Coker, Jerry. “Clear Solutions for Jazz Improvisers.” Jazz Education Journal 37, no. 3 (2004): 66. Music Index, EBSCOhost (accessed March 16, 2014).

Coker, Jerry, Larry Vincent, and Bob Knapp. "Hearin' the Changes.” Acoustic Guitar, (March, 1999). 26, Music Index, EBSCOhost (accessed March 16, 2014).

Covington, Kate R.. "Improvisation in the aural curriculum: An imperative." College Music Symposium 37, (January 1, 1997): 49-64. RILM Abstracts of Music Literature, EBSCOhost (accessed March 16, 2014).

Crist, Stephen A. "The Role and Meaning of the Bach Chorale in the Music of Dave Brubeck.” Bach Perspectives, no. 5, (January 2002): 179-215. Academic Search Complete, EBSCOhost (accessed March 16, 2014).

Fidom, Hans. "Organ Improvisation - An Introduction.” New Sound: International Magazine For Music no. 32 (December 2008): 53-67. Academic Search Complete, EBSCOhost (accessed March 16, 2014).

Henry, Robert E. "Improvisation through Guided Self-Study.” Music Educators Journal, Vol. 79, No. 8. (1993): 33-37. http://www.jstor.org/stable/3398595. (accessed February 1, 2014).

Goldsby, John. "Using classical music in jazz improvisation.” Strad 121, no. 1442 (June 2010): 7073. Academic Search Complete, EBSCOhost (accessed March 16, 2014).

Guderian, Lois Veenhoven. "Music Improvisation and Composition in the General Music Curriculum.” In General Music Today 25, no. 3 (April 1, 2012): 6-14. RILM Abstracts of Music Literature, EBSCOhost (accessed August 25, 2013).

Kratus, John Kevin. “A Developmental Approach to Teaching Music Improvisation.” In International Journal Of Music Education no. 26 (1995): 27-38. Music Index, EBSCOhost (accessed August 25, 2013). 
Kuzmich, John A. Jr.. "Improvisation Teaching Materials.” Music Educators Journal , Vol. 66, No. 5 (Jan., 1980): 51-55+161-163. http://www.jstor.org/stable/3395776 (accessed November 1, 2014).

Mickolajak, Mary T. “Beginning Steps to Improvisation.” In Teaching Music 10, no. 5 (April 2003): 40. Education Research Complete, EBSCOhost (accessed August 25, 2013).

Moersch, Charlotte Mattax. "Keyboard improvisation in the Baroque period.” In Collected Work: Musical improvisation: Art, education, and society. (2009): 150-170. RILM Abstracts of Music Literature, EBSCOhost (accessed March 16, 2014).

Monk, Augusto. "Symbolic Interactionism in Music Education: Eight Strategies for Collaborative Improvisation” In Music Educators Journal, Vol. 99, No. 3. (March 2013): 7681.http://www.jstor.org/stable/23364265 (accessed August 25, 2013).

Sarath, Edward. "Improvisation and Curriculum Reform.” In Collected Work: The New Handbook of Research on Music Teaching and Learning: A Project of the Music Educators National Conference. Pages: 188-198. (2002). RILM Abstracts of Music Literature, EBSCOhost (accessed March 16, 2014).

Sarath, Edward. “A New Look at Improvisation.” Journal Of Music Theory 40, no. 1 (1996): 138. Music Index, EBSCOhost (accessed March 16, 2014)”

Schenker, Heinrich, and Richard A. Kramer (Trans.). "The art of improvisation.” In Collected Work: The Masterwork in Music: A Yearbook. I (1925). (1994): 2-19. RILM Abstracts of Music Literature, EBSCOhost (accessed March 16, 2014).

Silberman, Peter. "Post-tonal Improvisation in the Aural Skills Classroom." Music Theory Online 9, no. 2 (July 1, 2003): RILM Abstracts of Music Literature, EBSCOhost (accessed August $25,2013)$.

Witmer, Robert and James Robbins. “A Historical and Critical Survey of Recent Pedagogical Materials for the Teaching and Learning of Jazz." Bulletin of the Council for Research in Music Education, No. 96, Research in Jazz Education II. (Spring 1988): 7-29. http://www.jstor.org/stable/40318207 (accessed January 18, 2014) 


\section{Organ Improvisation Books}

Bender, Jan. Organ Improvisation for Beginners: A Book of Self-Instruction for Church Musicians: Op. 59. Concordia Publishing House. 1975.

Davis, Roger E.. The Organist's Improvisation: Technical Studies \& Selected Compositions for the Organ. New York. Norton, 1985.

Hancock, Gerre. Improvising: How to Master the Art. USA. Oxford Press, 1994.

Johns, Michelle. Hymn Improvisation. Augsburg Fortress Publishers. 1987.

Overduin, Jan. Making Music: Improvisation for Organists. New York. Oxford University Press, 1998.

Rotermund, Donald. Off The Page: Tips \& Techniques for Creating Hymn-Based Organ Settings. Morning Star Music Publishers. 2007.

\section{Dissertations \& Theses}

Bitz, Michael Eric. “A Description and Investigation of Strategies for Teaching Classroom Music Improvisation.” Columbia University Teachers College, 1998. In PROQUESTMS ProQuest Dissertations \& Theses Full Text, http://search.proquest.com/docview/304436689?accountid=2837 (accessed August 25, 2013).

Check, John David. "Concepts of Compound Melody in Jazz Improvisations." Yale University, 1997. In ProQuest Dissertations \& Theses Full Text, http://search.proquest.com/docview/304383830?accountid=2837 (accessed January 18, 2014).

Chyu, Yawen Eunice. "Teaching Improvisation to Piano Students of Elementary to Intermediate Levels." The Ohio State University, 2004. In ProQuest Dissertations and Theses, http://search.proquest.com/docview/305140145?accountid=2837 (accessed January 22, 2014). 
Kim, Haejin. "Organ Improvisation for Church Services: A Survey of Improvisation Methods from 1900.” University of Cincinnati, 2011. In ProQuest Dissertations \& Theses Full Text, http://search.proquest.com/docview/899724483?accountid=2837 (accessed January 22, 2014).

Lee, Caroline Mia. "An Introductory Guide to Jazz Improvisation for the Classical Violinist.” University of Miami, 2000. In ProQuest Dissertations \& Theses Full Text, http://search.proquest.com/docview/304608462? accountid=2837 (accessed January 22, 2014).

Norgaard, Martin. "Descriptions of Improvisational Thinking by Artist-Level Jazz Musicians." Order No. 3324521, The University of Texas at Austin, 2008. In ProQuest Dissertations \& Theses. http://search.proquest.com/docview/304474120?accountid=2837 (accessed January $18,2014)$.

Ward, Adam Micah. "From Imagination to Improvisation to Realization: A Study of Pieces by Four Organists." Order No. 3387619, The University of North Carolina at Greensboro, 2009. In PROQUESTMS ProQuest Dissertations \& Theses Full Text, http://search.proquest.com/docview/250729592?accountid=2837 (accessed January 18, 2014).

\section{DVD}

Tomasi, Ed. Jazz Improvisation: Starting Out with Motivic Development. DVD. Berklee College. 2005. 


\section{Gary Scott Jones}

515 Crawley Run Apt. 207

Centerville, OH. 45458

U.S.A (937) 291-1749

gscottjones1@gmail.com

www.gscottjones.com

\section{EDUCATION}

Doctor of Musical Arts

Trombone Performance

ABD Anticipated Completion Spring 2014

West Virginia University

Research Topic: A Conceptual Method of Learning Improvisation Through Studying the Music of J.S. Bach

Master of Music

Improvisation

University of Michigan

Final Project: Original music album combining Jazz, Rock, and Hip Hop

Research Topic: What is Improvisation? Included interviews with Hank Jones, Randy Weston, Alex Blake, Marion

Haydon, Ellen Rowe, and Mel Wanzo

Bachelor of Music

Jazz Studies

Central State University (Wilberforce, $\mathrm{OH}$ )

Additional Coursework in Graphic Design

Trombone Instructors

Dr. H. Keith Jackson - West Virginia University

Dennis Wilson - University of Michigan

John Rider - Central State University

Dr. Richard Begal

Dr. Gretchen McNamara - Wright State University

Composition Instructors

Dr. John Beall - West Virginia University

Dr. David Taddie - West Virginia University

Dennis Wilson - University of Michigan

Christian Berg - Central State University

\section{CAREER HIGHLIGHTS}

Durban, South Africa - Wright-LEAD Points of Light Youth Leadership Institute

Hosted by University of KwaZulu-Natal - Durban, South Africa (Summer 2012)

Sponsored by Wright State University - Dayton, $\mathrm{OH}$

Co-lead high school Leadership Institute with approximately 100 participants

Developed workshops that integrated music and visual arts throughout a seven-day leadership curriculum

The curriculum was based on the Points of Light Youth Leadership Institute

\section{Music Performances}

National Tour - Nomo and Saturday Looks Good To Me: MI, OH, GA, MA, NY - Tenor Trombone Indy Rock and Afro beat (Summer 2004)

Regional Tour - Michael Berkowitz Big Band - West Virginia - $1^{\text {st }}$ and $2^{\text {nd }}$ Trombone. Tribute to the Frank Sinatra and Count Basie Orchestra album, Sinatra at the Sand.- Two-week tour (Fall 2011) 
Spyder Turner - Detroit, MI - Tenor Trombone - Motown Classics by Spyder Turner, Stevie Wonder, the

Temptations and others - Spyder Turner's biggest hit was a 1967 remake of Stand By Me (Fall 2003-Summer 2004)

National Jazz Orchestra of Detroit - Detroit, MI - $3^{\text {rd }}$ Trombone - Annual Ford Detroit Jazz Festival (Summer 2004) Additional Trombonists included George Bohannon and Mel Wanzo

\section{Assistant Director of Bands}

Conducted the Invincible Marching Marauder Band, Pep Band, and Chamber Winds. Composed and arranged music. Coached student arrangers. Taught proper playing techniques and fundamentals. Conducted brass sectionals.

Implemented music theory into rehearsal. Recruited students. Traveled with bands for performances and recruitment. Developed graphic design and website solutions for recruitment and publicity. (Summer 2007-Spring 2008)

\section{PROFESSIONAL EXPERIENCE}

Dayton City Schools - Wogaman 5-8 - Dayton, OH

Music Teacher (August 2013 - Current)

Developing general Music Education curriculum

Developing Instrumental Music Program

Developing Vocal Music Program

Aiding in implementing strategies to improve students' literacy

Central State University - Department of Fine and Performing Arts - Dayton, $\mathrm{OH}$

Assistant Director of Bands (Summer 2007-Spring 2008)

Conducted the Invincible Marching Marauder Band, Pep Band, and Chamber Winds

Composed and arranged music

Coached student arrangers

Taught proper playing techniques and fundamentals

Conducted brass sectionals

Implemented music theory into rehearsal. Recruited students

Traveled with bands for performances and recruitment

Developed graphic design and website solutions for recruitment and publicity.

\section{Adjunct Professor}

History of Jazz (Spring 2007-Spring 2008)

Edison Community College - Departments of Humanities, Music, Art, and Computer Information Technology Piqua, $\mathrm{OH}$

Adjunct Instructor (Summer 2007-Spring 2011)

Music Appreciation

Music as a World Phenomenon

Introduction to Humanities

Digital Design

Computer Graphics

Typography

Creating Interactive Media 
Concordia University - Music Department - Ann Arbor, MI

Adjunct Instructor (Fall 2004-Winter 2005)

Faculty Brass Quintet - Trombone

Curriculum Development

Music Improvisation - Music improvisation class focused on the fundamentals of Jazz, as well as other forms of improvisation

Improvised Art Ensemble - Ensemble focused on collective creativity and improvised art, open to all students (musicians, dancers, visual artists, etc.)

Additional Courses Taught

Hymn Adaptations - Music arranging class focused on Jazz and Rhythm and Blues arrangements of traditional church Hymns

American Experience Jazz - Heritage class about the influence of Jazz in American culture

\section{Applied Music Lessons}

Central State University

Music Mentors - Department of Fine and Performing Arts - Trombone, Trumpet, Tuba - Music Mentors was grant-funded, and provides musical lessons to students of all ages at no out-of-pocket cost (Spring 2008Spring 2010)

Volunteer F Horn Lessons (2008)

Freelance All Brass and Improvisation (2003-PRESENT)

\section{Trombone Sectionals}

Mountaineer Middle School - Morgantown, WV (PRESENT)

Weekly rehearsal with middle school big band trombone section

Pontiac Central High School - Pontiac, MI

Assistant Director of Bands - Marching Band Camp (Summer 2000)

Conducted rehearsals, arranged music, and lectured about brass fundamentals

\section{INTERNSHIP}

West Virginia Wine and Jazz Festival - Aided with program development, artist relations, grounds control, safety, and post-event wrap-up (Spring 2012-Fall 2012)

\section{GUEST LECTURES}

Wright State University EGO Conference - "From Bessie Smith to B. B. King: Blues, the Music and the Word" Designed to increase the participants' knowledge of the blues from a historical perspective by presenting its origins, purposes, musical, and lyrical structures. (March 31, 2007)

Sinclair Community College Black Man's Think Tank - "I Guess It Depends on What You Call Hip Hop" Facilitated a discussion on the current status and future of Hip Hop culture (2006) 


\section{PERFORMER TROMBONE}

\section{Big Band}

Michael Berkowitz Big Band - West Virginia $-1^{\text {st }}$ and $2^{\text {nd }}$ Trombone. Tribute to the Frank Sinatra and Count Basie Orchestra album, Sinatra at the Sand.- Two-week tour (Fall 2011)

National Jazz Orchestra of Detroit - Detroit, MI - $3^{\text {rd }}$ Trombone - Annual Ford Detroit Jazz Festival - Additional Trombonists included George Bohannon and Mel Wanzo (Summer 2004)

Mon River Big Band - Morgantown, WV - Bass Trombone - Swing, Latin, and Rock (Fall 2012 - PRESENT)

Eddie Brookshire's Big Band - Dayton, OH - $1^{\text {st }}, 2^{\text {nd }}$, and Bass Trombone and Arranger (Winter 2005 - PRESENT)

Miami Valley School - Kettering, OH - Tenor Trombone with Effects Pedal - Guest Artist (Winter 2009)

\section{Motown}

The Funk Brothers - Dayton, OH - Tenor Trombone - Legendary Motown Records House Band (Summer 2009)

Spyder Turner - Detroit, MI - Tenor Trombone - Motown Classics by Spyder Turner, Stevie Wonder, the Temptations and others - Spyder Turner's biggest hit was a 1967 remake of Stand By Me (Fall 2003-Summer 2004)

\section{Afro Beat}

Baoku and The Image Afro Beat Band - Cincinnati, OH - Afro-Beat Instrumentation: Trumpets, Trombone, Saxophones, Guitars, Bass, and Percussion (Fall 2005-PRESENT)

Nomo - Ann Arbor, MI - Tenor Trombone - Afro-Beat, Jazz, Blues and Funk (Fall 2003-Summer 2005)

\section{Latin Jazz/Salsa}

Son del Caribe - Cincinnati, $\mathrm{OH}-1^{\text {st }}, 2^{\text {nd }}$, and $3^{\text {rd }}$ Trombone - Salsa (2009)

Legend Vega - Cincinnati, OH - Tenor Trombone - Salsa (2009)

Poco Loco - Cincinnati, OH - Tenor Trombone/Arranger - Latin Jazz (2008-2009)

Descarga - Ann Arbor, MI - Tenor Trombone - Latin Jazz (Winter 2004-Spring 2005)

\section{Jazz Combo}

Phave Phive Project - Dayton, OH - Trombonist/Arranger - Jazz, Hip Hop and Rhythm \& Blues Instrumentation: Vocalist, Steel Pan, Trombone, Keyboard, Bass, and Drums (2008)

Afro Soul Ensemble - Yellow Springs, OH - Sousaphone - New Orleans-style Street Band Instrumentation: Trumpet, Saxophones, Tuba, Drums (Summer 2007)

G. Scott Jones Freedom Ensemble - Yellow Springs and Dayton, OH - Jazz, Funk and Electronics Instrumentation: Trombone, Trumpet, Bass, and Drums (Fall 2005-2007)

Mario Abney Quintet - Dayton, OH - Jazz and Hip Hop Instrumentation: Trombone, Trumpet, Bass, and Drums (2005-2007)

\section{Orchestra}

Vance Memorial Presbyterian Church - Wheeling, WV - Bass Trombone

Christmas Concert - (December 9, 2012)

Poulenc, Francis - Gloria

Rutter, John - Gloria

Buckhannon Choral Society - Buckhannon, WV - Bass Trombone

Oratorio The Wonder of Christmas, by David Hamilton - (December 1, 2012) 


\section{Brass Quintet}

Concordia University Faculty Brass Quintet - Ann Arbor, MI - $2^{\text {nd }}$ Trombone

(Fall 2004-Winter 2005) - Various campus events

St. James Catholic Church Pittsburgh, PA $-1^{\text {st }}$ Trombone

Easter Mass (2011 - 2013)

St. Joseph Catholic Church - Cincinnati, $\mathrm{OH}-2^{\text {nd }}$ Trombone

Funeral Service (Spring 2012)

New Years Eve Mass (2011)

\section{Trombone Recital}

Central State University - Wilberforce, $\mathrm{OH}$ - Alto Trombone - Eric Ewazen, Palmetto Suite; Tenor Trombone Franz Schubert, Aufenthalt; Original, Unity; for Trombone and Electronic Recording; Bass Trombone - Franz Schubert, Der Doppelgänger; T.J. Anderson, Minstrel Man (March, 2013)

St. Joseph Catholic Church - Cincinnati, OH - Alto Trombone - Eric Ewazen, Palmetto Suite; Tenor - Arthur Pryor, Annie Laurie; Bass Trombone - T.J. Anderson, Minstrel Man (May, 2012)

Central State University - Wilberforce, $\mathrm{OH}$ - Alto and Tenor Trombones - Original Concerto for Alto Trombone, Improvised music (2004)

Kettering Civic Band - Kettering, $\mathrm{OH}-3^{\text {rd }}$ Trombone - Concert Band Music for community events (Fall 2005)

Pit Orchestra - Pontiac, MI - Horn in F - The Wiz - Pontiac Northern High School (Spring 1999)

\section{Additional Genres}

Souse - Cincinnati, OH - Tenor Trombone with electronics - Funk (2008-2009)

Yours Truly - Ann Arbor, MI - Band Leader and Trombone - Hip Hop, Jazz, Rock, Blues and Improvised Music (Fall 2004-Spring 2005)

Instrumentation: 2 Trombones, Tuba, Electric Guitar, Electric Bass, Drums and 2 Poets

Saturday Looks Good To Me - National Tour with Nomo: MI, OH, GA, MA, NY - Tenor Trombone - IndyRock (Summer 2004)

Hullaballoo - Ann Arbor, MI - Tenor Trombone - Ska, Modal Jazz and Funk (Fall 2003-Spring 2005)

\section{COLLEGIATE ENSEMBLES}

\section{West Virginia University}

West Virginia University Symphony Orchestra - $1^{\text {st }}, 2^{\text {nd }}$, and $3^{\text {rd }}$ Trombone - Includes Alto, Tenor, and Bass Trombone (Fall 2010-PRESENT)

Osteology - Tenor and Bass Trombone - Jazz Trombone Ensemble (Fall 2010- PRESENT)

University Graduate Trombone Quintet - Morgantown, WV - Bass Trombone - Veteran's Celebration (November 2012)

Creative Arts Orchestra Tenor and Bass Trombone - Improvisers ensemble modeled after the Creative Arts Orchestra at the University of Michigan (Spring-Fall 2011)

Trombone Choir - Bass Trombone, Composer, and Arranger (Fall 2011-PRESENT) 


\section{University of Michigan}

Creative Arts Orchestra - Alto and Tenor Trombone, experimental instruments and spoken word Improvisers ensemble (Fall 2003-Spring 2004)

Electronic Music Ensemble - Tenor Trombone, performed Minimalist works by LaMonte Young. Created unique musical installment with recorded sounds, algorithms, and mirrors

Jazz Band - Arranger, $1^{\text {st }}$ and $2^{\text {nd }}$ Trombone - Swing Band led by Professor Dennis Wilson (Fall 2003-Spring 2004)

\section{Central State University}

Jazz Ensembles - Composer/Arranger and Trombone (Fall 1999- Spring 2003)

Invincible Marching Marauder Band - $1^{\text {st }}$ Trombone and Sousaphone (Fall 1999-2001)

University Chamber Winds - Horn in F and $1^{\text {st }}$ Trombone (Fall 2001-Spring 2003)

Brass Quintet - Trombone (2000)

University Chorus - $1^{\text {st }}$ Bass (Fall 1999-Winter 2001)

\section{RECORDING ARTIST/SIDEMAN}

Steve Arrington - Springfield, OH - Electronic Trombone for Sunrise on album, Pure Thang - Steve Arrington is the former lead singer of SLAVE (Funk Band from Dayton, OH) (2008)

G. Scott Jones Freedom Ensemble - Yellow Springs, OH - Composer/Arranger and Tenor Trombone on album, Faith: Live@ the Emporium - Jazz, Funk and Electronics (2006)

Baoku and The Image Afro Beat Band - Cincinnati, OH - Tenor Trombone on unreleased recordings - Afro Beat (Fall 2005-PRESENT)

Poco Loco - Cincinnati, OH - Tenor Trombone on unreleased recordings - Latin Jazz (2008-2009)

Nomo - Detroit, MI - Tenor Trombone on albums, Nomo (2004) and Nu Tones (2006) - Afro-Beat, Jazz, Blues and Funk

Hullaballoo - Ann Arbor, MI - Trombonist on album Hullabaloo - Ska, Modal Jazz and Funk (2004)

\section{AUDIO/VIDEO RECORDING TECHNICIAN}

\section{West Virginia University}

Graduate Assistantship - Recording studio technician - Recording and editing faculty, guest, and student recitals (PRESENT)

\section{Independent Music Production/Electronic Composition}

Unity - Trombone and Recorded Sounds (2010)

Alter Call - Trombone and Spoken Word (2009)

Basseq - Album - Trombone, Electronics and Spoken Word (2004)

\section{Central State University Bands}

Promotional/Recruitment DVD (2007-2008)

Comcast Television - Pontiac, MI - Local cable station - High School Sports, Religious productions (1994-1998) 


\section{COMPOSITION COMMISSION}

West Virginia University School of Theatre and Dance - Incidental music for production of Arthur Miller's The

Crucible (Fall 2011-Spring 2012)

\section{RELEVANT ACADEMIC EXPERIENCE}

Durban South Africa - Wright-LEAD Points of Light Youth Leadership Institute

Hosted by University of KwaZulu-Natal - Durban, South Africa (Summer 2012)

Sponsored by Wright State University - Dayton, OH

Co-lead high school Leadership Institute with approximately 100 participants

Developed workshops that integrated music and visual arts throughout a seven-day leadership curriculum

The curriculum was based on the Points of Light Youth Leadership Institute

\section{University of Michigan}

Minority Recruitment Program - University of Michigan Department of Jazz and Contemporary Improvisation Developed and implemented strategies for recruiting college students from the Metro Detroit region (2004-2005)

Mentorship Program - Discussed academic and career goals in weekly meetings with high school music student for total of twenty weeks (Fall 2004)

\section{Central State University}

Black Oak Project - Performing Arts and Poetry Troupe (2000-2009)

Live Performances in Dayton, $\mathrm{OH}$ and surrounding communities

Poetry Workshops in Miami Schools

Taught techniques for high school teachers and students to incorporate creativity into their classrooms

Designed graphics and communications for various events

Aided Director in event planning and coordination

"Early Access" - Summer Bridge Program - Facilitated workshops with high school graduates transitioning into college (Summer 2002)

KinderCare Learning Center - Teacher - (Fall 2005-Spring 2006)

Facilitated KinderMusic - group and individual general music curriculum for Elementary School-age learners

Conducted concerts

After-school lesson plan development

\section{HONORS AND AWARDS}

\section{West Virginia University}

Graduate Assistantship -

Recording studio technician - Recording and editing faculty, guest, and student recitals. (Fall-Spring 2012)

Cataloging Jay Chattaway Collection of music scores and sketches from Star Trek The Next Generation, Voyager,

Deep Space Nine, and Enterprise

Provost Fellowship - Included waiver of tuition and fees (Fall 2011-Spring 2012) 
Graduate Enrichment Fellowship - Included waiver of tuition and fees (Fall 2010-Spring 2011)

\title{
University of Michigan
}

Department of Jazz and Contemporary Improvisation - Development of a minority recruitment strategy (Spring-Winter 2004)

Dean's List (Fall 2003-Winter 2004)

\section{Central State University}

Dean's List (Fall 1999-Spring 2003)

Honors Recitals (1999-2003)

Honors Program (2001)

On-campus Summer Sabbatical - Defining 'Soul' in American music (Summer 2002)

\section{PUBLICATIONS}

JO Magazine - Bi-monthly. Primarily focused on popular music, film, and stage productions. (www.jomagazineonline.com) and in print.

Creative Director (Spring 2010-Fall 2012)

Managed creative team of designers and photographers

Collaborated with CEO to conceive and develop publication

Brand development

Supervised print layout

Website development

\section{Conducted Interviews}

Rickey Minor - Music Director of the Tonight Show with Jay Leno (Dec 2010)

JD Lawrence - Playwright, director and music composer (June 2011)

\section{PROFESSIONAL AFFILIATIONS}

\author{
American Federation of Musicians Local 101-476 Dayton, \\ OH International Trombone Association \\ International Society for Improvised Music \\ College Music Society \\ Mu Phi Epsilon - Co-ed professional music fraternity \\ Ohio Diversity Officers Collaboration - former Web Master
}




\section{RESEARCH INTERESTS}

Teaching improvisation using the music of J.S. Bach

Interdisciplinary/Multidisciplinary Arts and Music Education

Jazz History

Using technology in music curricula

\section{CONFERENCES ATTENDED}

Eastern Trombone Workshop - Fort Myer, VA (March, 2013)

Cincinnati Trombone Symposium - University of Cincinnati College Conservatory of Music (March, 2013)

International Society for Improvised Music - Ann Arbor, MI - University of Michigan (December, 2010)

Black Man’s Think Tank - Dayton, OH - Sinclair Community College (2006, 2007)

University of Michigan Trombone Week - Ann Arbor, MI - University of Michigan (2004) 


\section{REFERENCES}

Dr. H. Keith Jackson

West Virginia University

Director, School of Music

College of Creative Arts

keith.jackson@mail.wvu.edu

(304)293-4841

Context: Trombone Professor at WVU, and Chair of my Doctoral Committee

\section{Professor Paul Scea}

West Virginia University

Director of Jazz Studies, and Associate Director of World Music

College of Creative Arts

paul.scea@mail.wvu.edu

(304)293-4841

Context: Member of my Doctoral Committee

\section{William J. Winsor}

West Virginia University

Associate Dean,

College of Creative Arts

william.winsor@mail.wvu.edu

(304)293-4841

Context: Member of my Doctoral Committee

\section{Dr. Ed Sarath}

University of Michigan

Professor of Jazz and Contemporary Improvisation

School of Music, Theatre and Dance

sarahara@umich.edu

(734)763-1321

Context: Former Professor of Jazz and Improvisation

\section{Dr. Dennis Wilson}

University of Michigan

Professor of Jazz and Contemporary Improvisation

School of Music, Theatre and Dance

dwJazz@umich.edu

(734)615-4104

Context: Jazz Trombone Professor at U-M. I also studied composition and arranging with him

\section{Additional references are available upon request}

